University of Rhode Island

DigitalCommons@URI

Open Access Dissertations

2019

\title{
SCHOOL LEADER DEVELOPMENT: PERCEPTIONS OF SKILL DEVELOPMENT ON THE JOB
}

Nicole Rose Lyons

University of Rhode Island, nrsilvia@gmail.com

Follow this and additional works at: https://digitalcommons.uri.edu/oa_diss

\section{Recommended Citation}

Lyons, Nicole Rose, "SCHOOL LEADER DEVELOPMENT: PERCEPTIONS OF SKILL DEVELOPMENT ON THE JOB" (2019). Open Access Dissertations. Paper 886.

https://digitalcommons.uri.edu/oa_diss/886

This Dissertation is brought to you for free and open access by DigitalCommons@URI. It has been accepted for inclusion in Open Access Dissertations by an authorized administrator of DigitalCommons@URI. For more information, please contact digitalcommons-group@uri.edu. 
SCHOOL LEADER DEVELOPMENT: PERCEPTIONS OF SKILL DEVELOPMENT ON THE JOB

BY

NICOLE ROSE LYONS

A DISSERTATION SUBMITTED IN PARTIAL FULFILLMENT OF

THE

REQUIREMENTS FOR THE DEGREE OF

DOCTOR OF PHILOSOPHY

IN

EDUCATION

UNIVERSITY OF RHODE ISLAND

AND

RHODE ISLAND COLLEGE

2019 
DOCTOR OF PHILOSOPHY DISSERTATION

OF

NICOLE ROSE LYONS

APPROVED:

Dissertation Committee:

Major Professor

Kathy Peno

Minsuk Shim

Corinne McKamey

Anne Goodrow

Nasser H. Zawia

Dean, The Graduate School-URI

Gerri August

Co-Dean, Feinstein School of Education - RIC

Julie Horwitz

Co-Dean, Feinstein School of Education - RIC 


\begin{abstract}
This study explores the ways school leaders develop their leadership skills on the job as they navigate through the increasingly complex demands on them (Drago-Severson, 2009). This study sought to understand how school leaders of varying years of experience perceive their skill development once on the job. Participants in this study are members of an Association of School Principals in New England. Each participant was interviewed, identified their perceived skill development using the Five-Stage Model of Adult Skill Acquisition (Dreyfus \& Dreyfus, 1992) and supplied an artifact that supported their level of skill development. The interviews were transcribed and analyzed. The data analysis led to the following main themes- mentorship, reflective and self-reflective practices, time management, and collaboration. These themes will be useful in understanding what types of professional learning supports school leaders need to assist them in developing their skills to be, and continue to be, effective leaders.
\end{abstract}




\section{ACKNOWLEDGMENTS}

In the book, The Alchemist by Paolo Coelho, the Alchemist says, "And when we want something, all the universe conspires in helping you to achieve it." Getting a doctorate has always been a dream of mine, and I would like to thank those who conspired in supporting me to achieve this dream.

First, thank you to my husband Zachary Lyons, who supported my every idea in applying and seeing through a doctorate program. Zach was always there to give me the faith I needed. When I would take an entire weekend to work on my doctorate, he would see that I had everything I needed to complete my work successfully. Zach was always there to listen to me spew my stream of consciousness about theory and methodology. Though none was of interest to him, he would be patient, and listen anyway. I am truly blessed to have him as my husband and could not have done this without him.

Secondly, I would like to thank my major professor, Dr. Kathleen Peno. Kathy has been my driving force of support through every stage of the program. She has also supported me through some major life events such as, changing jobs from classroom teacher to school administrator, getting married, supporting my husband taking the bar exam, and moving out to live on my own for the first time, all while being a doctoral student. As her student, she was always available when I needed her. As our relationship developed, Kathy turned from professor and mentor to friend and mother figure. Kathy, I thank you for listening to me rant and always finding a way to support me. Thank you for teaching me how to 
be excited about my work and to always support those who need help because we all do/will at some point. Your passion for educating others has taught me to always be patient and appreciate the human condition. Also, I would like to thank the members of my committee, Corinne McKamey, Minsuk Shim, and Anne Goodrow for being insightful and supportive at all stages of my work. Further, thank you to Leslie Schuster for taking the time to be the outside chairperson for my defense.

Further, if I did not have the support of my superior, I would not be here today. Thank you to my current boss, and more importantly, my best friend, Adam Flynn-Tabloff. Adam values education and his continuous support helped me focus on my studies while working. When I gave him my written request for sabbatical, he fully supported me from start to finish. I would also like to thank Victoria Gailliard-Garrick, my mentor and work mother. Vickie afforded me the opportunity to start my path as a school leader and has mentored me since day one. Vickie's mentorship helped me develop my skills as a novice school leader. Her guidance as a mother has helped me understand to lead with compassionate and a student-centered focus. I cannot thank her enough for opening the door into school leadership for me.

Additionally, I would like to thank my friends and family. Thank you to my three incredible cohort friends, Abbey, Angela, and Michael. Your support, friendship, and sense of humor truly made the time fly by. I am happy to say that I have three new lifelong friends at the end of this journey. Thank you to my best friend Jen and her family for always being there for me and supporting me. More 
importantly, last, but not least, thank you to my family, my parents and my brothers, as well as my in-laws, for always supporting me in my life endeavors. Having the support of family makes me feel as though I can do anything. Thank you for listening to me, doing my laundry, encouraging me, helping with Zach, me and Louie, and always being there for a good laugh when I needed one.

In all, I would like to thank the universe for conspiring with me to achieve my dream of a Ph.D. Thank you to the higher beings above for guiding me when I felt lost and showing me signs to lead me down the right path. As Michelle Obama says in her memoir Becoming, "For me, becoming isn't about arriving somewhere or achieving a certain aim. I see it instead as forward motion, a means of evolving, a way to reach continuously toward a better self. The journey does not end." I am interested to see where the universe will take me next. This is only the beginning. 


\section{DEDICATION}

I would like to dedicate my dissertation to the late Edward P. Travers, my Vovo, and the late superintendent of Bristol schools. Though he died before I was born, his spirit has had a presence in my life. He was known to be a caring, loving man with strong beliefs in forming genuine relationships with students and teachers. Thinking before his time, he believed education should be engaging and equitable for all students. Though you passed before your time, your spirit lives on. Your wooden gavel will always sit on my desk. 


\section{TABLE OF CONTENTS}

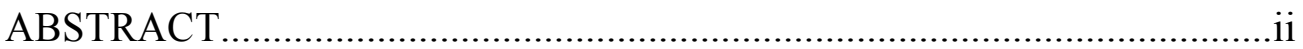

ACKNOWLEDGMENTS.................................................................. iii

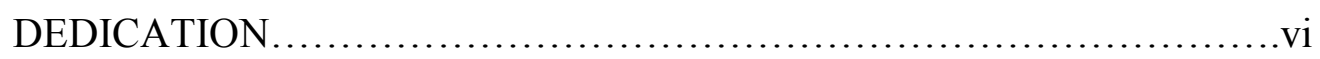

TABLE OF CONTENTS ......................................................................vii

LIST OF TABLES........................................................................

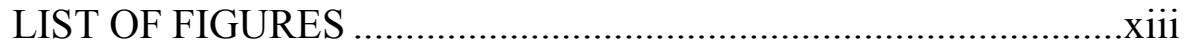

CHAPTER ONE: Introduction .......................................................

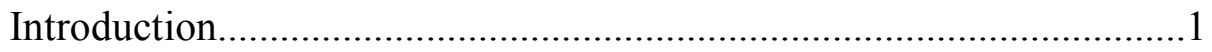

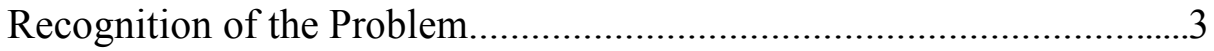

Statement of Purpose ...............................................................6

Summary and Structure of Dissertation...........................

Definition of Important Terms and Concepts...................................

CHAPTER TWO: Review of Literature .................................................. 10

Introduction.................................................. 10

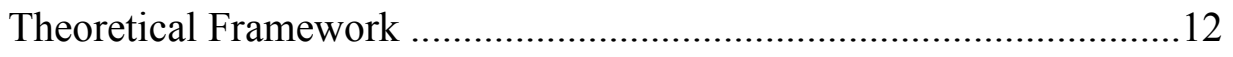

Adult Skill Development ...........................................................13

Novice................................................................... 14

Advanced Beginner ..................................14

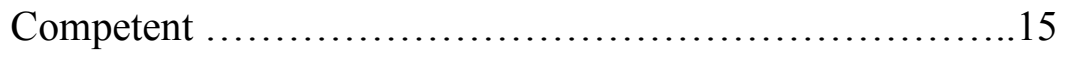

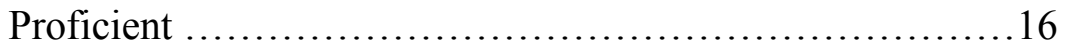

Expert............................................ 17

vii 
Supporting Adult Skill Development..........................20

Social Learning and Skill Development...................................... 20

Mentoring..............................................22

School Leadership Practices .............................24

School District Contexts...............................26

Research Questions........................................31

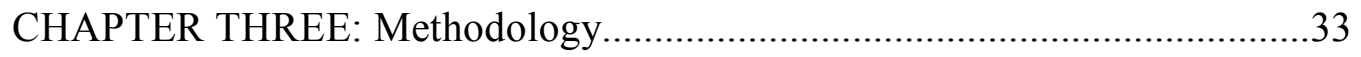

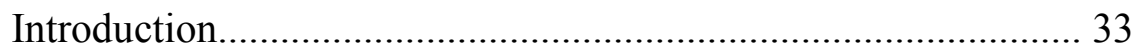

Setting ........................................................................ 33

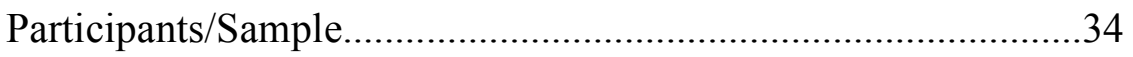

Data Collection................................................................... 36

The Model.......................................... 36

Interviews........................................ 36

Document Examination....................................

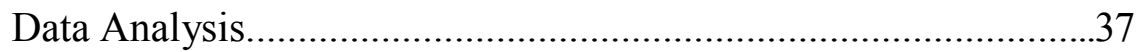

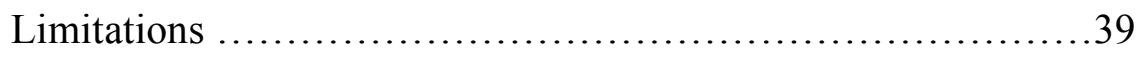

Role of the Researcher..........................40

CHAPTER FOUR: Findings............................................................. 42

Results.............................................42

Participant Vignettes....................................42

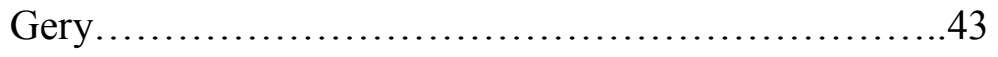

John............................................48

viii 
Jesse.

Jaime. .60

Mack. .63

Moe. .67

Remi. .73

Reese. .75

Marley. .79

Reily. .83

Summary of Vignettes............................................ 85

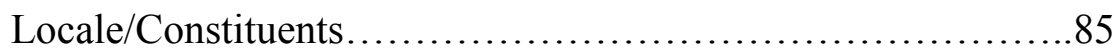

Organization..................................................... 86

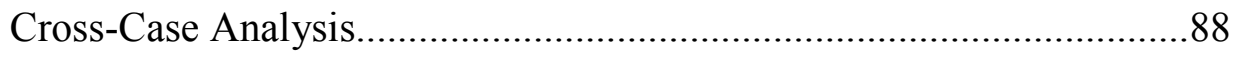

Introduction................................................... 88

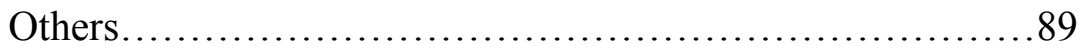

Know Your People.....................................90

Supports and Needs........................93

Building Relationships.............................99

Collaboration......................................96

Professional Development....................101

School Culture...................................103

Self.................................................. 105

Commitment......................................106

Listen........................................... 108 ix 
Decision Making...............................110

Reflection.......................................113

Self-Reflection..........................114

Time Management........................116

Prioritizing.............................117

Mentoring Others.........................118

Supports.........................................119

Mentoring.....................................119

Professional Development.......................120

Developmental Network.........................121

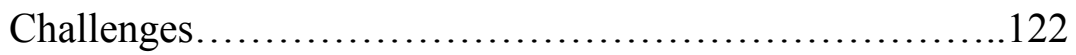

Dealing with Difficult Teachers..................122

Balancing Relationships........................124

Adaptive State...................................125

Dealing with the Power.........................126

Work-Life Balance...........................127

Time......................................... 128

Inequities..................................128

Summary.................................130

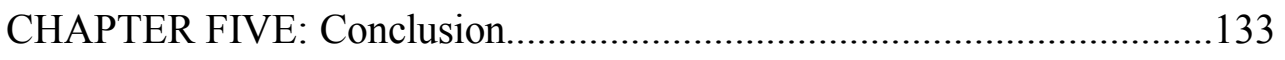

Summary of the Study........................................ 133

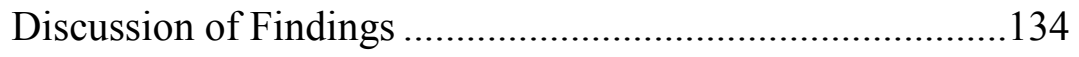

Implications for Practice.................................................................141 
Principal Preparation Programs...........................142

State Department Programs................................144

School District and School Leader Responsibilities...........145

Suggestions for Future Research....................................................146

Summary and Concluding Thoughts.............................147

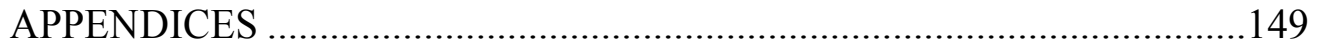

Appendix A: Five-Stage Model of Adult Skill Acquisition............149

Appendix B: School Leader Development Framework................150

Appendix C: Theoretical Framework...............................151

Appendix D: Research Questions and Method Table...................152

Appendix E: Participant Consent Form.............................154

Appendix F: Email Correspondence................................156

Appendix G: Interview Protocol..................................157

Appendix H: Trustworthiness Chart..................................158

Appendix I: Professional Standards for Educational Leaders...........159

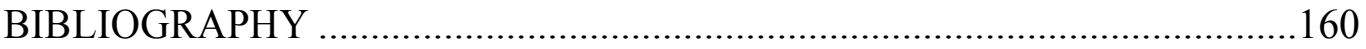




\section{LIST OF TABLES}

TABLE

PAGE

Table 1. Characteristics of Participants/School Districts ..................34

Table 2. Perceived Participant Skill Level.............................42 


\section{LIST OF FIGURES}

FIGURE $\quad$ PAGE

Figure 1. Cross-Case Analysis.................................... 89

Figure 2. Implications for Practice ...........................141 


\section{CHAPTER ONE}

\section{INTRODUCTION}

School leaders, both assistant principals and principals (hereinafter referred to as SLs) have been portrayed as authoritarian, iron-fisted figures in movies and TV shows, such as Ferris Bueller's Day Off and Boy Meets World. Perhaps, at one time, their work demanded a strict, disciplinary style, however, with a wave of educational changes, the role of the $21^{\text {st }}$ century SL has changed to be more dynamic with a focus on improving teaching and learning (Kominiak, 2018; Wallace Foundation, 2013). Their function within a school building is now multifaceted with a curriculum and instruction focus while managing the daily duties of the school, making them the driving force that impacts the whole school environment (Davis, Darling-Hammond, LaPointe, \& Meyerson, 2005; Elmore, 1996; Murphy, Golding, Cravens, and Porter, 2011; Wallace Foundation, 2013).

With recent educational policy focused on accountability of school districts, the demands regarding curriculum and instruction on the SL have increased, leaving them to adapt and juggle their various roles rather quickly (Davis, DarlingHammond, LaPointe, \& Meyerson, 2005; Elmore, 1996). According to DarlingHammond, LaPointe, and Orr (2008), "Principals are expected to be educational visionaries, instructional and curriculum leaders, assessment experts, disciplinarians, community builders, public relations/communications experts, budget analysts, facility managers, special programs administrators, as well as guardians of various legal, contractual, and policy mandates and initiatives" (p. 6). With the many roles SLs have to manage, it is hard to imagine going about the job 
alone. Today, school leadership requires collaboration among many to conquer the challenges and opportunities in education (Kaser et.al., 2013; Schmidt-Davis \& Bottoms, 2011).

The increased accountability on school districts such as high expectations for curriculum and instruction, raising student state assessment scores, decreasing teacher absenteeism, ensuring clear safety plans, etc. has reshaped the role of the SL. While principals may have dealt with the job of discipline, or seemed like a lone wolf in the past, today's principal makes his or her presence known as a supporter and collaborator where they create conditions to reach a critical mass (Kominiak, 2018; Wallace Foundation, 2011, 2013). Due to the high amount of collaboration required of SLs, many have had to rely more on their interpersonal skills to move their schools forward. According to the Organization for Economic Cooperation and Development (2018), SLs are the link between teachers, students and parents, and the wider community (Wallace Foundation, 2013). Kaser (2013), Drago-Severson (2009), and Johnson (1996) also support the view that school leaders are the connection to all stakeholders in the school community. Most principal training programs focus on the management of curriculum and instruction, rather than on instructional organization and organizational development (Wallace Foundation, 2013). Currently, a gap exists between what a SL should know and be able to do on the job, and what is taught in SL preparation programs in order for them to be effective. 


\section{Recognition of the Problem}

Due to increased responsibility on local education agencies to increase the effectiveness of curriculum and instruction, student achievement, decrease teacher absenteeism, and provide pathways for students beyond high school, amongst others, school systems are in need of effective SLs now more than ever (Crow \& Matthews, 1998; Elmore, 2004; Gronn \& Rawlings-Sinai, 2003; Miller, 2013; Zeitour \& Newton, 2002). However, according to a national survey, fifty percent of SLs reported their work load is one reason why they leave their school within three years (School Leadership Network, 2014; Superville, 2018; Wallace Foundation, 2013). Johnson (2005) found that principals left their jobs because of four main reasons- high accountability, having little influence, isolation, overwhelming workload, and preservice training that left principals feeling unprepared (Wallace Foundation, 2013). If principals are not prepared to deal with the workload, then how can they handle dealing with other issues within their school context?

Additionally, schools with high minority populations are more likely to experience higher rates of leadership turnover (Baker, Punswick \& Belt, 2010; Béteille et al., 2012; Gates et al. 2004). Johnson (1996; 2006) agrees that school context influences school leadership. In her work Leading to Change: The Challenge of the New Superintendency, Johnson (1996) discusses how leadership traits have to be viewed within the context of where the leaders are leading. Johnson (1996) argues that the behaviors of a leader that work in one setting may fail in others, therefore context influences leadership practices. In a survey by the 
National Association of Elementary School Principals, forty-four percent of SLs cited managing time as their top challenge (Superville, 2018). Another survey of new SLs found many hopeful new school principals are not receiving the support they need to be successful on the job during their internship (Good Principals Aren't Born, 2007; Johnson, 2005; Wallace Foundation, 2013). Even though 48 states require SLs to be certified in educational administration, the quality and content of the certification programs vary greatly. The demands of the 21 st century have reframed the role of leadership for schools, making it even more important to find ways to support SL skill development while on the job.

According to Samuels (2008), the shift from managing the school building, students, and personnel, to that of instructional leader, has also placed new and increasingly complex demands on SLs (as cited in Drago-Severson, 2009). The work SLs oversee is diverse and varies greatly. A school leader needs to be able to oversee the management of the school, while keeping curriculum and instruction at the fore of their work (Elmore,1996; Darling-Hammond, Wise, and Pease, 1983). According to Superville (2018), over fifty percent of principals reported spending more than 60 hours per week on school-related work. However, it is unclear what "school-related work" is. Elmore (1996) would hope it was work related to the improvement of curriculum and instruction; however, there seems to be a discrepancy between learning its importance and putting it into practice. The job of a SL now includes being visible in the classroom in order to observe instruction (Alvoid \& Black, 2014; Drago, Severson, 2009; 2012; Drago-Severson \& BlumStefano, 2018; Superville, 2018) in addition to the many other functions they 
perform. The most effective SLs create vibrant learning communities where faculty and staff collaborate to help every student fulfill their potential (Drago-Severson, 2012; Elmore, 1996; Roekel, 2008; Wallace Foundation, 2013). However, due to increased job demands, principal turnover has increased over time, leaving schools in a constant state of change and peril (School Leaders Network, 2014).

SL persistence (staying in a school for a longer period of time), is important for student achievement, as significant periods of time are required for SLs to have a positive impact on their schools (Berrong, 2012; Elmore, 1996, 2004; Heck \& Hallinger, 2009; Robinson, Lloyd \& Rowe, 2008; Seashore Louis, Dretzke \& Wahlstrom, 2010). Often, the changes SLs are implementing need to be overseen by them from start to finish. According to Elmore (1996), "at both levels it will readily become apparent that the existing structure of the curriculum is nested in a complex web of state regulations, local rules and conventions, community norms, traditional texts and materials, and special interest politics" (p. 10). A principal must understand all of the above to be able to lead their school effectively.

Changes like influencing curriculum and instruction, positive school culture, reducing absenteeism, and increasing state test scores, take more than three years to see to fruition. Recent research into the influence of SLs has shown their impact within schools increases over time (Bowers \& White, 2014; Coelli \& Green, 2012; Heck \& Hallinger, 2014) and, in particular, around student achievement (Clark, Martorell \& Rockoff, 2009; Miller, 2013). Some suggest that it takes seven years or more before SLs can successfully implement change within a school (Vanderhaar, Muñoz \& Rodosky, 2006). Given that the context of a school can 
influence SLs and that curriculum and instruction is embedded within the policies of the state, district, and community norms (Elmore, 1996), how do principals begin to navigate their work after their leadership development program and continue to develop their skills on the job?

\section{Statement of Purpose}

Although there have been multiple quantitative studies concerning turnover and the retention of SLs, there is a dearth of qualitative studies that explore how school leaders develop their skills on the job and which supports they need to be successful. The research indicates there is higher turnover in urban schools, but little has been done to retain principals in these schools (Miller, 2013; School Leadership Network, 2014; Wallace Foundation, 2013). Given that principal persistence is important for student achievement, there is a need to understand how SLs continue to develop their skills on the job and which supports are needed to retain them so they can have a positive impact on student achievement and the school community as a whole.

Policy-level interventions that treat all SLs equally are less likely to be in alignment with known retention strategies that involve connecting with leaders as individuals (Elmore, 2004; Herman et. al., 2017). Since there are many changes in education, school leaders (as adult learners) have not been prepared to meet the adaptive challenges of their job, meaning the challenges outpace the capacity of SLs (Drago Severson, 2009, 2012; Kegan \& Lahey 2009). With this said, SLs often do not progress past competent in their skill development (see the Dreyfus Five Stage Model of Adult Skill Acquisition, hereinafter referred to as The Model- 
Appendix A) due to a lack of support on the job. In a survey of 40,000 teachers conducted by the Bill \& Melinda Gates Foundation, supportive leadership was topranked to support teacher retention (as cited by the Wallace Foundation, 2013). If supportive leadership helps retain teachers, what supports are used to retain SLs? As a result of the increased demands on SLs, this study seeks to understand how SLs develop their leadership skills on the job in their various school contexts and which supports or deterrents to their skill development they have experienced.

\section{Summary and Structure of the Dissertation}

Chapter One introduces the reader to the context of the study and its importance to the field. Chapter Two explores the literature regarding the role of school leaders and introduces the theoretical framework used to support the research. In Chapter Three, the methodology used to select participants, collect and analyze the data is outlined along with the methods used to insure the Trustworthiness of the study. Chapter Four provides vignettes of the experiences of each of the study participants followed by a cross-case analysis that addresses the research questions. Finally, in Chapter Five, the author provides a discussion of the findings and explores the implications for practice in the field of school leadership development. Suggestions for future research round out Chapter Five.

\section{Definitions of Important Terms and Concepts}


Leadership - an individual's ability to work with others to accomplish an agreedupon result (in this case, the school's mission and vision) (Kaser, et. al., 2013; Darling-Hammond, 2012).

Leadership skills -SLs must have the following skills in order to be effective SLsshaping a vision, creating a climate appropriate for education, cultivate leadership in others, instructional leader, managing people, data, and process for school improvement, along with being an engager, learner and collaborator in order to move the school community to achieve school goals and maintain a positive school culture (Elmore, 1996; Halls et. al., 2016; Wallace Foundation, 2013).

Leadership practices - actions or strategies that school leaders use to perform their skills, such as organizing, listening, modeling, and reflecting, in order to move the school forward within the context (Darling-Hammond, 2012; Drago-Severson, 2009; Elmore, 1996; Halls et. al., 2016; Johnson, 1996).

The Model - Dreyfus and Dreyfus (1986) Five-Stage Model of Adult Skill Acquisition, used to define school leaders self-perceived leadership skill level (See Appendix A).

Developmental Network - a set of people from various social spheres who advance a protégé's personal and professional growth, formally, or informally assigned (Chandler, et. al., 2007, p. 2).

School Context - This study will define school context from the perspective of locale, organization, and constituents. These will be defined as follows:

Locale- Physical location of the school defined by its local education agency and town municipality- Urban, suburban, rural. 
Organization- Public, charter, level of school (Elementary, middle, junior high, or high school)

Constituents- Free/reduced lunch rates will be used to describe constituents

(Johnson, 1996; Kaser et. al., 2013)

Principal preparatory program - any formalized training a person partakes in order to become a certified school administrator in their state. 


\section{CHAPTER TWO}

\section{REVIEW OF THE LITERATURE}

\section{Introduction}

Chapter two provides an overview of the literature on the changing roles of a school leader, as well as the theoretical framework that informs this study: adult skill development, social learning, leadership skills and practices, and school districts' context.

\section{Changing Roles of the School Leader}

Through the various waves of educational change, the principal has been viewed as a manager, overseeing various operations of the school. Since No Child Left Behind (NCLB) and the age of accountability, the role of the SL has shifted from that of a manager, to instructional leader, which has brought dramatic changes in what public education demands of SLs (Kominiak, 2018; Wallace Foundation, 2013).

First, the work of SLs in schools is diverse and varies greatly (Elmore, 1990). The school leader needs to be able to oversee the management of the school, while keeping curriculum and instruction at the fore (Elmore, 1900; DarlingHammond, Wise, and Pease, 1983). Brazer \& Bauer (2013) define instructional leadership as the efforts to improve teaching and learning by managing effectively, addressing challenges of diversity, and fostering organizational learning (p. 650). An effective SL has to balance high levels of instruction with organizational

management. The Wallace Foundation (2013) reports five key responsibilities of an SL- sharing a vision of academic success, creating an environment hospitable to 
learning, cultivating leadership in others, improving instruction, and managing people, data, and processes. Nationally, standards for SLs have been developed that focus on vision, professional behavior, curriculum and instruction, equity, and management (NPBEA, 2015). A principal's focus on instruction and student achievement may seem like common sense to an outsider; however, more recently, principals have had to implement skills and practices around high expectations and levels of student achievement (Wallace Foundation, 2013) which has changed the way SLs need to lead.

In research conducted by Johnson (2005), principals reported leaving their jobs due to an impossible workload and a sense of leading in isolation. The principal as instructional leader cannot lead in isolation, but rather has to be a collaborator to ensure high levels of instruction (Elmore, 1996; Wallace Foundation, 2013). To be sure, teachers and SLs must work together to improve schools (Schmidt-Davis \& Bottoms, 2011). If a SL is to collaborate, then they must know how to collaborate within their school context.

There are several barriers SLs encounter when trying to keep curriculum and instruction at the fore (Wallace Foundation, 2013). Principals feel they have conflicting priorities and must respond to the needs of their constituents, and therefore, Darling-Hammond (2012) points out that SLs need to have a solid foundation in organizational management (Wallace Foundation, 2013). Organizational management of constituents within the school context influences how a SL leads (Johnson, 1996; Wallace Foundation, 2013). Without an 
understanding of organizational management, a SL can quickly lose sight of high levels of instruction and high expectations for all students.

Currently, the Every Student Succeeds Act (ESSA) places a focus on supporting leaders for leadership retention, because principal turnover can be toxic to student achievement (Alvoid \& Black, 2014; Burkhauser et al., 2013; Loeb, Kalogrides, \& Lai Horng, 2010). Further, supporting SLs in their role can assist them in continuing to develop their skills and practices so they can be effective leaders. The American Institutes for Research (2012) found that SLs are more productive when working within a supportive district context (Wallace Foundation, 2013). Because SLs have had to grow their leadership capacity, new leaders may be ready to handle certain aspects of the job, but to be effective, and develop, need experiential and professional guidance to assist them. Most recently, especially under ESSA, there is a call for research to hone in on the leadership skills that build organizational capacity and that are linked directly to school improvement (Young \& Crow, 2017). Ensuring SLs develop skills and practices to be effective instructional leaders is important to the very survival of education for all students.

\section{Theoretical Framework}

As previously mentioned, this study was informed by four areas that serve as the theoretical framework; adult skill development, social learning, leadership skills and practices, and the district context (see Appendix C). Each of these components is explored in this section.

\section{Adult Skill Development}


In order to understand how adults (SLs in this case) develop their skill while on the job, the researcher utilized the The Model (1992) to serve as a lens through which skill development was examined (while the authors refer to stages in their model, for purposes of this study, stages and levels are used interchangeably to incorporate the way the participants spoke about their skill development). While adult learning theories can be powerful in understanding how to support adult development of SLs in K-12 schools, they are underutilized (Drago-Severson, 2009, 2012). For example, the state in which this study took place does not have any state or district level supports, such as induction programs or mentoring programs to assist wit the development of SLs. Therefore, The Model (1992) was used in this study as an anchor to help school leaders describe their perceived skill development on the job. The Model was chosen because it is not domain specific, meaning it can be applied and tailored to any field.

According to The Model, adult skill development is dependent on experience. For example, "the novice chess player learns a numerical value for each type of piece, regardless of its position," and learns the rules of the game (Dreyfus \& Dreyfus, 2011). However, in order to become a better chess player, the novice needs to learn when to apply the rules, and exceptions to the rules, as they gain experience playing chess. The experience of playing chess allows the chess player to learn from their opponents, their own strategies, and their mistakes. Dreyfus (2011) says, "In general, if one seeks the safety of rules, one will not get beyond competence. On the other hand, experiencing deeply felt rewards or remorse seems to be necessary for the performer to learn from examples without 
rules" (p. 179). The model consists of five stages of development: novice, advanced beginner, competent, proficient, and expert.

Novice. The novice level speaks to the practice of one in a new situation. The novice's practice is driven by the rules they learned during pre-service training (i.e., school, professional development, etc.) which lacks the multiple contexts that a novice might face (Dreyfus \& Dreyfus, 2004). The novice school leader will respond to a situation by following the rules learned in their pre-service training. With little or no experience, the novice leader will struggle to respond to situations appropriately because she does not have a repertoire of experiences to assist in forming the most appropriate response. Individuals new to a job often need to learn "how we do things here" without rules or advice (Eraut, 2008). A novice leader may need to be guided through their experiences in order to learn how to respond to situations unfamiliar to them from more than one perspective. According to Eraut (2008), "the workplace appears to be concerned with your capability (what you do and how you perform), it is equally important to be able to do the right thing at the right time" (p. 1). A novice may struggle with the latter because they do not possess a deep understanding and have minimal situational experience.

Advanced Beginner. Once a novice has experience in different contexts, they begin to develop a variety of maxims or rules that guide their practice as advanced beginners (Dreyfus \& Dreyfus, 2004). According to Schön (1983), when a practitioner sees something she already knows in a different situation, she has a new way of viewing the issue and possibly a new way to act on the situation in the future. These new maxims are built with the repetition of issues and situations that 
need their attention (Eraut, 2008). After having a number of experiences, the practitioner learns to recognize and consider new views they could not previously, moving further away from the essential rules into maxims. For example, an advanced beginner SL may have to meet with two teachers who were coming into school late. The SL handles both situations the same, though both teachers are late for different reasons. One of the teachers tells the SL she is late because she has to drop her children off at school, while the other teacher says they woke up late. The SL handles both situations the same way by following up with a written warning. The SL handles both situations based on the teacher contract (the rules). However, as the year goes on, the SL realizes there was a more supportive way of handling these situations without the written reprimand. With more experience, the number of potentially relevant elements and procedures that the practitioner is able to recognize and follow can become overwhelming without assistance (Dreyfus \& Dreyfus, 2004).

Competent. The practitioner must learn to prioritize and organize which aspects of situations to respond to and which can be addressed later, to avoid being overwhelmed. Taking ownership of prioritizing decisions forces the person to rationalize why they made a certain decision and understand which elements are important and which can be ignored (Dreyfus \& Dreyfus, 2008). At the competent level, practitioners must decide for themselves in each situation which plan or perspective to adopt without being completely sure of the outcome. The best choice depends on the situation, and the challenge is to know which orientation is best for each situation (Kaser, Mundry, Stiles, \& Loucks-Horsley, 2013). For example, a 
competent SL may unexpectedly have to meet with a parent who is upset. The competent school leader is able to dissect the situation the parent is describing and understand what parts of the situation to respond to immediately and which one can wait. The competent school leader can also recognize criticism and take responsibility for their actions (or lack thereof) as they are speaking to the parent. Adults at the competent level can rationalize they were not given adequate rules, if their decision does not go as planned. However, they can become confused, fail, or experience elation that a beginner cannot (Dreyfus \& Dreyfus, 2008). When a competent adult makes a decision, and sees the decision through, he or she can experience joy for their accomplishment. Dreyfus and Dreyfus (2004) highlight that taking responsibility for one's successful and unsuccessful moments and replaying them over and over, move by move, will let them sink in and help the competent learner move forward. Competent is a pivotal stage, and for some, the highest one attained.

Proficient. Once the practitioner accepts the anxiety of the work, she is ready to advance her skill further. At the proficient stage, she understands certain aspects of situations will be salient, and others will be ignored and seen as irrelevant (Dreyfus \& Dreyfus, 2008). The proficient practitioner begins to view situations from an intuitive perspective, but may not yet have enough experience to know the best decision to make. She is in a constant state of deliberation (Dreyfus \& Dreyfus, 2008). There are a variety of responses and the proficient practitioner simply does not know what to choose. Because of the sheer amount of experience the practitioner has, she is able to understand many ways to respond to the situation, 
hence the difficulty in choosing the best course. At this stage, it is crucial for the proficient practitioner to have intuitive awareness of how things are going and be able to reflect in action in order to grow (Eraut, 2008). For example, a school leader may have an adult notify her that she overheard students talking about a weapon in the school building. In the moment of the conversation with the adult, the principal needs to consider the panic in the adult's voice, if any, and the students involved. The principal may be asking themselves questions like, "Have these students been a safety threat before?", "Did the students threaten the safety of the school?" or, "Is this teacher being hyper sensitive?" A proficient school leader is able to identify the protocols for a safety threat and make decisions based on the actions presented while in the moment, rather than looking back and reflecting retrospectively.

Expert. The expert learner has a sense of the best decision almost immediately without deliberation (Dreyfus \& Dreyfus, 2008). Expertise involves pattern recognition (Dreyfus, 2014), and the more experiences a person has, the more they will be able to recognize patterns and immediately know how to respond to a situation. According to Eraut (2008), experts are distinguished from novices mainly by their situational assessment abilities, not their general reasoning skills. Guided by intuition, the expert does not have to deliberate as long as the proficient learner to take appropriate action. The expert practitioner is able to navigate complex problems, going beyond self-awareness and monitoring to include framing the problem, thinking about the deliberation process, and how the situation can be handled (Eraut, 2008). According to Dreyfus and Dreyfus (2008), a practitioner 
becomes an expert only after tens of thousands of hours of experience in a particular domain.

The Model has been used in other fields to document skill development, however, it has not previously been used with school leaders. A study conducted by Cruess, Cruess, Bourdeau, Snell, \& Steinert (2015) used The Model as a framework to help understand how to shape the novice practitioner of medicine into an effective practitioner. Additionally, Benner (1982) used The Model to describe the stages of learning and skill acquisition of nurses across their careers and Peno and Silva Mangiante $(2013,2014)$ utilized The Model in their studies of the skill development of teachers and surgical faculty. Berliner (2004b), when studying the characteristics of expert teachers, posited that coaching and mentoring during the induction period reduced teacher dropout by up to $50 \%$, especially in schools with the most difficult-to-teach students.

It is important to study the skill development of school leaders because new ways of leading in education today require support for adult skill development (Drago-Severson, 2009; Drago-Severson \& Blum-DeStefano, 2018) and has not been the focus of previous studies. Researchers such as Hargreaves $(2007,2007 \mathrm{~b})$ support the belief that adult skill development cannot happen unless old ways of delivering professional development are altered, starting at the structural roots (policy level) of education (Drago-Severson, 2009; Elmore, 2000, 2004b). DragoSeverson's work explores the connections between professional development, adult developmental theory, adult learning, organizational development, and leadership practices (Drago-Severson, 2009). For example, she explains that a new learner- 
oriented model should be used to support the development of SLs through her four pillars of practice (see Social Learning and Skill Development section). As the foundation for Drago-Severson's work, Robert Kegan (1982) writes about assuming a constructivist view of learning and posits that adults make meaning of their experiences in order to develop to higher levels. Both Kegan and DragoSeverson focus on an adult's way of knowing and their meaning-making systems through which they filter and ultimately understand their experiences (DragoSeverson, 2004b, 2009; Kegan, 1982).

A criticism of models grounded in constructive-developmental theory, is that there is a lack of focus on a social lens. For example, the researcher could interpret participants's stories using a social justice lens for race, gender, women's development, etc. Though viewing the framework through these lenses could deepen understanding of supporting adult development, Drago-Severson (2009) supports the view that "a person's way of knowing is not connected to gender, age, or life phase, but there is a progression of increasing complexity from one way of knowing to the next" (p. 9). Constructivist-developmental theorists such as Kegan, "put the person as the meaning maker of experience, considering cognitive, affective, interpersonal, and intrapersonal experiences" (Drago-Severson, 2009, p. 33). Therefore, this study sought to understand how SLs made meaning of their experiences in regard to their skill development in their various school contexts.

Though this study data could have been examined through a sociocultural lens, approaching the research using a constructivist theory, via The Model, is more appropriate because the study focuses on how school leaders develop after their 
leadership preparatory programs. The Model provided a foundation for participants to consider their development as a leader.

Supporting Adult Skill Development. Some researchers believe that development through the levels of The Model does not occur simply through experience. Their work suggests the need for a more purposeful, supportive environment to assist practitioners through these stages (Benner, 1982; Peno \& Silva Mangiante, 2012, 2013, 2014). For example, Peno \& Silva Mangiante (2012) developed the Purposeful Ongoing Mentoring Model (POMM) to elucidate how mentors can use scaffolding (Vygotsky, 1978), and reflection techniques (Schön,1983), to guide a practitioner to higher levels of development using The Model. In subsequent research with teachers, clinical educators, and surgeons, they found the mentoring process was vital to the development of those practitioners, and conversely, was detrimental to their development if missing (Peno \& Silva Mangiante, 2013, 2014, 2016). The next section further explores the social nature of skill development.

\section{Social Learning and Skill Development}

The constructivist researcher understands that social and historical construction influences participant views, and context influences the participants' meaning-making. The social context of the participant's situation is important to a constructivist researcher because it helps the researcher make sense of the situation and draw conclusions in an open and dynamic way. In his book Mind and Society (1978), Vygotsky explores the relationship between a person and their

environment. Vygotsky's theory of the Zone of Proximal Development (ZPD), 
focuses on developmental change over time. The ZPD is described as the "distance between the actual developmental level as determined by independent problem solving and the level of potential development as determined through problem solving under adult guidance or in collaboration with more capable peers" (Vygotsky, 1978, p. 86). The use of a more experienced other within a situation can assist a person in developing their skill further than they could on their own. Researchers such as Darling-Hammond (2012), Elmore (1996), and MooreJohnson (1996) support the idea of collaboration and working with a more experienced other as a way to assist school leaders in managing teaching and learning.

Several studies have found different strategies that support social learning for school leaders after pre-service programs using a more experienced other. A study conducted by the School Leader Network (2014) suggests providing authentic formal and informal peer networks for principals to learn from one another, can help support development. This research also recommends one-to-one coaching to support principals in their novice years (School Leaders Network, 2014). Drago-Severson's Four Pillars of Practice- teaming, providing leadership roles, mentoring, and collegial inquiry provide a framework and supports for implementing social learning in schools to support adult development. Mentoring will be explored in the next section.

Mentoring. One approach for supporting adult skill development within a social context is mentoring. "Providing developmentally oriented support means recognizing, acknowledging, and affirming a person and how she is actively-in the 
moment, making sense of her experience" (Drago-Severson, 2009, p. 54). In a study by Riley \& Meredith (2017), 77\% of principals reported mentoring was an emerging priority for SL development in their state. Mentoring can be utilized at all levels of adult skill development to assist adults in gaining a deeper or different perspective on learning. In another recent study, Johnston, Kaufman, \& Thompson (2016) found principals placed a higher value on mentoring that focused on teachers' instruction (Elmore, 1996; Darling-Hammond, 2012). Those principals who reported their mentoring not focusing on instruction rated their experience as less valuable (Johnston et. al., 2016).

Kram (1985) found that mentors provide two types of developmental functions, career and psychological support (as cited in Chandler et al., 2016). Kram (using Vygotsky) defined mentoring in the traditional sense of a more experienced other guiding a less experienced other. The idea of mentoring is to have the less experienced other develop based on the experiences and knowledge of the more experienced other. Kram's later work speaks to redefining the traditional mentor model into a developmental network. A developmental network is the bridge between formal and informal mentoring for adult development and learning (Chandler, et. al., 2016). Chandler et. al. (2007), describe a developmental network as "a set of people from various social spheres who advance a protégé's personal and professional growth, formally, or informally assigned. Berliner's work (2004) on the review of incongruent teaching theory found that teachers who received coaching or mentoring along the way, developed to competent because their experiences were contextualized. Schön (1983) points out that seeing is not 
enough and a new view must be pointed out through action, but he does not indicate how this should be done. Peno and Silva Mangiante (2012) suggest a purposeful ongoing approach to mentoring for skill development that includes scaffolding and reflection. For example, using their model, a mentor could help a SL process their approach to a problem through reflection (probing questions and discussion), and offer possible alternatives of action in the future (scaffolding).

Being a mentor may benefit the mentor as well as the mentee in achieving higher levels of skill. Peno and Silva Mangiante (2012) found that surgeons' learning increased through their mentoring because they focused on their own practice when mentoring others. The act of mentoring can assist the experienced learner in fine tuning their ability to assess a situation and determine which approach is best. It can also assist the SL mentor in navigating difficult relationships and building capacity in their own school buildings. Based on the literature (Peno \& Silva-Magiante, 2014), mentoring can assist with skill development, but for SLs, mentoring is more beneficial when focused on instruction.

Approaches to SL skill development are not standardized for SLs in New England. Currently, a state department of education in New England offers grant programs to school districts to assist their school leaders in their jobs, but these supports do not necessarily make them a better leader. The state adopted new standards (see Appendix G for national leadership standards used to inform the New England state's standards) of leadership and will explore ways to train, support, and develop principals (Riley \& Meredith, 2017). Elmore (1996) would 
argue that adopting new standards around instructional leadership will not work without organizational changes in which they can be applied effectively in the context of the school.

Though there are several suggested methods to support adult skill development in school leaders beyond their pre-service program, such as mentoring and induction programs. What constitutes development, how to support these models, and how these models translate into practice, remains unclear (DragoSeverson, 2009; Wallace, 2013). Alvoid and Black (2014) conclude SLs need adequate on-the-job training and support in order to successfully lead change. We need a deeper understanding of practices that can support adult development and learning on the job (Drago-Severson, 2009). Several researchers have examined the practices school leaders engage in. These are explored in the next section.

\section{School Leadership Practices}

According to Leadership Matters (NASSP \& NAESP, 2013), SLs need to be educational visionaries; instructional and curriculum leaders; assessment experts; disciplinarians; community builders; public relations experts; budget analysts; facility managers; special program administrators; and expert overseers of legal, contractual, and policy mandates and initiatives. While their work is varied and important, a school leader clearly needs to be able to oversee the management of the school, while keeping curriculum and instruction at the helm (Elmore (Darling-Hammond, Wise, and Pease, 1983).

Kouzes and Posner (2003) define leadership as, “.... an observable, learnable set of practices" (p. 8). This view assumes that these practices can be learned over 
time. The Wallace Foundation (2011) found the five functions of a school principal to be - shaping a vision of academic success, creating a climate hospitable to education, cultivating leadership in others, improving instruction, and managing people (as cited by Wallace Foundation, 2013). These findings encompass the leader as both an instructional leader as well as a manager of an organization. Another source, The Principal Leadership Development Framework (See Appendix B) divides the role of the school leader into four categories -Visionary, Instructional Leader, Engager, and Learner and Collaborator (Hall et al., 2016). Similarly, Drago-Severson (2009) sees the school leader's role based upon four pillars of practice- establishing teams, adults with leadership roles, engaging in collegial inquiry, and mentoring. While there seems to be agreement on the basic leadership practices required of an effective school leader, what is less clear is how school leaders are supported to further develop these practices once on the job and what the focus of the support should be. Elmore believes that instruction should be the focus and policies should be focused around high quality curriculum and instruction (1996). Darling-Hammond says the principal's work should be organized around organizational design and development of instructional leadership (Wallace Foundation, 2013).

Darling-Hammond (2012) indicates that SLs need to seek out the best preparation programs that target instructional management and organizational management (Wallace Foundation, 2013). Elmore (1996) agrees that the starting point is to recognize that the inherent character traits said to make good leaders are "much less amenable to influence by education, training, and practice than are 
knowledge and skill," meaning the primary focus of leadership practices should be to enhance the knowledge and skill of teachers and instructional improvement, with everything else being secondary. Though the literature agrees on SL practices, the literature also points out that leadership practices are influenced by the overall school context. School district context and its influence on SL development will be explored in the next section.

\section{School District Contexts}

Though social learning through collaborative work can influence development of the organization and SLs, the overall structure of the school district can influence the access to developmental support. For instance, Elmore (1996) says schools change all the time, but never in a fundamental way. This means that rather than making small schedule changes or tracking systems, challenging the relationships among students and teachers is necessary (Elmore, 1996; DarlingHammond, 2012; Wallace Foundation, 2013). Elmore (1996) argues the inspirational view to be the status quo in education. This view "expects this type of control system to provide teachers with high levels of autonomy and to allow schools to accommodate the diversity of students and goals in American education and led to high levels of teacher and parent satisfaction" (Elmore, 1996, p. 53). High levels of teacher autonomy can be difficult for a SL to keep the focus of the school on "good instructional practice." Further, Elmore (1996) says that the structures within education vary very little, giving the U.S. public education system a "one size fits all" approach to all contexts of schools. Darling-Hammond (2012) would agree with Elmore that restructuring schools from the top down and starting 
from scratch would move schools forward, rather than the old structure adapting to new reforms where the structure does not fit. Under ESSA, schools across the nation are trying to find new ways to strengthen their school leadership, and with this, structural autonomy may be the answer.

According to Johnson (2008), leadership looks different - and is different depending on where it is exercised. SLs must attend to times, locale, and organization of their school districts simultaneously (Johnson, 2008). The context of the school district and school building will require the leader to use certain leadership skills and practices to be considered successful (Johnson, 2008). Johnson (1996) and Drago-Severson (2009), and others would agree that SLs have to operate with various contexts (Johnson, 1996; Drago-Severson \& Blum-DeStefano, 2018).

Like superintendents, principals and assistant principals have to operate within the set of embedded contexts of their school (Johnson, 1996, p. 14). The contexts of a school affect the way a leader makes change and accomplishes goals (Johnson, 1996; Kaser, et. al., 2013; ). The various contexts contribute to the demands on the SL (Johnson, 1996). Drago-Severson \& Blum-DeStefano (2018) focus building context around culture, the holding environment as referred to by Kegan. A holding environment can be defined as the fluid combination of supports and challenges needed to flourish and increase capacity (Drago-Severson \& BlumDeStefano, 2018). Building a growth oriented culture involves nurturing many other influences (i.e. teachers, stakeholders, policies) in order to move the school forward (Drago-Severson, 2009). Research does recognize the influence SLs can have on the environmental, instructional, and social-emotional factors that create 
the culture of the school (Drago-Severson, 2009). Susan Moore Johnson explains more about what defines the school context, or "holding environment."

Susan Moore Johnson (1996) explains school context in terms of the times, locale, organization, and constituents. These four demands influence school leadership and how they can navigate their jobs. First, time affects the overall focus of education of a historical period (Johnson, 1996, p.14). Education reform comes in waves and trickles down into state and local policy. The policies focus on different aspects of education affecting the goals of the schools. A school leader must be aware of the demands of the policies within their time in order to focus school goals and keep them focused around instruction.

Further, the locale of the school often plays a role in the demographic conditions, social customs, political practices, and financial conditions (p.15). The makeup of the school community can affect the focus of priorities and policies. For example, a community with a more affluent, well-educated community, active in school reform, while a poorer, less-educated community may not be as aware and less likely to know when to intervene their presence (Johnson, p. 15). Kaser et. al. (2013) agree that families and communities influence a school leader's craft. A school leader will have to consider questions like "What are families' and the community's interests and concerns about teaching and learning? To what extent do they support the mission and vision of teaching and learning and adult learning?" (p.117).

To continue, organization influences what a leader can and cannot do, and the leader must operate within the norms and established culture of the organization 
(Johnson, 1996, p.16). An SL needs to understand the traditions of their school in order to operate within them. Having an understanding of the organization can also assist the SL in understanding the management of the school (Darling-Hammond, 2012). A SL must understand how to manage within the organization and how to have influence on instruction.

Both Johnson (1996) and Kaser et. al. (2013) agree that knowing the constituents (stakeholders) involved influences school leadership. Stakeholders bring a diverse set of expectations, strengths, and skills (Johnson, 1996, p. 18). When a school leader implements change, the school leader needs to ensure the vested interests of the constituents (Johnson, 1996; Kaser et.al., 2013). Donaldson (2008), Elmore (2004a, 2004b), Sparks (2004) agree with Johnson (1996) and Kaser et. al. (2013) that challenges can become more difficult for a school leader in dealing with low income and non-native English speakers (Drago-Severson, 2009). Leaders in urban districts will have different demands than those in suburban school districts. For example, a school leader in an urban district will most likely have access to Title I funding they can use to assist in running programming to support ELA and Mathematics scores. Also, leaders in urban schools may deal with more diversity related issues, such as racism, with students and staff. Urban school districts have students with more needs and often have access to less resources than suburban schools (School Leaders Network, 2014). The context of an urban school can pose more challenges to SLs.

From a policy perspective, the overall structure of leadership can affect a SLs development (Darling-Hammond, 2012; Elmore, 1996; Johnson, 1996). These 
can be policies around fiscal matters, state testing, licensure for SLs and teachers that can trickle down to the school buildings. "But at both levels it will readily become apparent that the existing structure of the curriculum is nested in a complex web of state regulations, local rules and conventions, community norms, traditional texts and materials, and special interest politics" (Elmore, 1996, p.10). If the structures impeded collaborative work, hiring of quality individuals, etc., then this indicates that structures need to be changed in order to foster a hospitable environment for education (Johnson, 1996; Elmore, 1996, 2004). Elmore describes the top-down approach and various structural approaches and their influences on education. The most favored approach is the inspirational view where there is a high level of teacher autonomy and this approach often has high ratings of parent satisfaction. However, more teacher autonomy brings less control over what best practices are happening in the classrooms (Johnson, 1996; Elmore, 1996, 2004), hence why school leaders must work in a context where they can utilize collaboration and a shared leadership approach.

School context for this study can be defined from the perspective of locale, organization, and constituents as defined by Johnson (1996). These will be defined as follows:

-Locale- Physical location of the school defined by its local education agency and town municipality- Urban, suburban, or rural.

-Organization- Public, charter, level of school

-Constituents- Free/reduced lunch rates

\section{Research Questions}


With the belief that school leaders employ a variety of skills and practices that may differ depending upon the context of their school, this study will explore the perceptions of school leaders about their development and the experiences that have helped or hindered their skill development on the job. The following overarching question guided the research:

Overarching Question: What are school leader's perceptions of their skill development once on the job across contexts?

1. Using The Model, where do school leaders place their skill level?

2. How do school leaders perceive they developed to this level since leaving their pre-service program?

3. What are the leadership practices they perceive they have developed since leaving their pre-service program?

4. How do school leaders describe the challenges to their skill development since leaving their pre-service program?

5. How do school leaders describe the supports they believe have assisted in their skill development since leaving their pre-service program?

6. How, if at all, do school leaders perceive their district context has affected their skill development? 


\section{CHAPTER THREE}

\section{METHODOLOGY}

A qualitative case study design was used to explore the research questions. A case study design is employed when researchers seek to collect detailed information using a variety of data sources from individuals bounded by time and activity (Merriam, 1998; Yin, 2009). Yin (2009) defines a case study as an empirical inquiry that "investigates a contemporary phenomenon in depth and within its real-life context" (p. 18). In a case study, "the researcher justifies the selection of a case in terms of the goals of the study and existing theory and research" (Maxwell, 2013, p. 28). For this study, SLs who are members of a school leader association in New England were recruited using purposeful sampling of potential cases (Maxwell, 2013; Patton, 2009). Therefore, a case study approach is appropriate (See Appendix D).

\section{Setting}

This study utilized SLs from school districts and charter schools in a state in New England. This state was chosen for the context of this study because, though this state has many school districts, there is currently no statewide development programs or SL evaluation programs for SLs under ESSA. The state is currently working on redefining supports available to their school leaders. According to a recent report this state is currently working mainly on principal support and professional development (Riley \& Meredith, 2017) under ESSA. Further, there are many different pathways to become certified as a SL within the state. 


\section{Participants/Sample}

Participants were chosen using purposeful selection (Maxwell, 2013). Participants were chosen from the most recent membership of an association of SLs in New England at the time of the study. The association is an organization that SLs can voluntarily join any time in their career (membership is not required). The association is used as a developmental network for SLs within the state to collaborate and work together on fulfilling their leadership roles in their school districts. Members are exposed to professional development and networking opportunities through formal and informal professional development meetings throughout the school year.

Ten SLs were selected from rural, suburban, and urban, elementary, middle, junior high, and high schools, both public and charter, to provide sufficient perspectives across a variety of school contexts (see Table 1). As a member of the association, I was given access to the email listserv. I sent a recruitment email explaining my study to all members. Participants had to have at least three or more years of leadership experience in order to volunteer to be part of the study. SLs with three or more years of experience are able to provide better data on skill development (Dreyfus \& Dreyfus, 2004) (See Appendix F). Purposive sampling was useful for this study because members of the association are active in a larger developmental network of leaders who voluntarily seek to improve their leadership skills as part of their career. The members represent school districts under different district municipalities. When selecting participants, consideration was given to 
those SLs with three or more years of experience and the nature or context of their district (see Table 1). Those willing to participate were assured anonymity and asked to sign a consent form (See Appendix E). The participant's names provided are pseudonyms.

\begin{tabular}{|c|c|c|c|c|c|c|}
\hline \multicolumn{6}{|l|}{ Table 1} & \\
\hline \multicolumn{7}{|c|}{$\begin{array}{l}\text { Characteristics of Participants/School Districts- Breakdown of } \\
\text { participants by number of years in leadership, current position, and their } \\
\text { school context by type and free/reduced lunch rate. }\end{array}$} \\
\hline Participant & $\begin{array}{l}\text { Years } \\
\text { as SL }\end{array}$ & $\begin{array}{l}\text { Current } \\
\text { Position }\end{array}$ & $\begin{array}{l}\text { School Type } \\
\text { (Organization) }\end{array}$ & $\begin{array}{l}\text { School Type } \\
\text { (Organization) }\end{array}$ & $\begin{array}{l}\text { F/R Lunch } \\
\text { (Constituen } \\
\text { ts) }\end{array}$ & Locale \\
\hline Gery & 3 & $\begin{array}{l}\text { Assistant } \\
\text { Principal }\end{array}$ & Public & $\begin{array}{l}\text { Middle } \\
\text { (Gr. 6-8) }\end{array}$ & $91 \%$ & Urban \\
\hline John & 3 & $\begin{array}{l}\text { Assistant } \\
\text { Principal }\end{array}$ & Public & $\begin{array}{c}\text { High } \\
\text { (Gr. 9-12) }\end{array}$ & $4 \%$ & $\begin{array}{c}\text { Suburba } \\
\mathrm{n}\end{array}$ \\
\hline Jessie & 5 & Principal & Charter & $\begin{array}{l}\text { Middle } \\
\text { (Gr. 5-8) }\end{array}$ & $70 \%$ & $\begin{array}{c}\text { Suburba } \\
\mathrm{n}\end{array}$ \\
\hline Jaime & 6 & Principal & Public & $\begin{array}{l}\text { Alternative } \\
\text { School } \\
(\text { Gr. K-12) }\end{array}$ & $38 \%$ & $\begin{array}{c}\text { Suburba } \\
\mathrm{n}\end{array}$ \\
\hline Moe & 9 & Principal & Public & $\begin{array}{l}\text { Jr. High } \\
\text { (Gr. 7-8) }\end{array}$ & $15 \%$ & Rural \\
\hline Mack & 9 & $\begin{array}{l}\text { Assistant } \\
\text { Principal }\end{array}$ & Public & $\begin{array}{c}\text { High } \\
\text { (Gr. 9-12) }\end{array}$ & $45 \%$ & Urban \\
\hline Remi & 10 & Principal & Public & $\begin{array}{l}\text { Elementary } \\
\text { (Gr. K-6) }\end{array}$ & $37 \%$ & $\begin{array}{c}\text { Suburba } \\
\mathrm{n}\end{array}$ \\
\hline Reese & 12 & $\begin{array}{l}\text { Assistant } \\
\text { Principal }\end{array}$ & Charter & $\begin{array}{c}\text { High } \\
\text { (Gr. 9-12) }\end{array}$ & $50 \%$ & $\begin{array}{c}\text { Suburba } \\
\mathrm{n}\end{array}$ \\
\hline Marley & 14 & Principal & Public & $\begin{array}{l}\text { Elementary } \\
\text { (Gr. K-6) }\end{array}$ & $33 \%$ & $\begin{array}{c}\text { Suburba } \\
\mathrm{n}\end{array}$ \\
\hline Reily & 21 & Principal & Charter & High & $94 \%$ & Urban \\
\hline
\end{tabular}




\section{Data Collection}

Data was collected using three data collection methods including The Model, interviews, and documentation examination (Yin, 2009, 2012).

The Model. A visual of The Model (see Appendix A) was sent to participants via email before the interview to help participants familiarize themselves with the different stages of the model and allow them time to consider their skill levels and why they perceive they are at this level (Peno \& Mangiante, 2013). Participants were asked to read the definition of each of the five stages and then decide at which stage of The Model they perceive they are at relative to their leadership experiences. At the beginning of the interview, the participants were asked to identify their perceived stage at that time. This was used as an anchor for discussion about skill development and not as a determinant of their actual skill level. This helped the researcher develop additional, prompting questions during the interviews.

Interviews. Semi-structured interviews were used to gain the perspectives and experiences of school leadership development (Patton, 2002). Each participant was asked to participate in one interview between February and July of 2018. The researcher created an interview protocol of open-ended questions explored throughout the course of the interview to ensure the basic lines of inquiry were followed for each person interviewed (Patton, 2002) (See Appendix G). With participant permission, the interviews were audio-recorded and transcribed. 
Document Examination. Participants were asked to bring an artifact that they or have developed for their work that represents their skill level. This could be a set of procedures they developed, or a professional development program they implemented for their teachers, etc. This was explained to the participants in sufficient detail prior to the interview.

Data Analysis. Data in the form of transcriptions of the interviews, participant selections on The Model, and artifact examination were analyzed during and following the data collection process. As data was collected, the researcher kept a reflective journal to keep from being biased in the analysis. For example, the researcher had to keep her own bias about leadership practices from interfering with the data analysis. In one journal she wrote, "I found myself agreeing with all of the leadership skills and practices she mentioned. Though I agreed, I have to remember not to let my own beliefs around school leadership practices and skills get in the way of interpreting data."

Data was analyzed continuously throughout and after the data collection process to further pursue emerging themes in the interview process (Erlandson, Harris, Skipper, \& Allen, 1993). Data was then reduced and organized around specific research questions.

The following steps were taken to analyze the data:

1- Organized the data by categories for each participant into participant foldersinterview transcript, the Model, and document evidence provided by each participant. 
2- Read through each participant transcript twice and took handwritten notes on the general ideas participants spoke to. The handwritten notes for each participants were organized by grouping certain research questions together (See Appendix D). For example, interview questions 5 and 12 were meant to answer research question 1. The researcher looked to particular groups of interview questions within the transcripts to organize her notes.

3- Began the coding process for each individual case. Read through each participant transcription and notes and coded leadership pathway, skill model level, supports and challenges, and leadership practices for each participant. The researcher made a chart to represent The Model and begin writing each participant vignette.

4- The researcher wrote each participant vignette. When writing each vignette, the researcher utilized the documents provided by each participant as evidence to highlight particular parts of the participant's story. For example, if a participant spoke to building relationships as a key leadership practice and their document provided supported building relationships, then the researcher wrote about the document as further evidence of the participant's story.

5- Cross-case analysis - As the researcher wrote each vignette, the researcher also conducted a cross case analysis of each participant. The researcher used handwritten notes across participants as well as the vignettes to notice any similarities across participants. When a similarity emerged, a code was developed. For example, a color was given to each level of The Model and participant who reported that level. A color was also assigned to each code for leadership practices. 
6- The researcher organized the themes generated by the cross-case analysis into Figure 1. Later in the analysis, the interviews were compared and contrasted to one another (Patton, 2002). Figure 1 was used as the basis for the cross-case analysis description. The researcher inserted participant voice and document evidence into the cross-case analysis.

7- Interpretation of the data - As the researcher was writing the cross-case analysis, the researcher asked, "what were the lessons learned? to capture the interpretations that call for next steps and action" (Wolcott, 1994; as cited by Maxwell, 2014) and kept an on-going journal of interpretations as they arose.

8- Member checking - Once the vignettes were read and edited by the researcher, the researcher sent them to each participant to be reviewed to ensure the researcher's interpretations were accurate.

\section{Limitations}

Trustworthiness must be insured when conducting qualitative research. To do so, the researcher addressed credibility, transferability, dependability, and confirmability (Lincoln \& Guba, 1982). To address credibility, the researcher triangulated the data using The Model, interviews, and document examination. To address self-reporting, the researcher collected documents from each participant to provide more understanding of their self-reported skill level. The researcher used semi-structured questions to ensure interviews were more of a dialogue and to control for researcher bias. Further, to address transferability, the researcher used purposive sampling and thick description of each participant and their experiences in the findings so they can be related to similar contexts. The onus is on the reader to decide if the findings are generalizable to their own context (Lincoln \& Guba, 
1982). Thick description was provided for each participant vignette to interpret the perspectives and experiences of the participants (Lawrence-Lightfoot \& Hoffman Davis, 1997). While the researcher provides thick description of the participants and context of the study, it is up to the reader to determine transferability to their own setting (Strauss \& Corbin, 1998). The researcher addressed dependability by using semi-structured interviews, and developing a coding strategy when analyzing the data. Finally, to ensure confirmability, the researcher used member checking and peer review. (See Appendix H).

\section{Role of the Researcher}

As the researcher, it is important to understand your own biases and understandings when conducting interviews. The researcher was sure to ask questions that did not lead the interviewee; in particular, open ended questions were asked in a particular sequence after rapport was built with the interviewee (Roulston, 2010). As a school leader herself, the researcher sees the importance of school leader skill development and certain leadership practices, as well as the challenges and barriers school leader face. Through her own experience as a school leader, the researcher had to make sure her own biases and understandings did not interfere with participant interviews or interpreting data. Additionally, she established a codebook for content analysis and noted possible categories, patterns, and themes as they emerged (Strauss \& Corbin, 1998). The codebook was organized to insure anonymity of participants. This procedure also provided opportunities to analyze and discuss these emerging themes with peer debriefs and participants. 
The questions in the interview process were structured in such a way to triangulate data collection to ensure credibility and dependability (Creswell, 2014; Maxwell, 2013). The researcher chose to use semi-structured interviews in order to be able to ask follow-up or clarifying questions. This allowed the researcher to make the interviews more of a guided conversation (Yin, 2014) to ensure participants felt comfortable in sharing their experiences. The process of keeping a reflexive journal was used to ensure dependability.

Further, member checking was used to increase the reliability and credibility of the findings. This was used to solicit feedback from participants on the data the researcher interpreted to rule out the possibility of misinterpretation (Maxwell, 2013; Roulston, 2010). The member checking process provided a sense of accurate portrayal, but also provided a sense of networking. The raw data will be kept intact for three years in the event of a dependability audit. 


\section{CHAPTER FOUR}

\section{FINDINGS}

The finding are presented in two parts to explore the SLs' a) perceived skill development and b) the practices SLs utilize to be effective SLs. The results are presented in two sections; participant vignettes and cross-case analysis.

Participant Vignettes

These vignettes will explore and answer research questions 1, 2, 3, and 6 . They will explicate each participant's pathway to leadership, perceived skill development, supports and challenges, and perceived effective leadership practices in their school context, which will provide context for their skill development. Table 2 below provides an overview of the participants' perceived skill level at the time of the interview which will be revisited throughout each vignette.

Table 2

Participant Perceived Skill Level

\begin{tabular}{|c|c|c|c|}
\hline Participant & $\begin{array}{c}\text { Years as } \\
\text { Leader }\end{array}$ & Current Position & Perceived Skill Level \\
\hline Gery & 3 & Assistant Principal & Proficient/Expert \\
\hline John & 3 & Assistant Principal & Proficient \\
\hline Jesse & 5 & Principal & Competent/Proficient \\
\hline Jaime & 6 & Principal & Proficient \\
\hline Mack & 9 & Assistant Principal & Proficient \\
\hline Moe & 9 & Principal & Proficient/Expert \\
\hline Remi & 10 & Principal & Proficient/Expert \\
\hline Reese & 12 & Assistant Principal & Competent/Proficient \\
\hline Marley & 14 & Principal & Expert \\
\hline Reily & 21 & Principal & Expert \\
\hline
\end{tabular}


Vignette \#1-Gery

\begin{tabular}{|c|c|c|c|}
\hline Participant & $\begin{array}{l}\text { Years as } \\
\text { Leader }\end{array}$ & Current Position & Perceived Skill Level \\
\hline Gery & 3 & Assistant Principal & Proficient/Expert \\
\hline
\end{tabular}

It was 2008 when Gery would finally take his first steps into education. Going from the manager of a manufacturing company into education was not a surprise to Gery. Since he was a senior in high school, several of his classmates told him he would be a good teacher. Gery admits:

At the time I was appalled. I had the notion that teaching as a profession was 'settling' for a career. Even though I had no idea what I wanted to focus on as a major in college, or had any real concrete aspirations besides living on my own, there was something about being told I would align myself with teachers--even though I admired many of my own--that felt completely contrary to my teenage mind. 'Those that can do, those that can't teach,' was a quote I unfairly gave too much credence to as a wideeyed young man eager to come into my own. Undoubtedly, though, the seed had been planted, and as much as I tried to avoid the idea it slowly manifested in me and I would find myself gravitating toward substitute teaching when I came home from vacations, and I enrolled in an adolescent mentoring program at a local middle school in the town of my college.

Gery was a substitute teacher in an urban district in New England where he was exposed to all grades and content. During this time, he had a few mentors who helped him navigate through the trials and tribulations of being a substitute teacher. 
After two years as a substitute teacher, he was recommended by one of his mentors for a teaching fellowship program under The New Teacher Project (TNTP), funded as part of a new national education initiative, focused on transitioning career changers into educators in the most demanding urban environments. He underwent the intense, accelerated program for one year while also teaching high school ESL. At the completion of the program he was certified to teach in the state, and chose to stay in state, continuing as an ESL teacher, then to general education English at a different high school for five years. Gery came to some realization about urban education very quickly. He realized that in an urban school, he was the minority in every way possible- race, culture, language, seniority, etc. He did not look like his students, or grow up in the situations his students were exposed to, nor was his high school culture like this. Gery embraced the diversity around him and took note of what urban education had to offer him, just as much as he had to offer his students. His years as a teacher were deeply intense, but extremely rewarding. Gery said:

Teaching second language students helped me understand that the greatest lesson in the world will fall flat if you haven't established a relationship with your students. It was also the first time I began to become an advocate for people whose voice were not adequately represented in their own communities.

While teaching, he realized he would have more of an impact by becoming a school leader. He realized "urban education was driven by the wrong motivators, and all the systemic inequities from leaders to teachers to students, he felt 
compelled to affect change on a larger scale." At a Christmas party, his principal asked him to join a cohort of teachers to join the Center for Leadership in Educational Equity (CLEE) through a three-year city grant called, Turnaround School Leadership Program. With his work with CLEE, he became aware of the Principal Residency Network (PRN). The PRN is an intense, accelerated residency based alternative track to becoming certified as a school administrator. Upon completion of the program, he was hired as the assistant principal at a city middle school and has remained there for three years.

Having a "deeply intense, but rewarding experience" in urban education, Gery perceives himself to be a mix of proficient and expert on The Model. Gery perceives he is proficient because he "values the bigger picture and situational context rather than inflexible rules." Gery said:

I can admit that this has disadvantages because it takes more time to evaluate and consider all angles, but for me, I would lose sleep and probably change jobs if I ever found myself being an automaton to inflexible rules.

Gery believes that not taking social emotional needs, poverty, abuse, etc. into consideration when making decisions, would be a grave injustice to jump to conclusions and punish a student for something they have no control over. For example, Gery explains a concrete explain of his perceived level:

A teacher calls the office and said they need help. An administrator comes and the teacher explains that a student swore at them, and they expect the student to be punished accordingly. Sure, I can save time, take the teacher's word without asking the student because, hey, they're the adult and should 
always be believed, and take the student out, give them detention, suspension, etc. However, making a decision solely based on what the teacher said and not considering the student could be a disadvantage to the student and teacher. Making a decision without placing value on the bigger picture could do more harm than good. I would talk to the student and find out why the student reacted the way he/she did towards the teacher.

Here, Gery replaces rules with the situational intuition. Gery has a hunch that this student did not swear at the teacher as a personal attack, but something deeper caused this reaction. In talking to the student, he may find that the student has not slept all night, that their parent never came home, that they had not eaten, that they were working before coming to school, or any other issues that students come to school with. This would lead Gery to think that perhaps detention or suspension is not the route to take, but rather a restorative practice to help the student deal with their social/emotional needs and reflect on appropriate ways to deal with their needs. Of course the student needs to own up to their mistake, but the real challenge is repairing the relationship between the student and teacher, rather than drive a wedge deeper between the two.

Having the student's perspective gives Gery a more detailed bigger picture a which he can then make a decision to move forward with to repair the relationship. Unfortunately, not only is time a major obstacle in achieving restorative practices, teachers also need to be clear on what it is, and have the patience to let it work. One great experience that helped Gery develop into a proficient school leader was seeing the power of collaboration. In this one particular experience with 
collaboration, he truly saw his growth as a leader. One of his last projects in the PRN was to facilitate a whole faculty common planning time (over one hundred teachers) using a protocol that focused on a recent NEASC visit and their recommendations. Gery reports:

I was able to facilitate, and then trust in eight other teachers, some of which had never led a protocol before, to take groups into breakout rooms and come up with their own recommendations that they wanted based off of the results.

In the documents Gery provided, the teachers appeared to be engaged and invested in the work they were doing. Also, it appears that he had everything highly organized so the protocol ran smoothly. Gery further explains:

We then brought all the thoughts back, and as a group distilled everything into five concrete steps the school wanted to make for next school year. It was beautiful to see teachers become empowered by what they knew needed to be done, rather than being told what to do.

For Gery, this was a reaffirming example of the power of collaboration, voice, and empowerment that he knew he needed in order to be a proficient school leader. Since this experience, he has cultivated, developed, and facilitated school wide PLC.

Being a leader for three years, Gery feels that he is a proficient leader by taking time to build relationships, being a creative problem solver, creating genuine learning communities, and finding ways to advocate for his school. Gery enthusiastically said: 
Once you build relationships, and work hard to maintain them, it is much easier to be a creative problem solver on the spot, because others are more willing to help. There is a very common misperception in schools, especially urban schools with high administrative turn-over, that the principal is the hero of the school. The quickest way to burn-out is to believe that as an administrator, and the easiest way to tune-out as an educator, is to believe that one person can change the culture or academic outcome of a school. It is essential that all parties involved in the daily running of the school know just how important they are to its success or failure, have a voice in that vision, and hold each other accountable.

Being a teacher and now a school leader in an urban district, Gery has a deep understanding of the challenges that face his school on all levels. Gery also realizes that he, as the school leader, cannot move his school forward alone. It is the culture of the school that moves students forward.

Vignette \#2- John

\begin{tabular}{|l|ll|l|}
\multirow{2}{*}{ Participant } & $\begin{array}{l}\text { Years } \\
\text { Leader }\end{array}$ & $\begin{array}{l}\text { Current } \\
\text { Position }\end{array}$ & Perceived Skill Level \\
\hline John & 3 & $\begin{array}{l}\text { Assistant } \\
\text { Principal }\end{array}$ & Proficient \\
\hline
\end{tabular}

The halls were quiet as I walked into John's office. Though it was a vacation week, John's office was far from quiet. Organized piles filled his desk, reference books were on the bookshelf, and pictures of his family were scattered throughout. $\mathrm{He}$ had notes shouting positive messages like, "You rock," or "Thank you!" hanging on his walls. Despite the business, John seemed like he was home. John's tall and 
confident stature was calm and organized as he sat amongst his busy-ness. John started his career in education as a teacher at a suburban high school in New England. John always wanted to be a teacher, then eventually in higher education with undergraduate students. While he was teaching PE, he worked towards his Masters and enrolled in a PhD program at a state university. Very determined, John knew what he needed to be able to move into higher education. In his ninth year as a teacher, the principal at John's school approached him and asked him to be the interim vice principal though he did not have an administrative certification or experience. A situation arose where the vice principal had to be out on an unexpected prolonged leave. John said with his confident tone, "I did not want to be in an administrative position. That was the antithesis of what I wanted. I was really nervous about being an administrator because I thought I could not handle it." The principal said, "You're a leader in this school. You can handle it. The other two people who are certified do not want the position for one reason or another." With the support of the principal, John accepted the position. After completing his time as interim vice principal John affirmed he "didn’t particularly like [being a school leader]." Within the year, his tenth year as a teacher, an assistant faculty position was posted at a state college in Rhode Island. John applied, thinking this would be a long shot, but with his experience, he was awarded the job. John did not see himself working in higher education so soon, but he did not let his timing stop him.

When he first started the faculty position, it was great. But the position quickly began to lose its luster. First, John did not expect there to be so many rules 
as a new professor. Also, financially, the compensation was not what he expected. However, most of all, John did not realize that he would be one of the youngest professors on campus. John found he was "kind of in his own silo." He was always in his office doing work or going to class, where as a public-school teacher, he was constantly interacting with students, his peers, and parents. John said, "even though you have this open canvas, there really wasn't much conversation and collaboration. John's dream of being a professor in high education became lack luster at best, he began to think how he could stay in education, but go beyond the classroom. Though he did not particularly care for being an administrator, John decided to take courses and earn his administrator certification. He had already taken some of the required courses for the administration certification through his PhD program, so he figured, "why not."

Shortly after, John completed and received his school administrator certificate, and his $\mathrm{PhD}$. John quickly left higher education in pursuit of a school administrator position. John is now the assistant principal in one of the highest achieving suburban districts and has remained there for three years. John said, "If you look at test scores, we are in the top $5 \%$ of the state. We do not have a diverse student population, mostly white, upper middle class families." Though John does not have to face the issues that arise in an urban district, John does have to deal with a lot of pressure that parents and students put on themselves, informally and academically. He said, "students here are extremely conscious of their GPA, class rank, and post high school aspirations. There is a lot of pressure amongst students and from families and teachers on students to succeed academically." John works 
with an administrative team and a team of teacher leaders at his school. The emphasis on working hard to achieve goals was in the air and very present as we were talking.

When he first became a school leader, John thought of the job solely from a structural perspective. He perceived SLs worked on the budget, deal with discipline issues, litigation, and other behind the scenes aspects that, in the big picture, make the school function. John viewed the function of a school in two tiers, SLs at the top handling the structural aspects, and then the teachers handling teaching and learning. However, John discovered a third tier-being a human being. "From my experience, there was this third tier of being a person, being a human being." Unlike his experience as a college professor, John could relate to his teachers on a personal level and began to understand that building relationships with his teachers was crucial to his success as a school leader.

Though at first John did not particularly care for being a school administrator, he quickly grew into the role. After three years, he perceives himself to be proficient according to The Model. John said, "according to The Model, being proficient seems to emphasize experience and deliberating when making decisions, not relaying on rules, and hard and fast policy." Also, John adds that, "Considering all aspects of a problem is where I am right now." John believes in looking at the whole situation before making a decision on how to proceed forward. John also has learned that the result of a situation depends on two things- the situation and the players involved. For example, a group of students approached John in the 
lunch room, appearing to be concerned about a student. John listened to the group of students. One student said,

"There is a serious problem with hate language in this school, and there is a specific student who has really scary beliefs. And I think you need to do something about it." The group of students pointed out the student they were concerned about. Rather than make a quick decision based on only this one piece of information, John met with the student with "scary beliefs." When John met with this student, John realized that the student had cognitive disabilities. John knew this student struggled socially, and academically. The student reported that the group of students who approached him said to him at lunch a few days prior,

"Hey, you're the kid that said, "Airsoft guns are $\mathrm{f}^{* * * * * *}$ gay, you should use real guns." The student replied,

"Yeah, I did." And then one student in the group said,

"Okay. Well, you know, you sound like you're like Donald Trump." The student replied, "Yeah, I do." The student kept egging him on and said,

"Oh, well, you must like Adolf Hitler then." The student replied, "Yup, I do." Then, the one student said,

"Oh, so you think all Jews should die." As John put it, "not being a rock," this kid looked back and noticed the group of students was making fun of him. When the student realized this he said,

"Yeah, I do think all Jews should die." The student then said, “So even Black people should?" Finally, the student replied, "I do think Black people should die," and just parroted back. 
At this point, John giggled a bit because, though the situation was serious, he could not believe he had to deal with such he-said, she-said situations. After meeting with the student, John looked at the handbook. The handbook stated that this type of infraction called for five days suspension. John had to consider the student's disability, and his struggles. John thought that "it did not seem fair to suspend the student for five days given the situation." The student seemed as though he was set up and did not understand the severity of what he was saying because he was trying to defend himself to this group of students. John met with the student and his parents. All parties decided that the student would be suspended for two days, and he had to meet with the school resource officer three times to help him understand the severity of his actions. As for the one student who approached him, John met with this student. This student did not receive any punishment because it could not be determined if this student was targeting or baiting the student. In all, John approached the situation holistically, and considered all aspects of the problem before making a decision.

Though this particular experience went well for John, he still struggles with knowledge around Special Education. He has "very little experience with special education from an administrative perspective." He constantly calls upon the school LEA for guidance. For instance, at an IEP meeting, John had to be the representing administrator in the absence of one of his team members. The parents of the student disagreed on the student's IEP. The parents were divorced and very hostile. John said, "I had no idea what to say, what legally I'm able to do in this situation. I leaned on my interpersonal skills and tried to calm the parents. I then said I would 
have to correspond with the Student Service Coordinator (SSD) before I made a decision.” Though John admits he needs more experience navigating special education, he was able to identify there was more to the situation in this IEP meeting than what met the eye. John also recognized that he would be doing the student a disservice by pretending to make a decision that he did not know much about. By saying he needed to consult with the SSD, it shows that he considers situations in terms of "whole," rather than parts.

Being a school leader for three years, John has learned to like the job and now thoroughly enjoys it. He can interact with students, teachers, peers, and parents, and ultimately be a part of a collaborative environment. John said that in order to develop as a school leader, he had to learn how to be relatable with his teachers and ultimately learn the human side of the job. John said he also has grown to be a proficient leader from being open to feedback from his teachers. "I welcome concerns with me and my practice. Any type of constructive criticism, I may or may not take." John has had to be reflective in learning how to develop as a leader. Vignette \#3-Jesse

\begin{tabular}{l|l|l|l|} 
& Years & \\
& as & \multicolumn{1}{c|}{ Current } & \\
Participant & Leader & Position & Perceived Skill Level \\
\hline Jesse & 5 & Principal & Competent/Proficient \\
\hline
\end{tabular}

As we sat down at the table, Jesse looked at me starry eyed and enthusiastic to begin talking about leadership. Her world is filled with school leadership stuff research, mentorships, group facilitation- as she is the leadership fellow for her state department of education. Jesse never saw herself in education, but was glad she 
switched careers. Jesse has spent most of her adult career in the insurance industry. Being a bodily injury claims adjuster was convenient when her children were little because she could build her own schedule, and balance her career with being a mother. During this time, Jesse always volunteered at her children's school. While volunteering, Jesse realized she enjoyed not only spending time with her daughter at her school, but being with all of the students. Volunteering a few hours per week in her daughter's classroom was enough to persuade her to go back to school and earn her degree in elementary education. Jesse began her career in education as an early childhood teacher. She was a teacher for eight years. She was a founding teacher at a charter school in New England. Jesse and eight other teachers started at the charter school the first year in operation. Jesse proudly said:

This year, we will have our first graduating class. We've actually grown our district. So we started off with one school of just kindergartens, and we added a grade each year after that. Boy now, we've grown to three elementary school, two middle schools, and high school.

Being part of this growing school since day one has given Jesse a sense of commitment and motivation to want to grow as a professional along with her school.

While teaching, Jesse was a teacher-leader. She also was part of a twoteacher model, which allowed her to work with a co-teacher on a daily basis. When her current head of school went on leave, her superintendent placed her as temporary head of school at the middle school. Once in this temporary leadership role, Jesse saw a new way to deepen her roots and love for education. The head of 
school did not return, so Jesse naturally became the acting head of school. However, Jesse was not certified as a building administrator yet, and still had lots to learn. Jesse loved her new role and wanted to stay. Jesse enrolled in the Principal Residency Network (PRN) through the Center for Leadership and Educational Equity (CLEE) to get certified as a building administrator. Jesse's mentor was her current curriculum director. Jesse has been the principal at her school for five years. She said, "I never remember a moment saying, 'Someday, I want to be a principal.' I have not really thought about it and then voila."

Being a school leader for five years, Jesse perceives herself to be between competent and proficient as a school leader. About her five years as principal Jesse said:

I got all kinds of professional learning opportunities, so I engaged in a leadership program with the KIPP schools and some other leadership programs around the country. I visited a lot of schools around the country. So really [I have had] great learning experiences as a leader.

She perceives that she is competent because she "still contemplates when making decisions." Though she has five years of SLship experience, she "really deliberates when making decisions." Decisions are based on considerable conscious contemplation of a problem (Dreyfus \& Dreyfus, 1980). She attributes her deliberation to having a "strong leadership team and respecting their opinion." She deliberates because she values the input of her leadership team. Jesse also speaks to, "Able to see their actions in terms of long-range goals or plans" (Dreyfus 
\& Dreyfus, 1980). She said, "I'm driven by long term goals that we set for our school in general."

Jesse perceives she is proficient in her level of flexibility. "The leadership team works really cohesively so I'm inclined to never make a decision without including them in the process." She perceives she gets better and better each year, as her understanding of being a principal and her school needs deepens. Jesse has a deep understanding for the needs of her school since she was a founding teacher and now leads the school. However, since her school has developed she said, "Its like building the plane while flying." Jesse said, "I don't lack confidence or fear of losing control. So for that reason, I think I would be proficient.” Making mistakes has helped her get to where she is at. Jesse said with a lighthearted smile:

I remember very vividly that the first year really thinking that I was good at my job if my staff liked me type thing, and I really avoided having any really hard conversations. I remember wanting to please everybody and then feeling really frustrated because there was no way to please everybody. I didn't have the systems in place or even know of what types of systems I needed that would really help to grow our teachers. I was working with a huge population of brand new just out-of-school teachers or TFA corps members and really not having any type of systematic approach to developing them.

As Jesse began to get experience as a leader, she realized that it was her job to build equity, not to get everyone to like her. Jesse said that, "Years of soliciting feedback 
and analyzing the feedback and not excusing the feedback or ignoring the feedback" has helped her develop as a school leader.

Jesse puts herself out there to elicit feedback several times throughout the year in several different ways. Every school leader in her building has a complete 360 survey, "done on them every other year. The data that comes back from that is always really eye opening and pretty deep." Jesse also came to realize that its not just her who needs to be reflective and in the classrooms, but her colleagues as well. Jesse has built a protocol for teachers to follow that gets them observing one another's classes and then having follow up, reflective conversations. This protocol is documented and mandatory for all teachers to participate. Jesse is a firm believer in reflection. Jesse always asks herself, "how do I create those opportunities to get feedback." Jesse continues, "I also do a listening tour towards the end of each year. I will meet with every staff member just to sit down and have a cup of coffee, and I pick their brains midway through the year."

One challenge Jesse points out is time. "I feel like a lot of times, there [are] things I want to do or try to do or try to get feedback... but just time has not allowed me to." Jesse also alludes to time being a challenge because she feels exhausted and overwhelmed at times. Jesse said with an honest tone:

I think there have been times where I haven't been receptive to feedback so that has kind of hindered me. I also think working for a school district where we are like building a plane while we're flying it, the learning opportunities kind of take a back burner then. 
Though time and the demands of the job can be challenging to navigate, Jesse "has many touchpoints every day with teachers and kids" that assist in her being effective at her job. Jesse has "systemized everything from relationships to communication" and this seems to work for her.

During her time as principal, she applied and received a position as the leadership fellow for her state department of education for two years. She is currently a mentor in the PRN program. Jesse aspires to be an expert leader, especially when it comes to "being aware of contacts and the needs of those they serve" (Dreyfus \& Dreyfus, 2004). Jesse believes in constant professional development that a school leader needs to seek out on their own. Jesse said, "I push myself to grow, whether it's participating in a program for SLs, visiting other schools." Jesse perceives as she continues to grow in a school that helped her grow, her teachers and students will grow along with her.

Vignette \#4- Jaime

\begin{tabular}{|l|l|l|l|}
\multicolumn{3}{c}{ Years } & as Current \\
Participant Leader & Position & Perceived Skill Level \\
\hline Jaime & 6 & Principal & Proficient \\
\hline
\end{tabular}

Phones were ringing, people were talking, and beeping was happening. All the while, Jaime remained calm, as if there is nothing was going on around him. At one point during the interview, Jaime had to leave to deal with a situation. He politely removed himself from the room and then calmly returned a few minutes later. Nothing seemed to phase Jaime. The situation was serious, but Jaime remained composed. Once we began the interview, Jaime's calm nature seemed to be exactly what his school needed. In a previous decade, Jaime was a financial 
planner and had his own health care brokerage business. The uncertainty of the corporate world seemed to break him in for the uncertainty happening around him. Jaime enjoyed his former job and was very successful as a manager and being his own boss. Though Jaime loved his job, he felt something was missing. For fun, Jaime coached boys' lacrosse and loved everything about being a coach from dealing with challenging personalities to helping the kids grow as athletes. One day, Jaime realized his passion was working with kids and looked forward to coaching lacrosse more and more. Without a second thought, Jaime changed careers into education because he wanted something more rewarding. Jaime began his career in education as a special education, business teacher at a suburban school in New England. He taught in a behavior classroom for five years. Though his job involved managing students with severe behavior problems, Jaime loved teaching and most of all coaching his students reach their goal.

One day, his assistant principal approached him in the hallway and told him he would make a good administrator. Jaime had considered being a school administrator, but it was his assistant principal who supported him to take the steps to become a school leader. At this point, Jaime shifted in his seat in a proud way. Jaime enrolled in a school administration program and earned his school administrator certification. Jaime was concerned that moving from being a teacher to a school leader would take him further from his students. He recalls his assistant principal saying, "The further up the ladder you go, the further away you get from the kids. That is why I always like staying in my position as assistant principal because I work with kids more." Also, Jaime knew that if he were to get a position 
within his district, it would be difficult leading in his own land. The staff at his school was very difficult to lead. "For eight years there was a new assistant principal at the middle school in which he was a teacher." Jaime did not let his fear of staff or moving away from the kids deter him from pursuing his pathway to SLship.

Jaime became assistant principal out of the district he taught in and was the first assistant principal to stay more than one year in nine years at this middle school. Eventually became principal of a collaborative school his district opened. Jaime loves his position as principal because the collaborative is a "small program with three middle school classrooms, three high school classrooms, and three different programs for high school." Also, the Briggs Program is within his building. "Mostly every student in his building receives special education services and has emotional and/or behavior disturbance issues." Jaime enjoys being principal in the small setting because he "gets to use both his special education teacher and administrator hats." Jaime said with a laugh, "I'm in a behavior school, and when I say we have a fun day, it can be a whole lot of fun." By "fun," Jaime means unexpected situations arise that can make his day very interesting. He taught in the behavior classroom when he was a teacher so he feels as though he never left.

After being a school leader for six years, Jaime perceives he is proficient at being a school leader. Jaime perceives he has grown from competent to being proficient. Jaime said in his even-keeled tone, "I connect most here where the scale states, 'The whole in terms rather than the specific parts." Jaime always looks at 
situations with the "big picture" in mind. He does deliberate when making decisions and "needs to talk it out." He said, "the school has been opened for three years and we keep building the plane as we are flying, so we come across things that we have not come across before due to the nature of the school." Because the school is new, Jaime is very flexible when making decisions and opened to solutions that will be best support the students and staff at his school. Jaime said, "It is the rigid teachers that are the most difficult to work with. They have the most problems within their classroom because they're so rigid." Jaime perceives that being a successful school leader, and teacher for that matter, in his school, requires flexibility. Though Jaime is flexible, he does know when to draw the line on a decision and move forward towards a solution.

One aspect of the job that Jaime finds difficult is dealing with difficult teachers. He finds navigating difficult conversations challenging because most of the time he does not want the person he disagrees with to feel he is personally attacking them. Most of the time, the difficult teachers have extremely difficult personalities and traits that make navigating the conversation hard. Jaime understands that addressing the difficult teachers is needed, rather than ignoring their behaviors. Jaime said, "it is difficult to get rigid thinkers with difficult personalities to change not only their thinking, but their behavior."

Despite flying the plane while building it, Jaime perceives he has been a successful school leader. Because Jaime and his teachers often have to de-escalate situations with students, Jaime remains calm, and chooses to be flexible. He perceives his flexibility and demeanor to be why teachers want to stay at the school, 
despite the situations. He said, "every year, teachers have the chance to bid out of school building within district and no one ever bids out of his building." $\mathrm{He}$ interprets his staff staying as an attribute to his flexible and supportive leadership style. Over the past six years as a school leader, Jaime has had the opportunity to find and develop his leadership philosophy, and ultimately, make it work for him. Vignette \#5-Mack

\begin{tabular}{l|l|l|} 
& \multicolumn{3}{c|}{$\begin{array}{l}\text { Years } \\
\text { as }\end{array}$} & \multicolumn{1}{c|}{$\begin{array}{l}\text { Current } \\
\text { Participant } \\
\text { Leader }\end{array}$ Position } & Perceived Skill Level \\
\hline Mack & 9 & $\begin{array}{l}\text { Assistant } \\
\text { Principal }\end{array}$ Proficient \\
\hline
\end{tabular}

Being part of a family of educators, Mack wanted nothing more than to work in education. His confident tone filled the air as we spoke. Mack began his teaching career in 1995 as a middle school teacher. Mack loved being part of the middle school environment. He loved working as part of middle school teaching teams, and more importantly, has a passion for working with middle school aged students. Within his first few years as a teacher, he started to take on leadership roles because he wanted to make a larger in education. At the time, Mack had gone from teaching in one suburban middle school to another to be in a leadership role. He was a grade leader where Mack said, "I was part time in the classroom and part time performing leadership in terms of scheduling, management evaluation, and some discipline." Though Mack loved being part of his middle school team, he said, "I was interested in the leadership role." Mack wanted to teach in another school not only for the leadership role, but "because of a mentor that I had who was 
the principal there at the time." Mack said, "I saw what my principal did, I had a lot of respect for him and he encouraged me to move in the direction of SLship. This is where I really became interested in being a school leader.”

After encouragement from his mentor, Mack became serious about being a school leader. Mack earned his Masters in School Administration and in 2004, he became an assistant principal of a suburban middle school, not too far from his current school district. Mack quickly realized, “what's interesting about education is that the higher up you go, you take on more responsibility and more work." After seven years as an assistant principal, Mack became the principal at his school in 2011. After three years as principal, Mack needed a change. Mack said with a serious tone:

Being a leader for a while, there are times when you are tired. You get burned out. Part of me leaving the [job] was the amount of expectations that come, especially when you're a principal, when you're number one. There are things you are going to do right. There are things you are going to give up. You cannot have it all.

Having a troubled sense of work-life balance, Mack decided to pursue another path. "For two years I was an executive director for a non-profit what was involved in schools. I oversaw middle school sports for the state." After two years away from the school building, he realized the pastures were not greener. Mack quickly returned to SLship and became an assistant principal at an urban high school. Though he had never worked in a high school or in an urban setting, Mack applied his experiences he had and took this opportunity to grow. 
After nine years as a school leader, Mack perceives himself to be a proficient school leader. Mack said, "I am a systematic thinker" meaning, "if a problem arises, I'm sort of thinking systematically on how to solve it." When solving problems as a leader, it is important to think of a solution that will have the least amount of consequences. Mack said, "decisions that you make [where] there are unintended consequences, you have to really do your best to sort of figure [solutions] out [as best you can]." Though he has only worked in an urban high school environment for three years, he feels as though he is a well-respected member of his leadership team. He can relate to his principal because they both have middle school experience. He works as part of a team of three, two assistant principals, and one principal in the same building.

Building personal relationships has helped in his work with his leadership team, teachers, staff, and students. Mack tries to make decisions systematically by collaborating with his peers, other administrators, and staff members to ensure that whatever decision is made, he can see it through with the least amount of complications as possible. Mack believes that thinking systematically comes with experience, "and [having time to think decisions through] comes with experience."

Mack approaches leadership in three or four dimensions. As if he is giving advice, Mack said, "I think [SLship] is a terms of a three or four-dimensional idea that you have to support yourself, students, staff, and teachers." To support these four dimensions, Mack works "very collaboratively both with my peers, the administrators as well as with staff." With a chuckle, Mack said: 
A lot of times, if you have an idea, you might think it's the greatest idea in your office and have it all figured out. But when you work collaboratively, what happens is you see your blind spots and that's good because if you can do it in a small working environment, and those questions may come up later, some questions may change how you approach what the situation is.

Mack finds it pleasant to collaborate because "I'm good at making personal connections with people and that helps in the work that I do with the leadership team, my students, and with our staff."

Since he has returned to being a school leader, Mack still finds the worklife balance a challenge. Though he finds the balance tiring at times, he perseveres on and focuses on other things like setting goals for himself, or seeking out professional development opportunities. Mack believes that "good leaders keep themselves abreast of best practices" and one way to keep abreast of these best practices would be to attend professional development. Mack said, "working in education can be very rewarding, but also very frustrating." Mack urges, "You have to be collaborative about it. You really need a team to kind of come out and say, 'look, here are some ways to think about [the subject]." Though he is not at a middle school, he loves working part of a supportive leadership team at his high school. With each year of experience, Mack's idea of SLship and how to be an effective leader has solidified for him. Mack said, "Sometimes we need to give than to practice. I'm in a different place [as a school leader] today than I was ten years ago or even five years ago. I think some that comes with experience.” Vignette \#6-Moe 


\begin{tabular}{l|l|l|l|}
\multicolumn{3}{c}{$\begin{array}{l}\text { Years } \\
\text { as }\end{array}$} & $\begin{array}{l}\text { Current } \\
\text { Participant }\end{array}$ \\
Leader & Position & Perceived Skill Level \\
\hline Moe & 9 & Principal & Proficient/Expert \\
\hline
\end{tabular}

"So I kind of always knew I wanted to be a kindergarten teacher," said an enthusiastic and animated Moe. Based on Moe's outgoing and exuberant attitude, it was easy to see how she would have made an excellent elementary school teacher. Moe appeared put together and relatable. Something about her energy just made her seem fun and easy going. Though she is easy going, Moe's energy remained exciting throughout our conversation. She attended Boston University and majored in elementary education. While in classes, Moe had the opportunity to take a sign language class. Her sign language class deepened Moe's love and enthusiasm for education. She graduated with a Bachelor's Degree in elementary education and went on to receive her Masters in Deaf Education. At this point, it is clear to see that Moe set herself up for a natural progression into elementary education. However, this couldn't be further from the truth. Moe began her teaching career at a school for deaf children in New England and taught grades 6-9. Far from kindergarten age students, she said, "Turns out I actually preferred middle school aged students." While at her school, Moe received a second Masters degree in School Administration.

While teaching at her previous school, she "did take on a lot of leadership stuff; worked on a team, and was the unofficial team leader." Moe said, I did all of the scheduling for our team. I did a lot of administrative tasks for our team." Moe's excitement for education and involvement within her team did not go unnoticed. 
"One of the other people on my team who had moved into administration said, 'Would you ever consider getting into administration?'” Moe had not given school administration too much thought since her Masters program. Moe said, "Being able to see the big picture stuff, and seeing scheduling, and other stud like that, I kind of thought, "well, this would be a good, natural lead in." Moe also felt that there were some things in administration that frustrated her and she decided that she could do them differently. Moe eventually became a school administrator at the school for deaf children.

Due to many changes happening at this school, she decided to seek out other SLship positions. In the same year she received a principal position at a rural junior high school, she was enrolled in her first year of a $\mathrm{PhD}$ program in $\mathrm{New}$ England. With the utmost excitement and a hint of sarcasm Moe said, "I actually changed jobs the first year of the PhD program, so it's like, 'Oh, good, a new job, and I'm just starting a PhD program?!' Yeah, it was fun." Though she had what some would consider an overwhelming amount on her plate, she successfully earned her $\mathrm{PhD}$ and has been the principal at her current school for nine years.

As a school leader, Moe places herself between proficient and expert on The Model. Moe said, "I saw some good leadership qualities and things that I wanted. But I also, as a teacher, kind of knew that things that I thought would help me." Moe places herself in proficient because she "looks at deliberating when making decisions and operates from a deeper understanding of total situations." Moe makes a lot of decisions "but when it's something that I really want to be sure about, you need to have that person to deliberate with and discuss." For Moe, this 
person is her superintendent. "I find myself really fortunate that I have a superintendent who is really open and somebody that respects my deliberation." Because she needs to deliberate on certain instances, she perceives these conversations have forged a good relationship between them. Moe will also deliberate with "teachers [she] can trust, but at the end of the day, they do not know the whole picture." Moe said, "it's important to deliberate, but always to do that reflection on what you do and kind of be able to talk through it, and have somebody to talk through some things on." In one instance, her superintendent helped Moe deliberate and the outcome turned out, according to Moe, surprisingly well. One of Moe's teachers was constantly late to school. Moe had addressed her informally on several occasions, and eventually gave the teacher a verbal reprimand. At the meeting, Moe presented her with a letter that, if she was late next time, this letter would be in her teacher file as a written reprimand. The teacher did not see how serious her being late was until she saw the letter. The teacher asked Moe for one more chance. Moe was frustrated and stuck. On one hand, she had given the teacher many chances and was steadfast on following protocol to hold this teacher accountable. If she did follow protocol, this would also tell the other teachers that Moe respected all employees being on time to school, and she would hold those who are not accountable. However, on the other hand, Moe had given this teacher chances in the past, so what was one more chance before Moe drew the line. When Moe deliberated with her superintendent, the superintendent asked, 'Well, what do you want the outcome of this to be?" She replied, "I want her to come to school on time." Then the superintendent said, "So does it matter if she gets one more chance 
and you very clearly set the expectations for her? I can also come to a meeting and tell her that the letter is in her file and will not be activated until her next tardy. It's your call. Do you care that the letter is in her file, or that she is on time?" After deliberation, Moe realized that in order to get this teacher to get to school on time, she would give her one more chance. In retrospect, Moe said:

I decided one more chance and the teacher's behavior changed. It changed not just her behavior, but our relationship. This decision also really impacted the other teacher because they saw their colleagues' behavior change and it was not in a punitive way.

Moe takes pride in deliberating and finding the best solutions because she was victim to many "one size fits all solutions" at her previous school, which she found ineffective since the right people were not being held accountable. Because of this experience, Moe tries her best to differentiate things as much as she can for her teachers. "What works for one person, does not always work for someone else. You learn that in your teacher training, and I think we forget to apply that when we get to administration." To get away from the "one size fits all" approach, Moe "has teams at her school that do things very differently, but who all make it work within the context of what they are working towards." Rather than wasting time trying to make people fit the mold, Moe spends time trying to make the mold flexible for her teachers.

Moe's intentional choices shows that she knows her staff. Moe perceives part of herself as an expert because she is very reflective, which she said "[ reflective] is one of the hardest things to do especially in a very small district." Also 
being in a very small district can make building relationships a double edged sword. "I have spent a lot of time building relationships while also being personable and engaging with colleagues. I think relationships are a huge thing in administration and that's something they do not teach you-how to balance those relationships." At one point in her career, Moe realized she would avoid certain teachers and students because she did not want to interact with them. Her interaction with these individuals always seemed to be negative and she chose to avoid it. However, after reflecting, she realized, that avoiding them was not doing anything in regard to making their interactions more positive. One of Moe's favorite books, If You Don't Feed the Teachers, They Eat the Children, helps her remember that showing support to staff is important. This book helped Moe reflect even further on what building relationships meant and her role in balancing those relationships. Moe loves to bake so she bakes for every team meeting. Moe said with a giggle, "Its goofy, but the teachers love it and it is a small way to show them I appreciate them." Moe is aware of the context of her school and the needs of those she serves. She attributes her understanding to being reflective, as hard as it can be, to building and mending relationships.

Moe is the only full time administrator in her building. Despite time and staying organized being a challenge, "I think because the school is so small, we have that opportunity to build those relationships and then that kind of pays off in the end." Though working in a small district can be challenging, Moe has navigated the small town, close knit vibe of her school with grace. Moe loves the age group she works with and loves being with the students any chance she gets. Moe loves 
lunch duty because it is one of the times she can truly get to know and listen to her students. Moe said, "listening to what people have to say and having them feel heard. It's a big thing for parents. It's a big thing for students. It's a big thing for teachers." Though Moe perceives she still needs to improve on balancing the complicated dynamics and personalities when building relationships, her ability to listen has helped her earn respect from parents, teachers, and students. Moe wants all to realize that she is here for the betterment of the school and there to support her students and teachers. At one point, an administrative position opened up at the high and everyone thought she was going to leave her current position, Moe said, "No way. I love the junior high." Moe's sense of commitment, and persistent enthusiasm has helped her become a successful school leader in her district.

Vignette \#7-Remi

\begin{tabular}{l|lr|l|}
\multirow{2}{*}{ Participant } & $\begin{array}{l}\text { Years } \\
\text { Leader }\end{array}$ & $\begin{array}{r}\text { as } \text { Current } \\
\text { Position }\end{array}$ & Perceived Skill Level \\
\hline Remi & 10 & Principal & Proficient/Expert \\
\hline
\end{tabular}

It was the writing of John Dewey that influenced Remi, a college student at the time, to become an educator. John Dewey's philosophy on the importance of education in our society influenced Remi to want to be a part of something larger. Energetic and excited to talk about his SLship experiences, Remi has never looked back on switching his major to education. Remi switched his major from Computer Science and Engineering to Education. Needless to say, Remi became a teacher and taught for 13 years. Remi wore many hats as a teacher. Within his 13 years as a teacher, he took on many roles such as, teacher leader, union representative, and 
teacher leader in work for the State Alternative Assessment. Remi always strived to be more and more involved in the greater education community. He is always on the search to be part of something larger. After 13 years in the classroom, he realized he wanted to be able to grow a community beyond the classroom. Being very purpose driven, Remi enrolled in a Master's in Education Administration program in New England. His program "expanded his horizons" and exposed him to a different network of school environments and SLs. When in his program, Remi realized, "a good leader should be able to help and guide [the school community through] a shared vision and mission for what [all] want the school to be." This realization has been part of Remi's philosophy as a leader ever since. In 2009, Remi became a principal. He was the principal in two schools his first two years and has been the principal of a suburban school in New England since 2012, where he has remained principal for seven years.

Remi perceives himself to be high proficient, low expert. With a very proud tone, Remi said, "I create teacher teams that improve student achievement and close learning gaps." Remi based his perception of himself as a school leader on student achievement in his school. Working towards meeting the goals of the school improvement plan drives how Remi conducts himself as a school leader. Remi said, "[Its about] not using top down, but building capacity." In order to build the understanding of his staff and ensure all are part of improving student achievement and closing achievement gaps, Remi built collaborative teams that meet every month to "look at multiple measures of student data and challenges." Looking at multiple measures of student data helps Remi understand the needs for students and 
teachers in his building. At a building level, Remi said, "knowing your people" and "how to guide them" will help "lead our students." Remi knows his people well, and therefore understands how to navigate them towards meeting their goals. Remi said that developing trust and having a strong sense of confidentiality gives teachers the freedom to think critically. As the school leader, he "helps by guiding" the teams towards their goal. Leading people to solutions and have his teachers understand the goal and then discovering how they are going to get their by working collaboratively. Bringing groups together across the district has helped Remi and district leaders live out a shared vision and mission among all.

Remi is very proud of the gains in improvement him and his staff have made around student achievement. Though he is proud of the gains, he still has to face the challenges of time management and prioritizing many important issues at once. However, though trying to accomplish a goal is never simple, Remi finds the simplest path to achievement in working with a team. Remi finds that leading a team to a solution by knowing how to facilitate the people involved in the work achieves results. Remi said a school leader must "develop trust" among his staff in order to build effective teams that will achieve results.

Vignette \# 8-Reese

\begin{tabular}{|c|c|c|c|}
\hline Participan & $\begin{array}{l}\text { Years } \\
\text { as } \\
\text { Leader }\end{array}$ & $\begin{array}{l}\text { Current } \\
\text { Position }\end{array}$ & Perceived Skill Level \\
\hline Reese & 12 & $\begin{array}{l}\text { Assistant } \\
\text { Principal }\end{array}$ & Competent/Proficient \\
\hline
\end{tabular}


Being a school administrator was not in Reese's career trajectory. As we sat and talked, Reese laughed every time we discussed her leadership role because she cannot believe she is a school leader. Reese, a very soft and kind woman, always knew what she wanted. Reese began her career in education as a Physical Education and Health teacher. She "would hang out and play with kids all day." Though she did love "playing gym" with her students, Reese did eventually see herself as a guidance counselor. Reese's school was fairly new at the time and there was always much transition going on. One summer, Reese assumed a quasi-role of guidance counselor and administrator. Reese said, "I did the schedule [and other administrative things that summer." During that summer her current principal "saw her leadership skills and said, 'I want to groom you for this position." Within this time, she enrolled in a Masters program and received her masters in school administration. At her current school, there was a leadership vacancy and she was asked to fill the position for a few months. Her current school leader saw potential in her leadership abilities and helped her become the Dean of students at her current school where she has been for 12 years. She has had opportunities to be a principal within her district, but likes her leadership role.

Her role as Dean is very unique to her school. She is both guidance counselor and dean of discipline, and also absorbs other administrative roles such as teacher evaluations, building the school schedule, etc. Her role is almost as unique as her school. Reese describes her school as "eclectic." She said, "Our student population is very diverse, but our faculty population is not unfortunately. We've done more outreach [to get more diverse applicants].” Reese goes on to say 
with an exciting tone, "We have been adding more and more [support personnel] and being more creative with how [we add personnel]." Her school likes to "groom from within" because "when we see people skills [we want to keep them]." Just as she was approached by her principal to be a school leader, she likes to see the potential in others and do the same.

Reese perceives herself to be between competent and proficient school leader. In terms of her development, she perceives growing with her school from teacher to administrator, has been both a blessing and a curse. When Reese first became a school leader she had access to a principal who was experienced and who she saw as a wealth of knowledge. Reese said with a smile, "[My last school leader] would get emotionally charge about things and show his more human side. You had to realize that all his intentions were always about serving the kids and what was best for the school and best for the kids. His decisions were not about what was best necessarily for the adults. But he was always willing to listen. He was always open and have those conversations, you know, if you went in with a question or concern [he would listen and] validate how you were feeling." Reese felt her principal at the time was a wealth of knowledge whether she watched him handle others or asked for advice. She feels as though because he always made decisions that were best for the students, he was respected. She tried her best to balance decisions that are best for the students while still handling the adults. Reese's current principal handles himself differently as a school leader. Reese said, "My current principal is not quick to show emotions, and lets things fester, and then agitate him later. [Sometimes] you do not know where [his reaction] came from. 
He has empathy for the kids, but also empathy where the teacher stands." Reese has come accustom to modeling herself more after her first principal since she deals directly with students directly. Reese has felt her former principal has helped her truly reflect on situations and develop into being a competent and proficient school leader in her school.

Though Reese has been able to grow within her school, she perceives she has been hindered at staying in the same building. Reese said she wants to get better at knowing the broader curriculum at her school and supporting teachers with curriculum and instruction. Reese said, "Being the Dean of Students, that's where I was grounded and that's where I really spent all of my time is working with the students and developing metrics for Tier 1 [interventions], teacher strategies not a problem, and [differentiating lessons]. But raw-based curriculum, like backwards design, that sort of stuff, I didn't deal with it as much when [the school] developed [our curriculum]. So I'm a little behind that." Reese feels as though she would have access to more resources and see how other districts implement curriculum if she worked in other schools. Though she feels this way, she does not regret staying at her current school and growing with their programming. Reese said, "I feel like you definitely learn from others and their experiences, and [if you don't have shared experiences along the way, it makes it very difficult [to lean]." Reese is also still developing where to draw the line on decisions, especially knowing when to say, "No." Reese admits she spreads herself too thin by being supportive to teacher, but still grapples with knowing when to say, "No" to certain ideas. Sometimes saying no helps her give more attention to initiatives and see them through. 
Working at her school, she said "it's a lot easier to get to know the kids." Though her position is unique and challenging as she is trying to learn the aspects of her ever developing role, she loves how close she gets to work with the students and impact them directly. Reese said, "Going to a traditional district, I think I would have to find myself more at [events] to have these conversations, but if you're attending sporting events and other athletic clubs to just be more present there to develop that with the students at least. Its really important for kids to see you outside that traditional day." Reese loves being part of the state wide principals associate because it gives her access to professional development and school leader she otherwise would not have. Reese's continuous passion for her students and her school motivates her to want to continue to develop her practices and skills as a school leader.

Vignette \# 9-Marley

\begin{tabular}{l|l|l|l|}
\multicolumn{1}{c}{$\begin{array}{l}\text { Years } \\
\text { as }\end{array}$} & $\begin{array}{l}\text { Current } \\
\text { Participant }\end{array}$ & Leader & $\begin{array}{l}\text { Position } \\
\text { Perceived Skill Level }\end{array}$ \\
\hline Marley & 14 & Principal & Expert \\
\hline
\end{tabular}

Some people are able to handle more than others. Marley is one person who can handle anything that comes her way. She is never satisfied because she is wired to learn and keep learning. Her dedication to her job and her family parallels the work she does as a school leader. Marley welcomed any challenge she faced as a teacher and has taken that philosophy with her as a school leader. Marley is a veteran educator who is still excited about education. Marley has spent a lifetime in education. Marley was an elementary special education teacher for 28 years. 
During this time, she also took on teacher leader roles such as, being a representative on the School Improvement Team, chairing IEP meetings, and standardized testing coordinator. Marley was also the interim principal when her principal was out of the building. During this time, she developed a keen skill set for assessing students. She would then use the assessment data to write reports with actionable goals. After 28 years as a teacher, she felt she wanted more of a challenge. Marley said with happiness:

When my children were off to college, I decided I would like a new challenge in education. I have always been someone who likes to continue to excel and achieve. I also thought I had a lot to give as an administrator with my special education background. I wanted to be able to help a whole school grow.

Being a person who always wanted more out of education and herself, and who always put one hundred and ten percent of her effort in to her school, being a school leader was a natural progression for Marley. She began her first years as a principal in an urban community. Though she enjoyed her time here, Marley said, "The urban district was struggling financially so I decided to move to a district that appeared to be more solvent." She became the principal of a suburban district in New England where she has remained ever since.

After 14 years as a school leader, Marley perceives herself to be an expert school leader. During this time, she has earned her doctorate and speaks to how the schooling contributed to her leadership growth. She said, "Working on my doctorate five years prior was an important part of helping me become an expert 
leader." Marley said:

Working on my doctorate helped me to become an expert leader because I [used my school] as part of my doctoral [research]. I interviewed staff and students about their perception of respect. This gave me thousands of hours of time with the members of my school community. It helped me to see many new insights into the school culture and climate.

Spending time with her staff and students led Marley to see their needs on a deeper level. Marley is able to now "react flexibly with intuitive practiced, understanding from thousands of hours of reflective performance." Because of her deep understanding of their needs, Marley has been able to see through successful changes at her school. Marley said:

For instance, learning from the students that their learning was important to them and they did not like it when children's behaviors interrupted them, we made changes our behavior referral system to facilitate this. We provided at risk students with mindfulness practice weekly and saw their scores improve.

Marley believes that a school leader must seek out their own opportunities to learn in order to continue to "stay ahead of the curve on all new educational process" and meet the needs of her school community. Being the true overachiever she is, Marley provided a plethora of documentation that would help anyone understand her dedication to her school. In order to meet the needs of her school community, Marley puts a monthly newsletter out to staff highlighting important data to keep her teachers on track in meeting their school wide mission and vision. Marley also 
condensed her school improvement plan in to a graphic organizer to assist her teachers in seeing how the data relates to the overarching goals and action plans. Marley has taken her assessment and data analysis expertise and tailored it to helping her school meet their school wide goals.

Though Marley has a deep understanding of her school's needs and understands how to navigate her school towards achievement, she does face some challenges that hinder her development as a leader. Marley said, "micromanagement from central office has been a difficult experience for me." Marley knows her building and perceives that "[the principals of the schools] should have input into how many classes are needed in the building based on numbers and the types of students- but we are given a list to comply with regardless of expertise." Marley has wanted to implement new initiatives for her school, but could not due to the lack of support from central administration.

Marley has a hard time dealing with the lack of freedom and support she has at times, but knows how to balance the positives and negatives in working in her district. In her district, she has access to an "underground network" of administrators where she can access advice from peers anytime. This has helped her stay "positive and balanced." Because she has so many years as an administrator and the knowledge and understanding of assessment, she feels she wants to share her expertise to help her school move forward. 
Vignette \#10-Reily

\begin{tabular}{l|l|l|l|} 
& Years & as & Current \\
Participant & Leader & Position & Perceived Skill Level \\
\hline Reily & 21 & Principal & \\
& & & Expert/Master \\
\hline
\end{tabular}

Reily began his career in education as a per diem substitute teacher in an urban city in New England. He eventually became a full time English teacher. After a few years as a teacher, he became frustrated with the lack of equity in education. There were increasing number of students in classes, so few supplies needed to give students a fair and equitable education, and the school building was less than decent. These feelings of inequity made Reily think, "I can do something in this business beyond being a classroom teacher." Reily then said with a smile, "I never liked the way schools were treated like a second-class citizen when they should really be everything." Acting on his frustration, Reily became interested in charter schools. He was attracted to the charter school model because "I was just so into school, in making schools great, and the charter model answered everything for me. So, that was the path, it started with charter." In 1994 he founded the first charter school in his state and eventually went from English teacher to principal. In 2001, he created a statewide group for charter schools. He since has turned around a few charter schools and is currently the principal at a charter school in an urban city in New England.

Because he was at the forefront of the charter school movement in his state, and has been involved with charter schools for over twenty years, Reily perceives himself to be an expert school leader. Reily enthusiastically said, "I went from 
English teacher to novice principal, and it was very, very hard." Since his novice days, Reily has been the turnaround leader at several schools. Only six years into being a school leader, Reily went from being a principal at the first charter school in his state, to a turnaround principal. Reily said, "I was conscripted to be the turnaround guy at another charter school in 2004. That was the school whose charter had been revoked by the state. The state wanted the charter to go. The people didn't and in the end, the people prevailed because the kids, and the parents, and the leaders, 'Please don't kill (school name).' Reily said, "I had a baptism by fire, and I can't say I was prepared for it. The term fits. I had no experience. I didn't even have an internship as principal." Reily said he is an expert because, "People will stay with me." Reily has had many teachers who have stayed with him as he has navigated the charter school territory. Reily proudly said, "I was only able to be successful because I had no idea what I was doing. I mean seriously, I just went into it. We got the charter. It was very controversial. Because of my union background, I always was like scrap burner fighter who always wanted like a piece of the pie. But now, it was a piece of the pie for the school." Reily attributes his expertise to taking risks and placing himself in uncomfortable positions. Reily said, "Placing myself in very uncomfortable positions, where I had a tremendous chance of failure, was one of my best leadership traits. It kind of grew in every experience because I just placed myself in jeopardy.”

Being the founder of the charter school movement, Reily has much experience to speak from, and shares his experiences as a way of professional development for himself. Reily said, "[Professional development] comes to me. I 
keynoted the superintendents conference in Kansas City." Reily speaks at professional developments and conferences. He loves sharing his story and helping others understand the passion and determination needed to be an expert school leader. Being a school leader in uncharted territory, Reily said, "The school leader takes on the identity of the school."

Summary of Vignette Analysis

Locale/Constituents

Though the literature reports school context influences the various skills and practices used by SLs, there were no substantial findings around participants from different school contexts applying different skills and practices. Although the research indicates (use earlier citation) SLs in urban districts tend to leave within the first three years, this was reported by only one participant. Two participants spoke about leaving their SL roles at one point, but for different reasons. Marley reports that after working in a "high needs" district, she wanted to move to a more "stable" district with less financial issues, so she did. Marley's example supports principal turnover in urban schools. However, she did not speak to the difference of skill or practice applied to each context. In dealing with the different constituents at their various schools, there were no significant findings as to how locale and constituents influence their practices or skill development.

When participants were asked about the skills and practices that are most relevant in their school context, there were no varying differences in the findings. participants reported the major themes (in Figure 1- "Others") as relevant practices to manage their responsibilities of being an effective instructional leader and 
organizational manager. These skills and practices will be explored in the next section.

Organization

Although there were no noteworthy differences in the practices and skills developed after their pre-service programs in various contexts, all participants reported facing similar challenges in their district contexts due to the organization of their districts. The literature reports school leaders face more challenges in urban or high needs school districts (Baker, Punswick \& Belt, 2010; Béteille et al., 2012; Gates et al. 2004; Johnson, 1996, 2004; Superville, 2018); however, there were no substantial differences in the challenges faced by SLs in different school contexts. The biggest challenge that almost all participants reported was dealing with difficult teachers. Dealing with the organization of people with the buried contexts of their school districts was reported as a challenge by all. For example, Gery reports the structures of the teacher's union and rules stifle him from supporting good curriculum and instruction. He reported one teacher being out on leave for almost two years, and he cannot higher a full-time certified teacher within this time frame. He has to settle for substitutes and hope they are certified. Further, Jaime reports the rigid mindsets of teachers being difficult to deal with because they cannot see the value of change and adaptation. Finally, Marley reports her central office micromanages her decisions and therefore, stifles her ideas and creativity as a leader. She may see a creative solution to dealing with teachers and keeping them focused, but often cannot make changes she perceives are necessary. Overall, dealing with difficult teachers was a challenge within each organization. 
One difference in the school context was that the SLs who led in urban districts and charter schools (Gery, Jesse, and Reese) had more supports available to them as leaders. For instance, both Gery and Jesse went through the PRN program and their superiors supported them in other mentoring endeavors their first years on the job. Gery and Jesse were first year principals as they were going through their PRN program. Reese reported having the support of her superior in continuing her education and utilizing him as a mentor whenever she needed him. It is unclear whether or not participants in public and suburban districts had these supports available to them; however, these participants seemed to take a more traditional pathway into school leadership. These participants reported getting a master's degree in school administration, becoming state certified, and then getting a position. Most reported having the support from another within their district in doing this, but did not report the same amount of support those who lead in urban districts receive.

This finding is contrary to the literature. The literature reports SLs do not receive the amount of support they need as novice principals (Good Principals Aren't Born, 2007; Johnson, 2005; Wallace Foundation, 2013). Based on the participant reports, it is clear the work the state department is doing in building principal support and principal development under ESSA (Riley\& Meredith, 2017) is being utilized in urban districts and charter districts. This does not mean other public schools districts within the state are utilizing these initiatives; however, based on the sample of participants, it can be said that urban and charter districts are utilizing the supports. 
Cross-case Analysis

Introduction

The cross-case analysis analyzes the major themes that emerged across the ten participant interviews. The cross-case analysis will answer research questions 3, 4, and 5. Figure 1 represents practices and processes revealed by participants of all skill levels. The themes are organized and are presented in two parts - "Others" and "Self."

Figure one illustrates how participants oversee the various goals in their school. This managerial model supports Brazer \& Bauer (2013) and the effort SLs use to improve teaching and learning by managing effectively and handling challenges. Participants spoke to how they manage their daily tasks over how they manage curriculum and instruction. This finding was surprising because it shows how far removed SLs can be from curriculum and instruction, even though they are instructional leaders (Darling-Hammond, 2012; Drago-Severson,\& BlumDeStefano, 2018; Elmore 2004). Participants reported that working with teachers on issues of curriculum and instruction was a way to get to know their people. Participants reported that as SLs they need to know their people both as professionals, instructional practitioners, and individuals. However, the participants did not discuss their work with around instruction any further. This is supported by the point Darling-Hammond makes in her interview with the Wallace Foundation (2013), “'Well, there's leadership over there and there's teaching over here.' That misses the boat in terms of creating effective learning organizations" 
(p. 18). The findings suggest that once SLs have an understanding that teaching is happening in all classrooms, they are satisfied. Though SLs need to be aware of teachers and their instructional practices (as seen in Figure 1 in Know Your People), looking at the model, SLs manage it from a distance. Figure 1 provides a visual of the themes that emerged from the cross-case analysis. Each part of the figure will be explored in this section.

Figure1

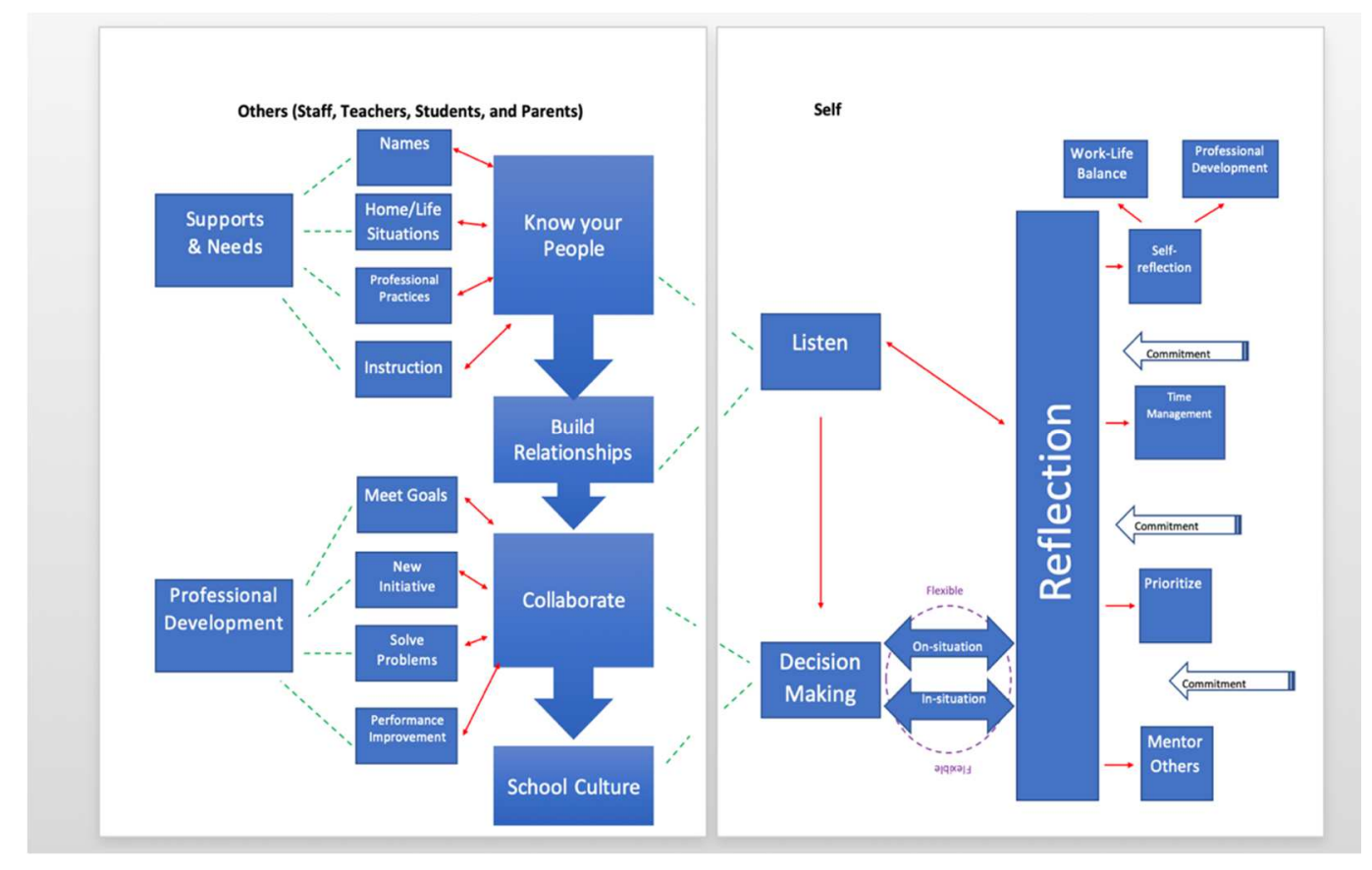

Others

SLs oversee a complex system of people who are involved in and affect the culture of the school. As Darling-Hammond (2012) suggests, school leadership must focus on instruction and organizational management (Wallace Foundation, 2013). The school leader's role is to ensure that the organizational management and the school culture, in particular, embraces a positive, inclusive energy that helps meet the mission and vision of the school (Hall et. al., 2016). In Figure 1, "Others" 
refers to the people SLs organize, other than themselves, in order to meet the goals of the school. The others are students, teachers, staff, parents, school board members, constituents, etc. When asked what leadership skills and practices the SLs used at their schools to be effective, participants often spoke to the organizational management. Often, participants spoke to how they get "their people," as if they were chess pawns, strategically placed in the unseen fabric that forms the school culture. When there is a positive school culture, participants said they could work towards school goals in the school mission and vision. Four main themes emerged that ultimately influence the culture of the school. The four themes that emerged in the data are 1) Know your People, 2) Building Relationships, 3) Collaborate, and 4) School Culture. These four themes will be explained in the next section.

\section{Know Your People}

Just as a chess player must know the rules and limitations of each chess piece, and the overall strategy of the game, a school leader must know their people in order to know when and how to strategically use them to build a positive school culture within the school. Unlike chess pieces, with clearly defined rules, the people that a school leader interacts with have no rules attached to them. This means the school leader must get to know their constituents (i.e. parents, community, etc.) in order to help them succeed within the school culture. A school leader must get to know and understand the strengths and limits of their people, to then apply how to fit them strategically into the school goals and culture. SLs view their people as "their most important asset" (Bolman \& Deal, 2013). Participants spoke to getting 
to know their people as a critical part of their job, not only as professionals in the context of the school, but their lives outside of school.

As seen in Figure 1, there are four subcategories to know your peopleNames, Home/Life Situations, Professional Practice, and Instruction. These subcategories represent the aspects of people's lives, in and out of the work environment (school), SLs use as platforms to get to know their people. For instance, to get to know his people, John, a third year assistant principal, "took a yearbook home prior to [my first day] and studied every teacher and their name." Aside from knowing his teachers first and last names, John said more importantly, “knowing people's living situations outside of school...being able to talk to them and share condolences or give support in that way is important." Knowing people's lives outside of school can give a school leader insight into job performance and professional practice in school. Participants spoke about knowing the instructional and professional practices teachers in the building used as a way to get to know their people. Jaime, a fifth-year principal said, "As an administrator, I have to deal with all types of people in the building. I have to be able to work with every teacher in the building." Also, knowing about people's home and life situations can help a school leader understand the more human side of their people. Participants spoke to how knowing their people in school (professional life) and outside of school (personal life) help them support their skills, attitudes, energy, and commitment to their work (Bolman \& Deal, 2013; Johnson, 1996). 
For SLs, knowing their people helps them understand what approach to take in order to support and guide their people. For instance, Jaime, a sixth-year principal said:

I know I have to approach one teacher one way and if I approach another teacher the same way, there's going to be an edge. Then, there are some people I can't approach at all. Its like I'm going to talk to someone else to have them [approach the other person] because they won't hear it from me. If a school leader knows their people and views them as an asset, then the school leader can better understand how to strategize their approach to ensure that the person is working in accordance with the greater school culture (Drago-Severson, 2009; Hall et. al., 2016). Another participant differentiates her approach to make her approach as individualized as possible. Moe, a principal in her ninth year said, "I try to differentiate things a lot because what works for one person doesn't always work for someone else. And you learn that teaching, and I think we forget to apply that when we get to administration." Knowing his/her people can help a school leader understand how to approach and support each of their people to build the human capacity in their school. The four subcategories and their connections to Supports and Needs (as seen in Figure 1) will be further explained in the next section.

Supports and Needs. Just as teachers support the different needs of students in the classroom to assist students in building their skills, schools leaders support the different needs of adults (i.e. teachers, faculty, parents, etc.) in the school to build capacity (Darling-Hammond, 2012; Drago-Severson \& Blum-DeStefano, 
2018; Wallace Foundation, 2013). Knowing people by name, and aspects of people's home/life situations, professional practice, and instruction, can give the school leader insight into what a person may need or how to support them (Bolman \& Deal, 2013; Drago-Severson, 2009; Hall et. al., 2016;). When a school leader understands the supports and needs of each person, then the school leader can start to strategize how to support them within the school context to ensure instruction is being delivered effectively to students.

Principals need to be able to provide teachers with individualized instruction as part of supporting them in their teaching practice and to keep instruction at the forefront of school goals (Elmore, 1996; Darling-Hammond, 2012; Drago-Severson, 2009). For instance, Moe said, "My first year, my whole plan was to get to know my teachers, listen to them and not make any drastic changes." "Consistent with core human resource assumptions, high-performing companies do a better job of understanding and responding to the needs of both employees and customers" (Bolman \& Deal, 2013, p.113). Moe does exactly this and takes advice from one of her favorite leadership books, If You Don't Feed the Teachers, They Eat the Students. Moe said:

The book itself isn't talking about food but it is talking about that if teachers' needs aren't met, then they're not as happy to be with the kids. They're not as effective. And so trying to figure out ways to kind of meet their needs.

Some participants spoke about doing small things to support their staff to ensure they feel a sense of commitment and appreciation. Moe said, "I bake for 
every one of my teacher meetings. I love to bake. Whenever we have a big PD presentation or something...they love it." When teachers do not feel supported or that their work is not being recognized, teachers among other adults, can have a negative effect on school culture. Part of knowing your people and putting oneself in their shoes can help a school leader support them. For instance, Marley, a principal of fourteen years said:

Remembering to take the other person's point of view [is important]. Also people do things because they need something or their needs are not being met. I try to remember if I am calm and thoughtful it will help them to be so.

Putting oneself in another's shoes can assist the school leader in understanding how to utilize that person's strengths and how to support them, again, to ensure instruction is being delivered effectively (Elmore, 1996; DarlingHammond, 2012; Drago-Severson, 2009). One theme that emerged as a way to help support people was through professional development. As seen in Figure 1, there is relationship between professional development as a support and need, but also as a means to collaborate. Professional development as a means of support will be explained further into the analysis.

\section{Building Relationships}

Once SLs get to know their people, it becomes easier for them to build relationships, and ultimately build the capacity of their school. Participants spoke to these relationships being the foundation for moving work forward (Bolman \& 
Deal, 2013; Darling-Hammond, 2012; Drago-Severson, 2009; Wallace Foundation, 2013). Gery, an assistant principal in his third year states, "Once you build relationships, and work hard to maintain them, it is much easier to be a creative problem solver on the spot because others are more willing to help." Further, Moe said, "I think relationships are huge... and that's something that they never teach you and never really teacher you how to balance that. Because how do you balance being friends with people that you are directly supervising?" Participants spoke to building relationships in many ways. For instance, Jesse, a fifth year principal said: I would say the communication piece is huge. It's actually more than a communication piece. I'd say it's more of relationships. I use communication to build those relationships but it's making sure I have as many touch points every day with teachers and kids.

Some participants spoke to "touch points" or visiting certain teachers and students daily to build and continue building relationships. Having touch points also helped SLs stay aware of happenings in the school with teachers and students.

While some relationships are easy to build, others can be challenging. When SLs felt uncomfortable when trying to build a relationship, they forced themselves to keep going. For instance, Moe said:

I have a couple of teachers I would avoid because it was like every time you go in there, it's negative- you know, they have to complain about something. So I started going in when they were teaching more, then trying to identify a positive of something that happened when they were teaching. 
Participants also spoke to their role as a pawn to helping build relationships between others. For instance, Moe said, "One of the things I love about administration is that I get to see everything that is happening. So when I'm in a classroom and a teacher tells me that something is not working...I can say, 'Well, look, I've seen it over here. Why don't you meet with that person."' The school leader plays a role in building relationships with others, but also between others. Once SLs have established relationships with their teachers, and between others, the school leader can then utilize their relationships to collaborate.

Collaboration

Because there are so many people - teachers, students, staff, and parents involved in the daily work of the school, SLs spoke about collaborating with their people was one of the best ways to ensure commitment to their work and growth (Darling-Hammond, 2012; Drago-Severson, 2009; Drago-Severson \& BlumDeStefano, 2018). Participants reported collaboration as a means of shared leadership and also a way to accomplish tasks around goals, new initiatives, solving issues, and performance improvement of teaching and instruction. Johnson says, because teachers reinterpret the curriculum every time it is taught and improvise to meet student needs, superintendents rely on collaboration as a way of control, rather than their efforts to influence teaching practice (1996). In the same way superintendents use collaboration, participants reported using collaboration as a way to control and check-in on goals and new initiatives, rather than have an influence on them. 
In the context of the study, participants spoke about collaboration with others, or facilitating the organizational management of collaborative groups of people. Participants spoke to using collaboration in four ways- meet goals, new initiatives, solve problems, and performance improvement. Participants reported different instances where they have used collaboration with others as a way to best get to a solution and/or make a decision. Overall, participants said the main goal of collaboration was to "[Bring] groups together as a district [and] [develop] a shared vision and mission" (Remi). One of the basic human resource strategies presented by Bolman and Deal (2013) are to "develop a shared philosophy for managing people and then to build systems and practices to implement the philosophy" (p. 140). Collaboration was used to build systems to implement the school mission and vision at Remi's school. If a school leader has everyone play a part in the school mission and vision, then, the school leader can hold people accountable to the school goals and make sure people are staying invested in their work (Drago-Severson, 2009; Elmore, 1996; Johnson, 1996).

Having several people with different points of view or concerns, can assist a school leader in coming to a solution or making a decision (Fosnot, 2005; Kaser et. al., 2013). Participants also reported collaboration as a vehicle for decision making. Though participants were not collaborating to have an influence, rather push information along, check in on an issue, or solve a problem, the collaborative work will inform the SL on a possible decision to influence policy, if they see necessary. For example, Mack a current assistant principal involved in School Leadership for nine years said: 
When you work collaboratively, what happens is you see your blind spots and that's good because if you can do it in a small work environment and those questions will come up later, and you're better prepared to answer those questions. Some of those questions may change how you approach whatever the situation is.

To prevent any "blind spots" or create more issues for themselves, SLs find collaboration is not only a way to see the bigger picture of an issue, but also as a way to empower people. For instance, Gery, an assistant principal in his third year, speaks from an experience he had as part of his residency program. Gery said, "One great experience that helped me see the power of collaboration... was a faculty common planning time using a protocol that focused on a recent NEASC visit and their recommendations." Gery speaks to utilizing his teachers, some who have never led a protocol before, to get them to look at the data and make recommendations as a team so they all felt invested in improving the school. Gery said, "We brought all the thoughts back... and distilled everything into five concrete steps the school wanted to make for next school year. It was a beautiful thing to see teachers become empowered by what they knew needed to be done." Similarly, Mack said, "I don't want to call it a trick, but really, part of leadership is really getting everybody [to] work towards the same goal, recognizing that powerful goal [is the] place that we want to get to." Using collaboration as a way to get people invested in the process and feel committed to their work can help the school leader move initiatives forward. 
Further, some participants said they utilize teams or Professional Learning Communities (PLCs) to do collaborative work. According to Katzenbach \& Smith (2013), "Teams will enhance existing structures without replacing them. A team opportunity exits anywhere hierarchy or organizational boundaries inhibit the skills and perspectives needed for optimal results" (p. 53). SLs utilize teams to increase capacity around socialization, instruction and learning (Darling-Hammond, 2012; Drago-Severson, 2009; Johnson, 1996). For instance, Moe said, "I have teams at my school and the teams do things very differently but they all make it work within the context of what they're doing. It's a matter of trying to figure out balance with all of them." Also, Remi, a principal in his tenth year said he utilizes PLCs that look at data to ensure all teachers understand the gaps and where they need to go. Having teams that work together on a consistent basis around a certain goal, or new initiative can be a way to get people focused and stay invested in the work (DarlingHammond, 2012; Drago-Severson, 2009). It is the school leader's role to guide all teams to stay on track to ensure effective instruction and organizational management (Elmore, 1996; Darling-Hammond, 2012).

Though participants saw collaboration as a must, most participants said it was difficult. Often, it can be difficult to keep people on track, group certain individuals together, and find the proper protocols to lead to the right results. Remi cautions that, "[As a leader you need to remember] do not throw the baby away with the bath water. Sometimes as a leader we need to remember to keep the valuable pieces of things." As Moe said, "It's more of a matter of trying to figure out how it balances with all of them." SLs utilize collaboration to ensure all people 
are invested in the process of meeting a goal or solving a problem to move the school forward in line with the school mission and vision.

Collaboration has to take place to insure good instructional practice in the classrooms (Elmore1996; Darling-Hammond, 2012). Participants reported using collaboration as a vehicle for goals, new initiatives, to solve issues, and performance improvement, but did not refer to collaboration around "good practice.” Participants thought collaboration was a good practice, but did not speak to using it to promote good practice. Three participants specifically said they use collaboration to implement new programs with middle school teams or to collaborate to reflect around data. However, no one participant specifically stated they collaborate around good practice. This could be because "time" was reported as a challenge and collaboration is used as a means to save time on the SL part. Or, it could be that collaboration is present, but not necessarily creating an effective learning organization (Darling-Hammond, 2012; Elmore, 1996; Drag-Severson, 2009). This finding reveals that collaboration, though learned after pre-service program, is a practice SLs need to develop further.

When utilizing collaboration, SLs found it would reveal what types of professional development may be needed for people. Collaboration is a platform for professional development. SLs can find out what types of professional development their people need through collaborating. As shown in Figure 1, there is a relationship between collaboration and professional development, and professional development and supports and needs. Professional development and 
its relationships to collaboration and supports and needs will be further explained in the next section.

Professional Development. According to participants, professional development can be any type of in-school or out of school training that helps people learn something new, or gain a deeper understanding of a new initiative, best practice, student data, etc. Professional development can occur within the school, or off campus, as a way for others to learn new information to then apply within the classroom. Bolman and Deal (2013) indicate, "The human resource-oriented organization also recognizes that learning must occur on the job as well as in the classroom" (p. 147). One way participants said they get people to learn on the job was through collaboration (see Figure 1). Professional development should be aligned with the needs of the people and the mission and vision of the school to ensure effective instruction (Darling-Hammond, 2012; Drago-Severson, 2009; Elmore, 1996;).

Participants spoke about offering professional development in a variety of forms in order to meet the needs of their people. Further, one-way SLs can support their people would be through professional development (See Figure 1). Some participants use professional development as a support for their people. The professional development could be an intervention, on-going, or something that only a few people need. For instance, Moe said, "I try to differentiate things a lot because what works for one person doesn't always work for someone else." The supports and needs of their people will help a school leader understand what types of professional development their people want and/or need. Gery goes on to say: 
SLs must constantly look for new and innovative ways to keep their teachers focused through relevant professional development, giving opportunities to lead for those that hunger for it, and listening to their concerns so they know their voice is being heard. (Drago-Severson, 2009; Elmore, 1996; Johnson, 2012; Kaser, et. al, 2013; Wallace Foundation, 2013)

Gery adds, "A good way to gauge meaningful staff learning topics are through climate and culture surveys to mine trends that need to be addressed, student academic data, tweaking a planned school based event." SLs can provide professional development in a variety of ways as long as it meets the needs of the people involved, and aligns with the school mission and vision.

Some participants viewed professional development as on-going, rather than an isolated occasion. For instance, Jaime said, "Professional development, it's on-going. And what I mean by that is people seek, say to me, 'Do you think we can get professional development for myself of for so and so? I think they can use it.' Its like, 'Great.”' Professional learning communities (PLCs) can also be a way of on-going professional development. As Moe said, "I have teams at my school and sometimes, the teams do things very differently but they all make it work within the context of what they're doing." Participants spoke about how they offer professional development in their schools based on what works best for their people. For example, Jaime spoke to one of his best teachers suggesting their own professional development. Jaime said, "I have one staff member who is my best teacher asking me, 'Can I get professional development over the summer.' I said, 'But you do not need it.' And she said, 'But I do.' She needs to hear that she's 
doing well, but again, that's why [she] is my best teacher because she is constantly trying to make sure you're doing the best you can." Though some teachers know exactly what they want to learn, or continue to cultivate and apply their learning to their classroom, other teachers rely on what the school provides for professional development. When school leaders provide professional development, they are investing in their people to move and support the school culture.

School Culture

School culture refers to the way teachers and other staff members work together and the set of beliefs, values, and assumptions they share. Becker and Huselid (1998) indicate that managers understand the need to develop an approach to people that flows from the organization's strategy and human capital need (as cited in Bolman \& Deal, 2013). School leaders know growing and maintaining a positive school culture requires an "all hand on deck approach" and requires organizational skills of a manager (working with predictable operations) as well as the organization of a leader (empowering staff) (Darling-Hammond, 2012; DragoSeverson \& Blum-DeStefano, 2018; Kruse\& Seashore Louis, 2010).

To manage, articulate, advocate, and cultivate school culture, participants speak to knowing your people, building relationships, and collaborating (as seen in Figure 1). A positive school climate and school culture promote students' ability to learn (Darling-Hamon, 2012; Drago-Severson, 2009; Elmore, 1996; Gallagher \& Thordarson, 2018; Kaser et. al., 2013). If these practices are in place, SLs can keep up to date on navigating school goals and moving the school culture forward. 
As a captain who navigates a ship through the sea, a school leader must navigate their people through the changes in education to maintain effective instructional practices and a positive school culture (Elmore, 1996; DragoSeverson, 2009; Johnson, 1996; Neumerski, 2012; Wallace Foundation, 2013). Participants defined themselves as the one person who holds the compass to guide those in the school towards a positive school culture. For example, Jesse said, "My job as a school leader to really establish what the culture is, and we have a very academic-focused culture and really high expectations and so really helping to define what those expectations are is my role." Though SLs are the one person at the helm of the ship, they rely heavily on input from their people to help them guide the way. In order to get a pulse on the school culture and then ensure how to create systems that align with the mission and vision of the school, participants spoke to doing a climate and culture survey. For instance, Gery said, "A good way to gauge meaningful staff learning topics are through climate and culture surveys to mine trends that need to be addressed, student academic data, tweaking a planned school based event." Like Gery, Jesse also issues a climate survey twice per year to her staff. Jesse said, "[The survey] gives me a lot of feedback about the culture of our school and in turn then about me, and how I'm establishing culture in our school, and how I'm meeting the needs of my staff." Jesse also gives a "family survey every year" to families to get feedback. Participants reported that the findings from the survey helped them understand what needs to be changed, maintained, or supported in the school in relation to the mission and vision to improve and/or maintain effective instruction and culture. 
SLs spoke about the thought process and practices they use in order to manage the many issues and obstacles they have to face. Participants reported the need to have an understanding of their self as a leader in order to manage others (staff, teachers, students, and parents) efficiently in working towards building a positive school culture. Participants reported seeing themselves as a learner within their context in order to be effective and improve their skills as a leader. Participants reported using their context as a basis for reflection and developing their skills. As stated by Wells (2016):

The personal narratives of SLs indicate that their world is one that included both joy and stress. The joy involved the passion of the calling in education and the positive energy of being with students. Stress, however, can drain the energy and life from a principal, leaving the leader with burnout or the feeling that the job is impossible. (p. 13)

Understanding their self means knowing their strengths, limitations, and what they personally need to do in order to maintain a healthy work-life balance so they can be mindful in their decisions in and out of school. Participants said that developing their practice of school leadership is on-going (Drago-Severson, 2009; Drago-Severson \& Blum-DeStefano, 2018; Kaser, 1982). For example, Mack speaks to the leader's sense of self by saying, "Leadership has to do with your own practices. If you're going to ask people to do something, then you better be doing it yourself." Like Drago-Severson suggests (2009), "SLs commented on the need to 'model' these habits of inquiry and to make time to teach other adults in the 
school 'how to reflect on practice"' (p. 174). Leaders are role models and need to be aware of their practices in order to model how they would like others to behave and act. Participants see themselves as a learner in the process (Drago-Severson, 2009; Drago-Severson \& Blum-DeStefano, 2018; Kegan, 1982, 1994). Participants reported implementing practices for themselves as a way to help manage their instructional leadership. The self-lens participants spoke about was how they saw themselves within their developmental process as a SL.

As seen in Figure 1, commitment overarches the self side of the model because commitment drives the school leader to be reflective. Participants speak about an underlying sense of commitment to their schools and positon that drives them to be reflective to make mindful decisions for their schools. The major themes in the self-model and connections to the self and others model will be explained in the next sections.

\section{Commitment}

SLs need to have a sense of commitment that drives their practice in order to make the best decisions for the school. Commitment can be defined as a feeling of dedication to one's role and/or school. More than half of the participants reported having a sense of commitment to their school which contributed to their drive to be an effective SL. Most participants did not see themselves as a SL previously, and when asked to consider the possibility of being one, most reported feeling a sense of commitment to their school that motivated them to pursue this role. One participant said, "I think first of all the commitment that I had to my school and my organization [drove me to want to continue]." When taking her 
position as a school leader, Reese said, “I don't want to say self-sacrificing- but I felt like where I was at with the position...[I was] doing a principal's job more... so I really felt like the kids needed [me]." Though Reese did not see herself as a SL, nor wanted the job, her sense of commitment to her school, particularly her students, drove her to be want to be an effective school leader.

A SL's sense of commitment can help them be seen as a support versus a barrier by teachers. The commitment of a school leader shows teachers that the school administrator is willing to work with them versus against them (DragoSeverson, 2009; Johnson, 1996). For example, Moe said, "For my teachers, they know that I'm there and that I'm there for them. I think the commitment of being there too. The high school position opened up at one point, and everybody was like, 'Oh, you're going to try to go to the high school?' I'm like, 'No way. I love [it here].' I think [the teachers have] seen my commitment of being there so I think that relationship piece of it makes a big difference." Further, Jaime said, "I left [my previous school as a teacher] because of staff and they've brought administrators out. I think they've had something like 27 administrators over so many years. I was the first assistant principal that repeated in nine years." Jaime then speaks to how asking teachers, "What can I do for you?" has helped him show a sense of commitment and support for them. Both Moe and Jaime, among other participants, speak to how knowing their people and building relationships proved to their people they had a sense of commitment. Showing a sense of commitment to the school can assist the teachers working with the school leader. Listening, and how it relates 
to knowing your people and building relationships will be explained in the next section.

Listening

When people feel heard, they often feel validated (Llopis, 2013). For SLs, listening to their people not only assists in getting to know them on a personal and professional level, but also in building relationships with them (as seen in Figure 1). Taking time to listen to constituents and encourage responsibility for proposing solutions may assist the SL in being decisive when time is of the essence (Johnson, 1996). Listening also plays a role in a SL's decisions making process (as seen in Figure 1). Leaders who listen are able to create trustworthy relationships that are transparent and breed loyalty. Leaders who have their employees' best interests at heart, truly listen to them (Llopis, 2013). Listening plays an integral role for SLs to understand what is going well and what is troubling their people both practically and politically (Johnson, 1996). All participants spoke about the importance listening plays in their role. For example, Jaime said, "As a good leader, I think first, listen more." To elaborate, Moe said, "Listening to what people have to say and having them feel heard. I think that's a big thing for parents. It's a big thing for students. It's a big thing for teachers. I think just to be able to take the time." Simply taking the time to listen can show people that they are important and what they have to say is valued. Listening can assist a SL in understanding what people may want or need at a particular time.

Listening goes well beyond being quiet and giving someone your full attention. It requires you to be aware of body language, facial expressions, mood, 
and natural behavioral tendencies (Llopis, 2013). Being aware of these behaviors assists SLs in making decisions. For instance, Moe said, "I actually care what everybody has to say. But sometimes, I have to make a decision that might not be exactly what you want, but might be better for some of the other people on the team." Hearing the perspectives of different people around a topic can assist the school leader in making a decision that is best for the school. The decision may not satisfy everyone; however, when people know the school leader took the time to consider their input, they feel they have been part of the process in moving the school forward. Participants spoke about ways they listen to their people. For instance, John said, "I think even being relatable, having an open-door policy and having teachers really feel comfortable coming to my office and share problems they're having, concerns. Even concerns with me and my practice, I welcome that." John uses listening, not only as a way to know his people, but also as a way to get feedback on his own practices. On a slightly different note, Jesse uses listening to elicit information and to get ideas. Jesse said, "I conduct a listening tour each end of year, and I'll meet with every staff member just to sit down and have a cup of coffee, and I pick their brains." Listening is more than sitting quietly (Llopis, 2013). As a leader, it's difficult to really know what your employees are thinking about, what's troubling them or how to help them get out of a performance slump -unless you take the time listen to them. Once a SL listens to their people, they can make more informed decisions. As seen in Figure 1, participants reported that listening helps inform their decision-making process.

Decision Making 
SLs have to make an overwhelming amount of decisions to tend to on a daily basis. They must take the information gained from listening and their "own theory from unstructured information gained through his own interactions with others" (Argyis \& Schön, 1974, p. 159). According to participants, there are several factors that influence their decision making. The decision-making process is a culmination of collaboration, school culture, and listening (as seen in Figure 1). The next sections will explain how these components influence a school leader's decision making.

Listening assists SLs in their decision-making process (Drago-Severson, 2009; Johnson, 1996). When trying to get to know their people and build relationships, the SL gathers valuable information they can then use to make decisions. This information may be teacher opinions, information about students, personal information, etc. that offers a school leader insight into making decisions for the school. Almost every participant reported listening as one of the most important practices SLs should adopt, because they have the most influence on decision making for the greater good of the school (Drago-Severson, 2009). According to Gery, "Listen to your staff... [and] react meaningfully" to let "good things happen." Gathering information through listening can assist SLs in making meaningful decisions in which all stakeholders were invested in.

Further, SLs can utilize their people as a resource when making decisions through collaboration. As seen in Figure 1, participants use collaboration as a way to build school culture. "When leaders relay on their position power, others may do what the leader wants and not be committed to the work (Kaser et. al., 2013, p. 
2). The school leader can utilize information gained through collaboration to make decisions for and/or around school culture. SLs can gain valuable information from working with their colleagues. For example, Mack said:

When you work collaboratively, what happens is you see your blind spots and that's good because if you can do it in a small work environment and those questions will come up later, and you're better prepared to answer those questions. Some of those questions may change how you approach whatever the situation is.

Depending on what SLs learn from their colleagues can assist them in making a decision that is in line with the mission and visions, but also that has the path of least resistance. Making a decision can influence the school leader's style of leadership. All participants spoke about having a participatory style of leadership, or 'decentralized' leadership. A participatory leadership style is collaborative by definition (Kaser et. al., 2013).

As seen in Figure 1, reflection and collaboration play a large role in assisting SL's skill development and practice. Looking at an issue in full will help a school leader approach the issue holistically. Decision making can also come in the form of shared decision making, with the teachers, parents, and/or students involved in the process of making a school-wide decision. For instance, Moe said in her first year as a school leader, she focused on working with her colleagues to find out issues that were important to be addressed and as she said, "[collaborate] why as opposed to me going in and saying, 'Well, you do this." Getting people invested 
in the decision making process through collaboration can influence the decision the school leader makes, and cultivate a positive school culture. Further, Gery said, Collaboration can influence how creative a school leader gets when making decisions. Educational leaders must constantly look for new and innovative ways to keep their teaches focused through relevant professional development, giving opportunities to lead for those that hunger for it, and listening to their concerns so they know their voice is being heard.

Collaborating with colleagues can assist the SL in taking action on what others in the school are concerned about or want to see happen. Creating this sense of participation in decision making can also help the school leader model best practices as a learner. For instance, Jesse said:

Modeling being a learner is huge when you're in a leadership role and modeling is not just for students but also for teachers. I think as I push to engage my teachers to get better at being teachers and to learn more about the craft of teachers, I have to be doing the same thing with them, not just dictating them to do it.

According to Dreyfus and Dreyfus (2004), SLs at the proficient stage are able to make and change decisions while a situation is taking place, while competent SLs are only able to reflect on their decisions after the situation has happened (Dreyfus $\&$ Dreyfus, 2004) and change how they might approach that situation in the future (Schön, 1983). Reflection, and how it relates to decision making, will be further explored in the next section.

Reflection 
Participants identified reflection as a vehicle to help them make decisions, but moreover, to manage their work-life balance. As researchers suggest, SLs have identified reflective practice to support personal and professional learning (Kegan \& Lahey, 2009; Wagner et. Al., 2006; York-Barr et. al., 2006; as cited in DragoSeverson, 2009). Reflective practice can bring about new awareness and clarify thinking that can assist SLs in making decisions about their own practice and for the school (Schön, 1983; Drago-Severson, 2009; Drago-Severson \& BlumDeStefano, 2018). Under reflection, four themes emerged- 1) Self-reflection, 2) Time Management, 3) Prioritization, and 4) Mentoring Others. These themes will be explained in further detail in the next sections.

Self-reflection. According to Drago-Severson (2009), as reflection increases, the decisions and actions involved in leadership become more effective (p. 155). Schön suggests (1983), "When a practitioner becomes a researcher into his own practice, he engages in a continuing process of self-education" (p. 299). Reflection can assist SLs in developing a deeper sense of awareness about the nature of their performance (Drago-Severson, 2009). Several participants of varying skill levels reported practicing reflection as essential to being an effective school leader. For example, Jaime said:

I go home, look at my day, whether it's the day or the week, or you know like, 'This is the time of the year we're all tired' but then it's like, 'Big issue. Well, it worked well last year. What do we need to do differently for next year? 
Jaime uses both in-situation and on-situation reflection, but finds he best reflects on his day when the day is over at home. Reflecting helps Jaime affirm or revise decisions he needs to make. Jaime also speaks to his approach on improving himself. He said:

'What do I need to do to get better?' But I'm asking, 'What do you need from me?' To me, that's the professional development- that daily, that weekly- "what do you need from me? What can I do better for you?

Jaime said, "Professional development is within ourselves." He provided a reflective form he created for colleagues after a situation occurs. The form guides the teacher through a series of reflective questions. Jaime then uses that form to further engage in reflective dialogue with that teacher. The dialogue must be purposeful in order for the school leader to develop their skills. This practice resonates with the strategies used in the POMM, which Peno \& Silva-Mangiante, (2012) suggest to assist learners move from novice to expert skill levels over the course of their careers. Drago-Severson (2009) found, "when we engage in reflective practice, we are intentionally working to understand thinking, behaviors, and events from a variety of perspectives" (p. 157).

Participants spoke about purposeful practices they use to develop their skills through reflection. For example, Moe said, "I think it's an important thing to deliberate, but always to do that reflection on what you do and kind of be able to talk through it and have somebody to kind of talk through some things on." As part of her skill development, Moe deliberates with her superintendent to assist in her decision-making skills. Moe is confident in her abilities to make decisions in and 
on situations, but understands that refection will only make her grow. Moe said, "How I could have dealt with something differently, and I think that's kind of what I [do in situations]." Jesse also spoke about reflection through purposeful mentoring. When Jesse was in her principal residency program, she had an indistrict mentor at her disposal. Jesse said, "I think a lot of [learning] has been mistakes, for one. It's always really helpful in making you better. But I think a lot of it has come from feedback, and I've gotten better over the years of soliciting that feedback and also better in really analyzing the feedback." Having her mentor offer her feedback and guide her helped Jesse not only learn from her mistakes, but see the value in feedback (Neumerski, 2012; New York Leadership Academy, 2015). Jesse has developed her skills in soliciting feedback and using feedback as a vehicle for reflection to improve her practice as a school leader. However, it is often difficult to find time for reflection. Reflection and time management will be explored in the next section.

Time Management. People often say, "There is never enough time in a day." Time poses a barrier for SLs, but often, this can be overcome if SLs manage their time properly. Participants reported they had to find which time management tools and practices worked for them through trial and error. "One implication is that adult learning experiences must transform current thinking and practices rather than simply adding new skills and ideas on top of the old" (Kaser et. al., 2013, p. 101). By practicing which time management practices worked and did not work, participants were able to transform their thinking about time and managing their day. For instance, Remi said, "Time management [is always something] you can 
improve on. Work smarter." Remi, along with other participants, reported that taking the time to reflect on better ways to manage their time helped them be more efficient leaders. One time management practice most participants reported using was managing time through a Google Calendar. Jesse said, "I put everything in my Google calendar so that way everybody can see it. And, if anyone wants to schedule time with me, they can just go in and check and see when I'm free." Jesse and Moe also reported using a paper planner as well. Some participants like Jesse and Jaime reported delegating certain tasks to their secretary to help them maximize their time in one day. SLs have many things to navigate, such as, teacher evaluations, curriculum and instruction, parent meetings, safety and security protocols, professional improvement meetings, and a constant influx of emails and out-ofbuilding meetings. SLs must figure out how to manage their time in order to effectively balance the many priorities they have. Prioritization will be explored in the next section.

Prioritizing. SLs have to navigate how much time is too much time, and in some cases, how much time is too little time. School principals can find themselves spending time that is important, but not urgent (Marshall, 2008). Participants spoke about reflecting on how to prioritize their goals to assist them in becoming more effective SLs. "It's vital for principals to identify a procedure for organizing priorities by the year, the month, the week, and the day. A daily to-do list is not enough" (Marshall, 2008, p. 18). SLs need to have a strong understanding of organizational management and be able to decipher what is important within a situation and what is not in order to manage effectively (Dreyfus \& Dreyfus, 2004; 
Neumerski, 2012). For instance, Jesse said, "I systemize everything and that might sound really badly that like systemized relationships or systemized communication, but I feel like you have to." Also, Moe said, "It's being able to prioritize what needs to be done today and then taking a step to make sure those things get done." Moe said she walks around with a note pad to jot things down. When she gets back to her office, she then prioritizes her issues. SLs must prioritize in order to intentionally plan their schedule to balance their time.

A school leader must be aware of the school's initiatives in order to prioritize goals. For example, in order to not over commit herself and stay focused on the school goals, Reese said, "I would say learning to say 'No,' feels very different to turn things down and be totally okay that we can move forward with the initiative if the teacher wants to move forward." Saying "No" can help a school leader re-direct a person to another initiative, one that is more related to the direction of the mission and vision of the school. Mentoring others will be explored in the next section.

Mentoring Others. Mentoring others can assist the school leader in supporting and challenging their people to grow and be excited about the work they are doing (Drago-Severson, 2009). According to Kaser et. al. (2013), "The ability to cultivate leadership in others and build commitment to the goals of the organization that is a hallmark of a good leader" (p. 2). Participants spoke about how they try to mentor others in their school to encourage growth in them (DarlingHammond, 2012; Elmore, 1996; Wallace Foundation, 2013). For instance, Gery said, "There [is] one teacher who I desperately [want] to help [and] push them into 
more of a leadership role." Just as someone saw Gery as a leader and pushed him to be a leader, Gery wants to do the same for others in his school to build commitment. However, Gery urges to know the limits of those who you are mentoring. Gery said, "In being a leader and recognizing when you've pushed someone, even with the best intentions, into their danger zone because it will not yield the results desired by any part."

On a similar stance, Reese speaks to "growing from within," or growing the people within the school, rather than hire new people (Drago-Severson, 2009; Wallace Foundation, 2013). Reese said, "I myself found an intern who has turned into a parent professional for us. We like to groom from within so when we see peoples' skills that's kind of what we do." Reese speaks to mentoring as an opportunity for her school to grow people's capacity. She said her school is "creative with how they add" different roles at their school. Reese said she was grown from within, so she tries to spot skills that people have and use them as a platform to help them grow within the school. Though participants spoke about mentoring others, it seemed mentoring others was done randomly, and not a systematically designed mechanism that was utilized. Mentoring seemed to happen in moments, rather than be a well-supported, on-going model.

Supports

Participants spoke about different supports they had in order to develop their skills and practices on the job as a school leader. This section will answer research question 5. Three themes emerged under supports- mentor, professional development, and developmental network. These supports speak to how SLs 
developed their skills and practices after their pre-service program. As seen in Figure 2, these were the three major drivers that assisted SLs in their skill development. These themes will be explored in the next section.

Mentoring. Various forms of mentoring assisted in the participant's development. As seen in Table 3, participants had an official mentor, four had an unofficial mentor, and three did not speak to whether or not they did have a mentor. Participants shared how their mentors supported their skill development as a leader. For instance, Jesse, who had an official mentor said, "My mentor was our curriculum director" through her Principal Residency Network. Her mentoring program was purposeful and meant to support Jesse in her first years as a principal. Jesse speaks to how her mentorship inspired her to always seek out professional learning opportunities. Jesse had such a positive experience with her mentor, and overall growth, that she said, "I had reached out to my superintendent and asked for a coach. So he paid for one year for me to have a coach from out of our district, who I would talk to once a week.”

Though not part of an official mentor program, Moe found her unofficial mentor helpful in her development as a school leader. Moe said, "I find myself really, really fortunate that I have a superintendent who is really open and somebody that [I can deliberate with]." Her superintendent is always available to help Moe talk through issues. Moe said he not only lets her make the ultimate decision in a situation, but supports her in her decisions. Moe also said her superintendent has helped her develop seeing situations holistically. 
Professional Development. "One of the critical skills for leaders is the generating and sharing of knowledge" (Darling-Hammond, 2012: Drago-Severson, 2009; Johnson, 1996; Kaser et. al, 2013, p. 15). Besides the district led professional development, that is usually a "one stop shop" as one participant called it, participants reported having to seek out their own professional development. Participants reported using professional development as, a) way to develop their skills as a leader, b) share knowledge with their district, and c) keep up with best practices in education. Of all the participants, Jesse was the most passionate in speaking to seeking out professional development. For instance, Jesse said, "I engaged in a leadership program with the KIPP schools and some other leadership programs across the country. I visited a lot of schools around the country [and had] really great learning experiences as a leader." Though all participants reported seeking out their own professional development, one participant had a different view of professional development all together. Joe views his daily environment as a land of opportunity for professional development, saying professional development is on-going. Joe considers reflecting on every day happenings a form of professional development. He can take his reflections and share his opinion and knowledge of the issue with his staff to improve for next time. When he feels he needs to learn more about an issue, he then will seek out more formal ways for professional development.

Developmental Network. Participants also said that having access to a larger developmental network within their district, and state, supported them in their skill development. For instance, Jesse said, "I've had the opportunity to 
engage with so many other SLs and in so many other schools in different contexts that it has really helped me to re-think my own context." Jesse speaks to how rethinking her school context made her more aware of the inequities in her school. Jesse now makes it a priority to make all aspects of her school equitable for teachers and students. Marley and Reese also speak to being part of their statewide association assists them in their skill development. Jesse said, "I think having opportunities to collaborate with other principals is huge." Marley, along with participants also speak to having access to other leaders within their district as a form of support. For instance, Marley said, "We have what we call an underground network to support each other when we needed to keep balanced and get advice from a peer. This support is important." In Jesse's district, she has access to “instructional rounds, basically [to] address problems of practice together." In all, participants utilized their developmental network as needed to support them in their leadership.

Challenges

In the data, participants reported facing challenges in their leadership development. These challenges were reported to be hindrances in their leadership skill development. Seven themes emerged under challenges- dealing with difficult teachers, balancing relationships, adaptive state, dealing with power, work-life balance, time, and inequities. As seen in Figure 1, the following themes hindered their leadership skill development. The following themes will be explained in the following sections. 
Dealing with Difficult Teachers. SLs need to hold the people involved in their school accountable for their contributions to the school (Drago-Severson, 2009; Elmore 1996). Participants report that dealing with difficult teachers was a challenge to their development. One participant reported it getting easier over time, but having these conversations is difficult, especially when the teacher is a rigid thinker. Although participants referred to a variety of contexts when having difficult conversations, one context was holding them accountable regarding the cultural expectations of the school (Elmore, 1996). The fact that SLs find dealing with difficult teachers a challenge could mean that their schools do not have an established code of expectations, and therefore it is difficult to hold teachers accountable. Alternatively, the act of crafting responses regarding teacher issues and having the difficult conversations with teachers is the skill that needs to be developed in practice. The findings around challenges speak to deeper rooted structural context issues that prevent SLs from developing their skills and having a positive influence on their school.

All participants reported that dealing with difficult colleagues poses one of the biggest challenges for them. These difficult colleagues are people who "are just miserable," "not invested in the work," and/or "have a rigid mindset." Jaime asked a profound question, asking, "What does it mean to tackle the difficult teacher, and its really their personal qualities and their traits." Jaime said as a leader, you walk a fine line when trying to have a conversation with a difficult colleague because you do not want to make it seem you are attacking their personal traits. But Jaime finds having difficult conversations challenging because no matter how many 
conversations you have or ways you address the person, they stay the same. Jaime said, "Well other people in this building are not so reflective, and that's why they don't change because they don't see what it is they're doing...they just keep saying, 'I don't know what else to do.' So as a leader, its like both helping me but helping them move along to it in being reflective." Jaime said, "The most difficult thing for me this year that I tried doing a better job with is just having those difficult conversations that I normally would have avoided. But I've also learned that getting through or pass that conversation has made things better. You pick your battles." However, Jaime does say he does address the difficult people and knows the conversation will be over. He knows not addressing the difficult colleague can create more of an issue.

At times, the difficult teacher may be someone the school leader does not expect. Moe speaks to an experience where no matter how much she rationalized her decision to her colleague the colleague still took personal offense to the situation. The colleague was someone Moe usually got along with and who was not difficult, but in this particular situation, the colleague was posing a challenge for Moe. After Moe made a decision to switch a computer cart from one learning team to another, a colleague stopped talking to her. Moe said, "At first it really hurt, and I tried to figure out is there something I could have done differently, and what could I have done. Then I [realized my colleague] was going to have to get over it because sometimes I have to make decisions not everyone is going to like. I've learned to let that go." Though difficult colleagues do pose a challenge, participants said that they either had to "let it go" so they did not affect their personal life, or 
"remind themselves their decision was the right thing to do" no matter who disagreed. Perhaps dealing with difficult teachers was noted as a challenge because the SLs do not have the skills to use their positional authority (Johnson, 1996). Conversely, the SL may not possess the skills to see to hold this person accountable within the structures of the school context. Another reason dealing with difficult teachers may have been reported as a challenge could be the lack of autonomy they have in dealing with difficult teachers because of existing policies (Elmore, 1996; Johnson, 1996).

Balancing Relationships. Dealing with difficult colleagues requires balancing relationships. Figure 1 shows knowing your people as the pinnacle to drivingt the school culture; however, balancing relationships can be a challenge for leaders. Five participants were once teachers in the schools they now lead. These five participants reported balancing relationships to be especially challenging. Moe said, 'It's always trying to keep that line and always remembering that you're not [and they are] not just a friend first. You have to always think that." Gery said, "I had no idea how difficult it could be working with some teachers. Many teachers want blind loyalty to them, no matter what, but it is incumbent on a school leader to be very clear that your role is to be non-partial and to support all parties." Moe said, "It took a long time to build relationships and get them to trust that I was here for all of them...not just looking at my own needs, or one team's needs. There was always this idea of favoritism..."

Adaptive State. Participants spoke to the constant adaptive state, or a state of change, there school was in. Most schools are, in fact, constantly changing; 
however within the process of change, basic issues of curriculum and instruction and classroom level structures can be lost, leaving student learning static (Elmore, 1996). The more recent change for this state was a shift in supporting additional work around the state's vision of shared leadership under ESSA (Riley \& Meredith, 2017). Over the past five years, the state has shifted state testing batteries and redesigned their entire state testing system model, leaving SLs to lead in a state of constant change.

More specifically, three participants described the adaptive state as, "building the plane as we are flying." Jaime and Jesse say, "we keep building the plane as we're flying" meaning, "we're coming across things that we haven't come across before just because of the nature of the school." The constant state of change poses a challenge for leaders because there is little guidance or experience with some changes and they cannot see how to best apply them in their schools. This leaves SLs vulnerable to making wrong choices, or wasting time investing in decisions they did not see through. As Reilly said, the main pawn in getting charter schools into his state was, "[You have to be] willing to place yourself in almost impossible situations." SLs cannot assure their results will be positive or that their efforts will be worth it if policies are changing without structural changes like school funding, or leadership structures within the state. All systems have to change together in order for the focus to stay on best instructional practices and effective organizational management by SLs (Darling-Hammond, 2012; Elmore, 1996). 
Dealing with the Power. With great position comes great responsibility and power, as some participants said. The structural breakdown of school personnel places principals and assistant principals at the top of the chart in their building. Many associate "being at the top" with power. Some participants reported the power is challenging to deal with. Mack said:

Leadership [is] more than a name that authority is sort of created by a title.

But that's not the case at all, you know leadership has to do with your own practices. If you're going to ask people to do something, then you better be doing it yourself.

Jesse also said, "Practice what you preach" to show the people that you are a learner as well. Jaime said, "Some people get nervous because I'm their boss. Moe said, "It took a long time to build that relationship and get them to trust that I was here for them and hopefully make the whole school a better place, not just looking at my own needs." Participants described their leadership style as collaborative and democratic; however, many people they lead still view the principal from a structural lens (Bolman \& Deal, 2013). This view of structural leadership has not adapted with the most recent educational wave of shared leadership and collaboration in practice. Striking a balance of self and where the SL sees themselves as a SL to manage the organization around instruction can be difficult to do without effective training (Darling-Hammond, 2012; New York Leadership Academy, 2012). Sometimes reorganizing the school must occur so that it supports the work in a more productive way to approach supporting change (DarlingHammond, 2012; Wallace Foundation, 2013). The current structure of leadership 
makes it difficult for some to see past the power and often participants reported the power as a challenge.

Work-Life Balance. As cited earlier, there is a high principal turnover rate, especially for principals in their first three years. The high turnover is partially due to the challenge of finding and maintaining a work-life balance. Participants reported finding the work-life balance was a challenge, but also varied day to day. One participant reported leaving the principalship for two years because his worklife balance was so askew. For instance, Mack said, “There are times when you're just tired. You get burned out. Part of me leaving that principalship [at one point] was [because] there are a lot of expectations that come... To do the job right, there are things you have to give up." Mack did return to the principalship, and still finds the work-life balance a struggle. Reilly, a principal for more than twenty years regrets missing important family milestones, like his son's preschool graduation because he was working. Reilly said, "It's balance of organization. It's balance of temperament. It's balance of life. It's seek and achieve balance." Further, Moe said, "Balance what can I get done today and what can I leave unfinished before I go home because otherwise you could take it home. Its that fine line of where do you draw that line" and say enough is enough. Work-life balance was a challenge across contexts. Participants did not report having more or less of a challenge with striking a work-life balance. This finding shows that SLs in this state are overwhelmed, and perhaps greater state-wide policy needs to be adjusted in order to assist the SLs in feeling more balanced (Darling-Hammond, 2012; Elmore, 1996; Wallace Foundation, 2013). 
Time. According to a survey conducted by National Association of School Principals, 44 percent of principals reported managing time was their top challenge" (Superville, 2018, p. 8). School principal's have so many issues and goals to juggle, it can be challenging to manage time, even if a school principal has systems in place. For instance, Jesse said she systemizes everything, but, "Time. I feel like a lot of times, there's things I want to do or try...but just time hasn't allowed me to." Similar to Jesse, Gery said time is a challenge for collaborating with teachers. Gery said, "If we are lucky we'll get 7-8 hours a year for PLC's with our staff, which simply isn't enough." Lack of time poses a challenge for SLs in trying to stay focused on keeping instruction at the helm and the management of the organization to support the work (Darling-Hammond, 2012; Elmore, 1996; Wallace Foundation, 2008).

Inequities. Though SLs try to eliminate inequities, they always exist. Inequities can be anything that hinders students from having an equitable education with high levels of effective instruction. Recognizing inequities in schools and then trying to close gaps poses a challenge for SLs because the inequities are hard to spot, and often finding solutions are can be nearly impossible. The Wallace Foundation (2013) reports that SLs do have an influence on student achievement, but navigating the systems of education for all students to receive a highly effective education can be challenging and often impossible (Elmore, 1996; Wallace Foundation, 2013). Participants reported inequities to be frustrating and a challenge to close the achievement gaps. For instance, Jesse said, "Maybe in my first couple of year I didn't even recognize when inequities were existing in our schools. But 
then, it got to a point where now I could see them, and I would start to act on them. But now feel like, I look for them. I actively seek them out now, and I'm very proactive in addressing them." Jesse goes on to say:

I was realizing that it's not enough to just have it, and it's not enough to just put kids from different backgrounds together in a school and think you're going to solve all of the issues of race... but really not knowing how to tackle that or where to start.

SLs are constantly trying ways to make sure the systems in their school are equitable for all students, but this is not always easy.

Summary

Throughout the research process, data was analyzed by case and between cases to determine what practices assist SLs in their skill development. The data was presented in two parts, vignettes and a cross-case analysis. Vignettes were used to gain a deeper understanding of each participant's skill level within the context of their school. The cross-case analysis was used to describe the themes that emerged in the analysis. The data analysis revealed two major themes, under which six major themes emerged, with several sub themes (see Figure 1). Participants chose their perceived skill level using The Model and then provided evidence of how they have developed to their perceived skill level. Each participant was also asked to provide document evidence to also support their development. The interviews along with the document evidence provided details into the skill development and leadership practices of the participants. 
Important findings emerged around skill development and the role of a mentor. Seven of the ten participants reported having an official or unofficial mentor. All seven who had a mentor said the mentor assisted them in growing their thinking and overall leadership practices. The data revealed that no matter the pathway each participant utilized to become a school leader, a sense of commitment to one's school was the main driver of their development and leadership practices. The commitment to want to be better for their school drove things like professional development, reflection, and decision making.

Document examination provided a deeper snapshot into the skill development of the participants. Participants provided documents like a principal blog, monthly newsletter, reflection tool, pictures of PLCs, and a discipline case study. Since participants self-reported their perceived skill level, the documents provided a way to affirm their skill level. All forms of documents were created and/or adapted by the SLs themselves. All of these documents help support the school leader's perceived skill development.

Another noteworthy finding emerged around the leadership practices SLs have developed on the job. SLs spoke to practices they utilize to facilitate the organizational management, and also practices they utilize for themselves so they can be an effective school leader. School context did not play a role in this matter. All participants, no matter their years in school leadership or skill level, spoke to knowing their people, building their relationships, and working collaboratively in order to build a positive school culture (Darling-Hammond, 2012; Drago-Severson, 2009; Drago-Severson \& Blum-DeStefano, 2018; Wallace Foundation, 2008, 
2013). Participants also spoke to practicing listening and reflection as part of their routine in order to be effective leaders (Johnson, 1996). As reported by participants (see Figure 1), they learned practices to manage the vision, instructional practices, and operation of the school. Managing the job is one thing, but discussion about having an understanding of their influence on student learning and moving the school forward was lacking. A call for principal preparation programs to focus on not only instructional leadership, but organization developmental, mighyt assist SLs in being more prepared to balance the job (Darling-Hammond, 2012; Neumerski, 2012; Wallace Foundation, 2013).

SLs spoke to a wide range of supports they have access to in order to assist in developing their skills as a leader. Participants spoke to utilizing their superiors or other principals/assistant principals within their district when needed. Also, participants spoke to utilizing the state-wide principals association they belong to as a form of support for professional development and guidance. Those in urban or charter schools spoke to utilizing these supports more and having them more available to them.

Further, SLs are faced with many challenges that are barriers to their skill development. There were no major differences around the challenges reported in different school contexts. Participants said dealing with difficult teachers and getting teachers to change their mindset about certain initiatives can be a barrier to moving the mission and vision of the school forward. Also, four participants spoke to the challenges of being the first leader of their new schools and flying the plane as it is being built. Though these leaders have learned to navigate being in an 
adaptive state, the constant sense of change and unknown can be a challenge. All participants reported time as a challenge to not only work with people, but to do get things accomplished. Finally, all participants said time and striking a work-life balance was a major challenge they face because some issues and goals are ongoing. Having a constant flow of work makes it difficult for SLs to stop working. The significance of these findings and implications for future research is discussed in Chapter 5. 


\section{CHAPTER FIVE}

\section{CONCLUSIONS}

\section{Summary of Study}

According to Leithwood et al. (2004), leadership is second only to classroom instruction among all school-related factors that contribute to what students learn at school (Wallace Foundation, 2008, 2013). Yet, according to multiple studies, principal preparatory programs are often insufficient to prepare SLs for the demands of the job, and professional development for SLs is sporadic at best (Alvoid \& Black, 2014; Chapman 2005; Gray et al., 2007). Moreover, a common finding across studies of principal retention is that schools with a high percentage of poor students, minority students, and/or low-performing students, experience more principal turnover than their counterparts (Loeb, Kalogrides, \& Lai Horng, 2009; as cited in Burkhauser et al., 2013). The job of a principal can often be daunting and therefore, principals need support and professional development in order to build their leadership skills to be effective.

For this study, the researcher wanted to answer the following research question- how do K-12 assistant principals and principals develop their leadership skills and practices on the job after their pre-service programs in various school contexts? The researcher used purposive selection, gathering participants from a state association of school principals in New England. The researcher conducted semi-structured interviews with each participant and gathered The Model results as well as documents to support the participants perceived skill level. Inductive analysis was used to analyze the interviews, The Model, and document 
examination. A cross-case analysis was conducted to reveal practices SLs have developed in order to be effective in their school contexts. In order to address issues of trustworthiness, researcher utilized member checking, triangulation (interviews, skill model, and document examination), coding strategy, peer review, and thick description to address credibility, transferability, dependability, and confirmability. These methods are outlined in Appendix H.

The analysis revealed that having a mentor and utilizing other leaders within their district assisted in participant's skill development. Further, the cross-case analysis revealed that leaders of all skill levels spoke to using similar practices to be effective in their school contexts. There were no major differences between those skills and practiced utilized by SLs in different contexts. All participants approached their leadership and used similar skills and practices despite their school context. There was a distinction between knowing yourself as a leader, as defined as Self, and knowing how to manage others, defined as Others. The process and themes under and in between each section can be seen in Figure 1.

\section{Discussion of Findings}

This study was conducted in order to find out how school leaders develop their leadership skills on the job in order to be effective SLs in their school contexts, since the state these SLs work in has many pathways to leadership and no formal statewide support or evaluation system for SLs. The researcher was concerned with school leader skill development, but also common practices used by principals in their various school districts. Also, the study aimed to understand leadership practices SLs used within their school context in order to be effective leaders. 
Because research indicates a higher turnover rate of principals in urban school districts, the researcher was interested in understanding skill development and leadership practices utilized by assistant principals and principals in various school contexts. The findings can provide indications of the types of supports that can assist SLs in their skill development on the job, but no difference was found between the skills and practices developed on the job across contexts. By understanding what the SLs reported as supports and challenges to their skill development and leadership practices, the researcher can suggest approaches and policy changes to support the development of future SLs. Leadership development programs and the state department of education should be investing time into how to offer new leaders development with a structured design and accountability system.

Elmore (2006) would argue that the findings in Figure 1 show that participants practice through an inspiration view, meaning, the organization speaks to providing teachers with autonomy and accommodates them within the school context (Elmore, 1996). What is interesting about this is that participants spoke to one of their challenges to their skill development was being a constant adaptive state. The inspirational view often leads to high levels of parent satisfaction and helping schools rationalize reforms, yet, participants reported this being in a constant state of change was a challenge to their skill development (Elmore, 1996). This supports the finding that being in an adaptive state is a challenge for SLs, and further change needs to be made at the policy level in order to truly accommodate 
the current educational trends under ESSA, or else educational improvement will stall.

The evidence signifies that having a mentor and developmental network of support assisted in the development of SLs (Drago-Severson \& Blum-DeStefano, 2018; New York Leadership Academy, 2015) . Having an official mentor or selfproclaimed mentor, participants reported helped them understand a problem more globally and see all sides of the problem before coming to a decision. In turn, a mentor assisted the school leaders in developing their decision-making skills. Drago-Severson (2009) has said, "Leadership is doing the right thing: management is doing things right" (p. 32). Having a mentor to talk through issues with helped SLs essentially think like a leader (New York Leadership Academy, 2015; Peno \& Mangiante, 2012). Further, participants reported having a supportive network of people to turn to whenever they needed to access support or knowledge. The network of people was composed of fellow assistant principals and principals in and out of district, the superintendent in the district, and teachers within the district. Having access to mentors and a developmental network assisted SLs in making mindful decisions and showed them the importance of reflection in order to develop their skills further. Therefore, the researcher suggests there is a need for SLs to have access to mentors and a developmental network that can assist them in seeking the right decision and reflection process as needed.

The results also indicate that SLs seek their own professional development to develop their knowledge and understanding of their leadership skills. All participants reported seeing organizational management in the way presented in 
Figure 1. Instruction and professional practice as a focus was sparsely reported. The findings in Figure 1 support the notion that SLs are more focused on organizational leadership than instruction. This finding suggests that SLs may not have been prepared effectively to deal with organizational management as well as issues of instruction and student achievement in their pre-service programs or that a lack of mentoring to navigate all aspects of a SL's role was detrimental. This is supported Brazer \& Bower (2012) and Wallace Foundation (2013) findings that few principal preparatory programs focus more on instruction than on organizational leadership. An understanding of effective instruction and how to support teachers, as well as organizational management has to be present in order for a SL to be effective in their role.

Further, SLs felt inclined to seek a leadership position and pursue professional development when they felt a sense of commitment to their school and work. Five participants, in particular, were former teachers in their district and grew along with their schools, as their schools developed new programs. Growing with their districts and feeling a sense of belonging gave them confidence to lead and grow with their schools. Using collaboration as a way to support and insure commitment from all constituents within the school was supported in the findings (Darling-Hammon, 2012; Drago-Severson, 2009; Drago-Severson \& BlumDeStefano, 2018; Wallace Foundation, 2008,2013). It is clear that participants utilized shared leadership models that put collaboration at the fore to increase their capacity as a SL. Therefore, the researcher suggests there is a need to find SLs that are a good fit for the school district and vice versa. This may mean school principal 
preparatory programs focus on finding the future principal the ideal school context they would like to work in for their residency, and expose them to different schools while in the program.

Reflection was another finding which assisted with decision making as well as work-life balance. All participants reported some challenge with finding the ideal work-life balance. In the article titled "Principal Under Pressure" in Education Week, one principal reports, "I have seen way too many people get burned out...there needs to be a balance between [our] professional and personal lives, and that we are much more effective in each when it's in balance" (Mitchell, 2018, p. 11). One participant reported missing out on his child's preschool graduation because of work. Another participant left the principal job for two years, and then returned as an assistant principal at another school because his work-life balance was askew. To have a strong work-life balance, participants reported constantly reflecting on time management, mentoring others, and prioritizing their to-do lists, but also reflecting on self and how the work was affecting them personally. This struggle among SLs was reported at various levels of skill development. This finding shows that SLs not only struggle with building efficiency in organizational management, but also conflicting responsibilities. Reflecting on self, and viewing themselves as a learner within their school context assisted the SLs in understanding where to draw the line between ending their work for the day or week, and going to enjoy some time to themselves (Kaser, 1982; Drago-Severson, 2009). Therefore, the researcher suggests principal preparatory programs and on the job mentorships focus on reflection and developing practices 
to help the school leader with developing their necessary skills while striking a work-life balance (Brazer \& Bower, 2012; Darling-Hammond, 2012; Young \& Crow, 2017).

In terms of developing leadership practices to build school culture, participants reported that their practices involved others. The main driver of getting all to be committed to the school culture is knowing your people. Knowing the people who work within the school context, helps a school leader understand what supports and needs they have, and how to navigate relationships, collaboration, and professional development. To some, emotional intelligence (EQ) is more important than intelligence (IQ) in attaining success in a profession today because professions depend on our ability to read other people's signals and react appropriately to them (Bressert, 2018). Participants said during their first years on the job, they focused on getting to know their people in and out of school, and building relationships to assist with how they would utilize them within the greater organization to meet school goals. Having relationships and understanding people's lives (i.e. names, home/life situations, professional practice, and instruction) assisted them in moving the mission and vision of the school forward. Bolman \& Deal (2013) suggest when people and organizations fit, both benefit: "individuals find meaningful and satisfying work, and organizations get the talent and energy they need to succeed" (p. 135). Building relationships between people and supporting them in the work of the mission and vision of school, can build a positive school culture (DragoSeverson, 2009; Drago-Severson \& Blum-DeStefano, 2018). Therefore, the researcher suggests principal preparatory programs focus on tools to build 
relationships with staff, and to assist the school leader in developing their own emotional quotient to ensure their own behaviors are maximized within the school context.

In all, the research found that there are on-going supports after pre-service programs for SLs to improve their skill development across the state. However, the urban and charter schools seem to be utilizing these supports more often. This finding aligns with the higher levels of need that may exist within these districts; however, some of these supports are grant funded, and the researcher cannot speak to how the grants are awarded. It is important for a school leader to have a mentor, formal or informal, to help them develop their decision-making abilities. It is also important for a school leader to understand and define their developmental network of support available to them in a time of need. SLs should always seek their own learning opportunities to become a leader. Finally, possessing and developing a reflective mindset was a crucial skill and practice SLs possessed in order to be effective in their jobs.

In terms of leadership practices within the context of their school buildings, school leader's spoke to their soft skills and building relationships as important to driving the school culture and accomplishing goals. A school leader's skill development did not necessarily change the importance of needing soft skills, but SLs who had spent more time in their districts emphasized the importance of building relationship more than those leaders who were less experienced. In all, the importance of knowing the people who work with and for you and building relationships was key to a school leader's success. 
Implications for Practice

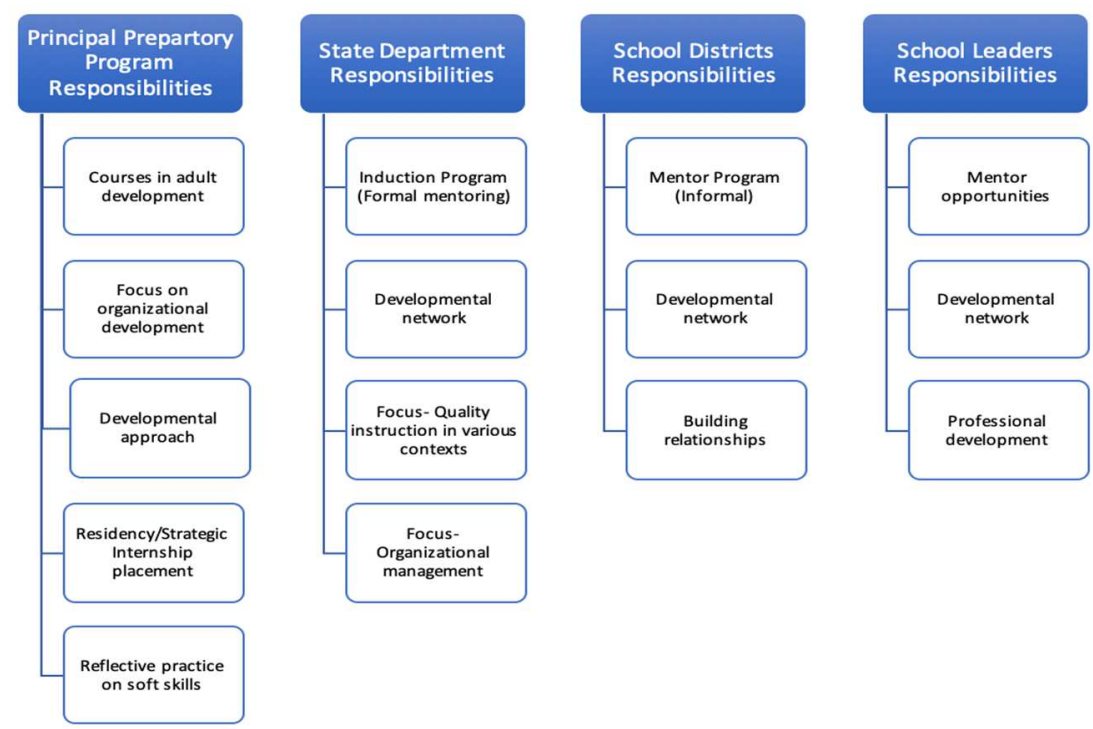

Figure 2 .

The job of the principal is more than managing people on a daily basis. The principal's job has shifted from being a manager to an instructional leader (Brazer \& Bower, 2012; Drago-Severson, 2009; Drago-Severson \& Blum-DeStefano, 2018; Johnson, 1996). Changes in the principalship have been occurring as a result of large-scale reforms at the policy level, resulting from the determination to ensure the provision of quality schooling (Chapman, 2005; Elmore, 1996). The role of a SL now focuses on ensuring all students receive high quality instruction as well as the organizational management within the context of the school (Brazer \& Bower, 2012; Darling-Hammodn, 2012). A call for principal preparation programs to focus on instructional leadership, as well as organization developmental to assist SLs in being more prepared to balance the multiple roles of the job (Darling-Hammond, 2012; Neumerski, 2012; Wallace Foundation, 2013). If changes in the job have occurred for the principal, then the changes need to be identified and carried out in 
principal preparation programs, sate policy, and school districts. Further, SLs need to see themselves as a learner within this adaptive process. Figure 2 describes the implications for practice and will guide the discussion in this section.

Principal Preparation Programs

ESSA has given more flexibility to states regarding how to support the development of their SLs. Changing one piece of the puzzle, for instance principal preparation programs, requires alteration at all levels of where SLs receives supports, concluding that restructuring schools requires restructuring the entire system of organization, governance, and accountability that concerns schools (Elmore, 1996, p. 26; Wang et.al., 2018). Thus, for example, the current wave of educational reform involves not only the development of centralized output and process controls for schools but also calls for pervasive reform of the professional system of training, licensing, and control (Elmore, 1996, p. 41). ESSA allows more flexibility at the state and district levels to produce more targeted supports for SLs (Riley \& Meredith, 2017).

First, framing of principal preparation can be looked at as a developmental process. The assumption that there is a structural deficit from preparatory program to on-the-job support is reflected in a current approach to organizational design (Bolman \& Deal, 2014; Elmore, 1996). The organizational design of SL development from preparatory program to on the job, is approached as a linear process where SLs are expected to be effective when hired; however, the SL is a learner within the context of the school in which they lead, therefore calling for ongoing, continued support for development once on the job (Drago-Severson, 2009; 
Drago-Severson \& Blum-DeStefano, 2018; Kegan, 1982; Neumerski, 2012; New York City Leadership Academy, 2015). A more developmental approach would assist in the effective development of SLs' skills. A developmental approach would support SLs in building skills and practices around effective instruction as well as organizational management (Darling-Hammond, 2012; Wallace Foundation, 2013) to ensure high quality instruction is present at all times. Since participants reported the practices they use as more managerial in terms of organizational management after their pre-service program, it is evident that preparatory programs could have a positive effect on SL development pre-service.

Within the context of organizational development, the SL will need to understand how to operate within the context, and therefore, principal prepatory programs could focus on assisting SLs in developing their emotional intelligence (Herman et al., 2016). Participants reported using "soft skills" like listening, etc. as skills they learned on the job to help in decision making and building relationships.

Further, a developmental approach would result in a more in-depth internship with an assigned mentor who is trained to use effective mentoring techniques (New York Leadership Academy, 2015; Peno \& Silva Mangiante, 2012). Another approach may be a residency where an aspiring school leader works for one year alongside the current school principal, as a nurse or doctor would in their preparatory programs. For example, according to Dreyfus (2004):

Using the skill model of adult acquisition, the internship model allows the student to take the rules learned and apply them to relevant experiences to 
help them develop from a novice to an advanced beginner. The advanced beginner now drives the decision process. (p. 177)

The developmental approach using The Model (1992) could allow states and districts to work together to develop and define what development at each level looks like (Riley \& Meredith, 2017). A developmental approach is more human needs-based than structural because the inclusive system is built to help the person develop and views the SL as a learner within the context. This approach could result in partnerships between school leader development programs and school districts with development addressed across a continuum of pre through in-service. State Department Programs

The findings suggest that state departments of education can help promote programming for school leader development under the Every Student Succeeds Act (ESSA). ESSA addresses the human needs perspective by allowing states and districts to invest funding into their priority leadership needs (Riley \& Meredith, 2017). Support for SLs at a state and district level can include a) improving principal certification and preparatory programs, b) providing professional development in areas such as emotional intelligence, building relationships and collaboration, and c) quality induction programs that include mentoring for novice and advanced beginner SLs (with trained mentors) (Elmore, 1996; Johnson, 1996; Herman et al., 2016; Riley \& Meredith, 2017; Drago-Severson \& Blum-DeStefano, 2018; Peno \& Siva Mangiante, 2012).

ESSA uses a human resources perspective by offering supports to help retain school principals, promoting aspiring principals and investing in their 
employees. As suggested by Aubrey \& Tilliette (1990), leadership in an organization takes place when three elements are in place: good mentors who teach others, a management system that lets people try new things as much as possible, and a very good exchange with the environment. Though ESSA provides opportunity for leadership support through grants, district management may not be structured to try new things and the environment may not be collaborative. The state department of education is currently working with SLs from around the state to draft supports for SLs (Riley \& Meredith, 2017). It is crucial that these supports are communicated to district leaders who will then have the flexibility to support their SLs within their context. Further these supports need to revolve around organizational management, while quality instruction as the main focus (Elmore, 1996; Darling-Hammond, 2012; Wallace Foundation, 2013).

School District and School Leader Responsibilities

School districts need to think carefully about why inequities exist and the internal and external forces that can influence change (Drago-Severson \& BlumDeStefano, 2018; Elmore, 1996). In equities that exist can be skill gaps amongst groups of students, teacher schedules and workloads, lack of consistency in high expectations, etc. If ESSA allows for more flexibility at the state level, then school districts must have more flexibility in supporting their SLs. This flexibility could like having more say in the hiring process, training process, and recruiting process of SLs (Elmore, 1996; New York City Leadership Academy, 2015). Further, districts will need to foster a developmental network that can provide a supportive environment for the SL as a learner within their district school context. 
Superintendents can support mentoring within their district and utilize grants to train their individuals interested in mentoring. Also, districts must form relationships and recruit SLs as potential leads for future leadership in their district. Currently, SLs are born within their district, or options for qualified and effective SLs are scarce.

SLs themselves must recognize they are a learner within the context of their school (Kaser, 1982; Johnson, 1996; Drago-Severson, 2009). The SL should understand what they need in order to develop to the next level of skill. School leaders themselves should be taking advantage of informal mentorships, developmental networks, and professional development as ways to continue developing their skills and practices. Further, SLs should be allowed the support of flexible policies to take time off (i.e. sabbatical) to further their knowledge of leadership and develop their skills as a current SL.

Future Research

In order to more fully understand SL skill development and leadership practices, future researchers may want to consider how SLs develop their skills and practices in various school contexts throughout the country (Brazer \& Bower, 2012). First, future research may consider using a larger sample size from different states, within and outside of New England. Having more participants from various states will increase the generalizability of the research. Further, future research may consider conducting a survey study to reach a larger sample of SLs. Conducting a survey study may also increase the transferability of the research. Finally, future research may consider doing a comparative study between assistant 
principal skill development and principal skill development. A comparative study may find similarities and differences in the skill development of SLs in these different positions.

Summary and Concluding Thoughts

This study affirmed the need for on-going supports to help school leader skill development. The researcher expected to find that most SLs took a single path into school leadership, this path being a teacher in their district, and then having a desire to go into administration. However, the findings revealed that most participants had someone who believed in them and motivated them to go into administration. The mentor, whether official, or a more experienced other, part of an informal relationship, played a significant role in leading the participants into being SLs.

The researcher found participants' willingness to share their honest experiences refreshing. Being a school leader, the researcher learned much about her own leadership practices while conducting the analysis. It is interesting that SLs in the state do not have more social time together as SLs, although they all belong to the same association and face similar challenges in their schools.

ESSA has put a new-found focus on support and professional development for SLs, but as every educational trend comes and goes, the researcher fears that the emphasis on school leader skill development will dissipate. The researcher hopes that there will be a continuous emphasis on school leader development, as they face continuous educational policy and social changes. 


\section{Appendix A}

Five-Stage Model of Adult Skill Acquisition

(Adapted from Dreyfus and Dreyfus, 1980, 1992, 2004)

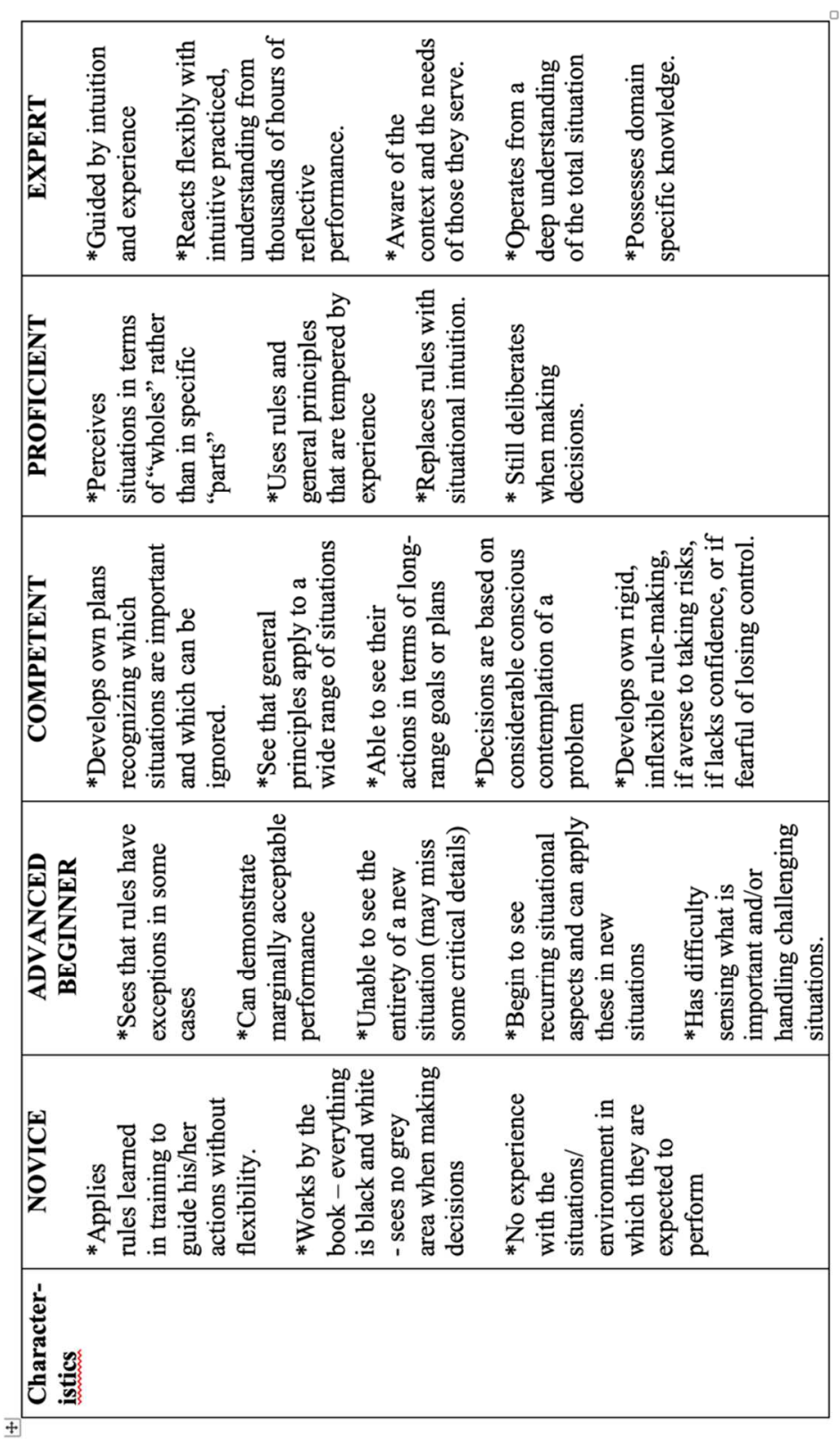

Instructions to Participant:

Please read each level and the corresponding characteristics and select the highest level you feel you achieved during your teaching career. Then, please think of examples/stories of your practice at all levels. If you have any questions regarding the levels, please feel free to contact Nicole Lyons at 401-749-5700 or at nrsilvia@gmail.com at any time. Thank you, in advance, for your time and consideration. 


\section{Appendix B}

\section{Principal Leadership Development Framework (Hall, Childs-Bowen, Cunningham-Morris, Pajardo, \& Simeral, 2016)}

Principal as Engager

1. Maintains an unwavering priority of establishing and fostering an environment that tends to the whole child: healthy, safe, engaged, supported, and challenged

2. Creates and cultivates partnerships within the parent, district, business, political, and greater community spheres to support the achievement of the school's mission and vision

3. Drives and navigates positive change by assessing, analyzing, and anticipating emerging trends and implementing change-savvy techniques with staff and the school community

4. Safeguards community values, ethics, and equitable practices, advocating for all children and displaying an appreciation for diversity

5. Develops policies and practices that cultivate staff as reflective practitioners

Principal as Learner and Collaborator

1. Facilitates the delivery of job-embedded, ongoing, coordinated professional learning opportunities that lead to increased student achievement

2. Develops internal leaders and nurtures and environment of distributed leadership, collective responsibility, and collaborative decision-making

3. Models reflective practice, confidence, humility, perseverance, and interest in continuous growth and lifelong learning

4. Participates regularly in professional learning organizations, a community of practice, and a leadership network

Figure 1.1 ASCD's Principal Leadership Development Framework (p.8)

Principal as Visionary

1. Articulates, communicates, and leads the collaborative implementation and ongoing revision of the school's mission and vision

2. Aligns and bases all decisions, practices, policies, and resources (e.g., human capital, time, budgetary, and facilities) on the school's mission and vision

3. Promotes the collaborative creation, monitoring, and refinement of short- and long-term school improvement plans

4. Compels the district and school community to embrace and work toward the attainment of the shared mission and vision

Principal as Instructional Leader

1. Builds collective capacity of the entire staff through the cultivation of a robust Professional Learning Community

2. Builds individual capacity of the entire staff through differentiated supervision, coaching, feedback, and evaluation practices

3. Ensures the alignment of rigorous curricula, research-based best practices in instruction, and comprehensive formative and summative assessment approaches

4. Promotes monitoring systems that use real-time data to inform instruction and intervention at the teacher, team, and school site levels 


\section{Appendix C}

Theoretical Framework

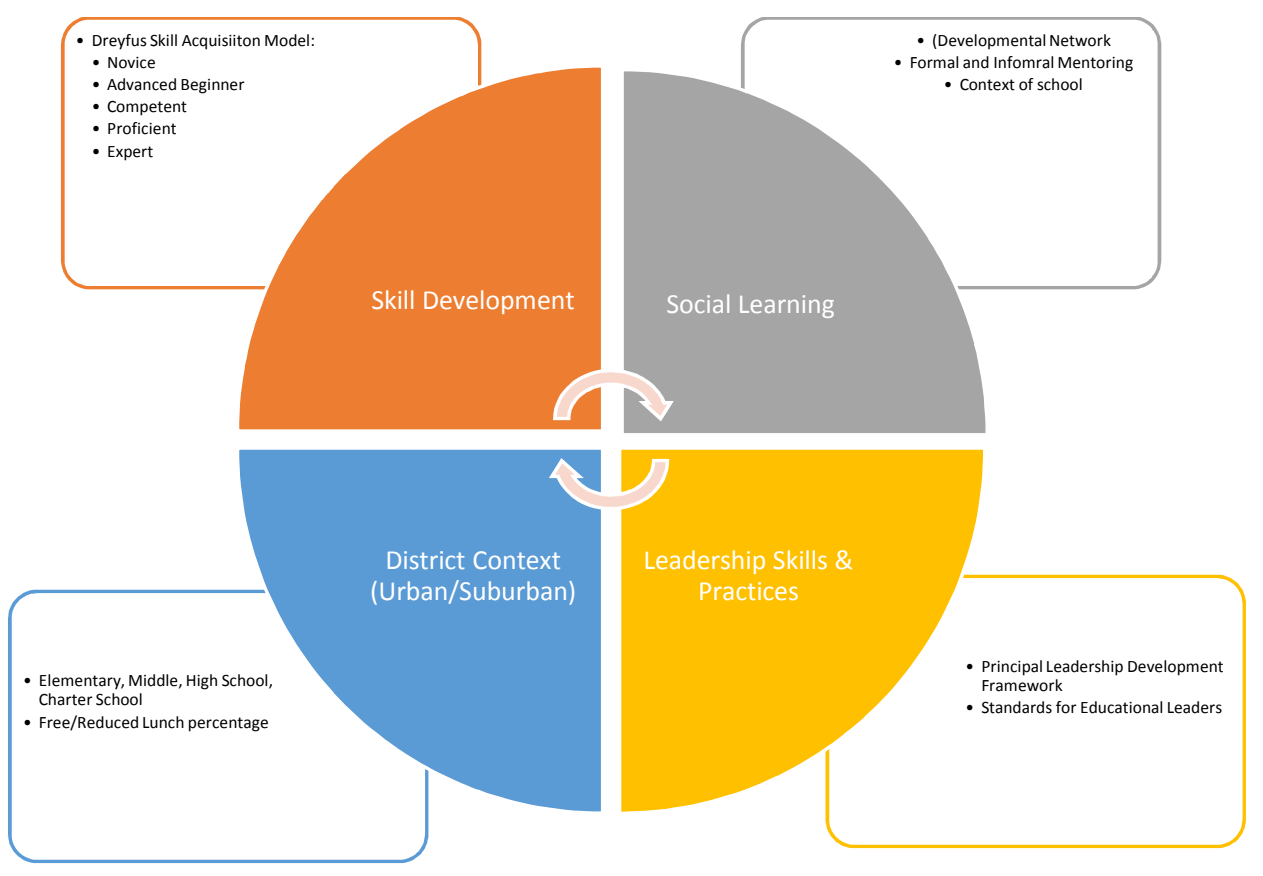




\section{Appendix D}

\section{Research Question and Methodology Table}

Overarching Question: Overarching Question: What are school leader's perceptions of their skill development once on the job across contexts?

\begin{tabular}{|c|c|c|c|c|}
\hline $\begin{array}{l}\text { Research } \\
\text { Questions }\end{array}$ & $\begin{array}{l}\text { What kind of } \\
\text { data will } \\
\text { answer these } \\
\text { questions? }\end{array}$ & $\begin{array}{l}\text { Analysis } \\
\text { Method }\end{array}$ & $\begin{array}{l}\text { Potential } \\
\text { Conclusions/Research } \\
\text { er Threats (Validity } \\
\text { Threats) }\end{array}$ & $\begin{array}{l}\text { Sample/ Initial } \\
\text { Codes }\end{array}$ \\
\hline $\begin{array}{l}\text { RQ \#1: } \\
\text { Using } \\
\text { The } \\
\text { Model, } \\
\text { where do } \\
\text { SLs } \\
\text { place } \\
\text { their } \\
\text { skill } \\
\text { level? }\end{array}$ & $\begin{array}{l}\text { - Interview } \\
\text { Q5, Q12 } \\
\text {-Skill Model }\end{array}$ & $\begin{array}{l}\text {-Case study } \\
\text { analysis- } \\
\text { compare and } \\
\text { contrast the } \\
\text { level of each } \\
\text { participant } \\
\text { (Patton, 2002) }\end{array}$ & $\begin{array}{l}\text {-Researcher bias- } \\
\text { Identify my bias in } \\
\text { terms of my } \\
\text { leadership role and } \\
\text { personal background } \\
\text { at the beginning of the } \\
\text { interview (Creswell, } \\
\text { 2014). } \\
\text {-Member checking } \\
\text {-Peer review }\end{array}$ & $\begin{array}{l}\text {-Novice } \\
\text {-Advanced } \\
\text { Beginner } \\
\text {-Proficient } \\
\text {-Competent } \\
\text {-Expert } \\
\text { (Dreyfus Skill } \\
\text { Model) }\end{array}$ \\
\hline $\begin{array}{l}\text { RQ \#2: How } \\
\text { do K-12 SLs } \\
\text { perceive } \\
\text { they have } \\
\text { developed to } \\
\text { this level } \\
\text { since } \\
\text { leaving their } \\
\text { pre-service } \\
\text { program? }\end{array}$ & $\begin{array}{l}\text {-Interview } \\
\text { Q3, Q4, Q5, } \\
\text { Q10 }\end{array}$ & $\begin{array}{l}\text {-Case study } \\
\text { analysis- } \\
\text { compare and } \\
\text { contrast the } \\
\text { level of each } \\
\text { participant } \\
\text { (Patton, 2002; }\end{array}$ & $\begin{array}{l}\text {-Researcher bias- will } \\
\text { be addressed by } \\
\text { asking questions that } \\
\text { do not lead } \\
\text { interviewee; open } \\
\text { ended questions will } \\
\text { be asked in a } \\
\text { particular sequence } \\
\text { after rapport is built } \\
\text { with the interviewee } \\
\text { (Roulston, 2010) } \\
\text {-Member checking } \\
\text {-Peer review }\end{array}$ & $\begin{array}{l}\text { - In-service } \\
\text { program } \\
\text {-mentor formal } \\
\text { (formal/informal } \\
\text {, professional } \\
\text { development } \\
\text { developmental } \\
\text { network, } \\
\text { journaling }\end{array}$ \\
\hline
\end{tabular}




\begin{tabular}{|c|c|c|c|c|}
\hline $\begin{array}{l}\text { RQ \#3: } \\
\text { What are the } \\
\text { leadership } \\
\text { practices } \\
\text { that they } \\
\text { perceive } \\
\text { they have } \\
\text { developed } \\
\text { since } \\
\text { leaving their } \\
\text { pre-service } \\
\text { program? }\end{array}$ & $\begin{array}{l}\text { - Interview } \\
\text { Q2, Q6, Q8, } \\
\text { Q10, Q11 }\end{array}$ & $\begin{array}{l}\text {-Case study } \\
\text { analysis- } \\
\text { compare and } \\
\text { contrast the } \\
\text { level of each } \\
\text { participant } \\
\text { (Patton, 2002) }\end{array}$ & $\begin{array}{l}\text {-Researcher bias- will } \\
\text { be addressed by } \\
\text { asking questions that } \\
\text { do not lead } \\
\text { interviewee; open } \\
\text { ended questions will } \\
\text { be asked in a } \\
\text { particular sequence } \\
\text { after rapport is built } \\
\text { with the interviewee } \\
\text { (Roulston, 2010) } \\
\text {-Member checking } \\
\text {-Peer review }\end{array}$ & $\begin{array}{l}\text {-Organization } \\
\text {-Collaborate } \\
\text {-Lead } \\
\text {-Articulate } \\
\text { (Principal } \\
\text { Development } \\
\text { Framework, } \\
\text { 2017) }\end{array}$ \\
\hline $\begin{array}{l}\text { RQ\# } 4 \text { 4-How } \\
\text { do SLs } \\
\text { describe the } \\
\text { challenges } \\
\text { to their skill } \\
\text { development } \\
\text { ? }\end{array}$ & $\begin{array}{l}\text {-Q2, Q5, } \\
\text { Q12 }\end{array}$ & $\begin{array}{l}\text {-Case study } \\
\text { analysis- } \\
\text { compare and } \\
\text { contrast the } \\
\text { challenges } \\
\text { participants } \\
\text { speak to } \\
\text { (Patton, 2002) }\end{array}$ & $\begin{array}{l}\text {-Researcher bias- will } \\
\text { be addressed by } \\
\text { asking questions that } \\
\text { do not lead } \\
\text { interviewee; open } \\
\text { ended questions will } \\
\text { be asked in a } \\
\text { particular sequence } \\
\text { after rapport is built } \\
\text { with the interviewee } \\
\text { (Roulston, 2010) } \\
\text {-Member checking } \\
\text {-Peer review }\end{array}$ & $\begin{array}{l}\text {-Time } \\
\text {-Schedule } \\
\text {-Structure } \\
\text {-Number of } \\
\text { responsibilities } \\
\text {-District location } \\
\text { (School Leader } \\
\text { Network, Drago- } \\
\text { Severson) }\end{array}$ \\
\hline $\begin{array}{l}\text { RQ \#5- How } \\
\text { do SLs } \\
\text { perceive } \\
\text { their district } \\
\text { context has } \\
\text { affected } \\
\text { their } \\
\text { leadership } \\
\text { skill } \\
\text { development } \\
\text { ? }\end{array}$ & -Q6, Q7, Q8 & $\begin{array}{l}\text {-Case study } \\
\text { analysis- } \\
\text { compare and } \\
\text { contrast the } \\
\text { challenges } \\
\text { participants } \\
\text { speak to } \\
\text { (Patton, 2002) }\end{array}$ & $\begin{array}{l}\text {-Researcher bias- will } \\
\text { be addressed by } \\
\text { asking questions that } \\
\text { do not lead } \\
\text { interviewee; open } \\
\text { ended questions will } \\
\text { be asked in a } \\
\text { particular sequence } \\
\text { after rapport is built } \\
\text { with the interviewee } \\
\text { (Roulston, 2010) } \\
\text {-Member checking } \\
\text {-Peer review }\end{array}$ & $\begin{array}{l}\text {-District Context } \\
\text {-Urban } \\
\text {-Suburban } \\
\text { (RIDE } \\
\text { Definitions) }\end{array}$ \\
\hline
\end{tabular}




\section{Appendix E}

\section{Participant Consent Form}

You have volunteered to be part of a research project described below. The researcher will explain the project to you in detail. Please feel free to ask questions and contact me, Nicole Lyons at 401-749-5700, or by email at nrsilvia@gmail.com.

Description of the research:

The purpose of this study will examine which skills, and practices leaders from various districts and school buildings and of varying levels of experience find the most useful in their leadership roles. In particular, this study will seek to understand: How K-12 assistant principals and principals perceive the development of their leadership skills after their inservice program?

If you decide to take part in the interview process, you will be asked to do the following:

1. You will receive an email after the completion of the course where you will be provided a copy of The Dreyfus Skill Model. You will read the descriptors of practice at each level from Novice through Expert and decide where you feel your leadership skill level is.

2. You will be asked to participate in semi-structured interviews, which will be conducted in-person between February and April of 2018. Interviews will last no longer than two hours. At the interview you will be asked to re-evaluate your skill level using the Dreyfus Skill Model.

3. Prior to the interview, you will be asked to bring an artifact that you perceive represents your perceived skill level. These documents may be redacted, re-written, or any other form you deem acceptable for the researcher's review. This will help the researcher understand your perceptions and reasoning of your perceptions.

4. Total Time: 3-4- hours

Risks or discomfort:

There are no anticipated risks involved in participating in this study. Your name and other identifiers will not be used in any way in the presentation of the research and all of your responses will be held in confidence. It is not anticipated that you will experience any negative effects because of this study and participation, nonparticipation, or withdrawal from the study will not affect your employment in any way.

Confidentiality:

Your participation in this study is confidential. None of the information will identify you by name or otherwise. All records will be saved in a password-protected file and pseudonyms will be assigned.

Decision to stop at any time:

The decision to take part in this study is voluntary. You do not have to participate. If you decide to take part in the study, you may stop at any time. Whatever you decide will in no 
way penalize you or affect your grades. If you wish to stop, simply inform Dr. Kathy Peno, (faculty supervisor: ktpeno@gmail.com, (401) 523-1477) or Nicole Lyons (student researcher: nrsilvia@gmail.com, (401) 749-5700), of your decision. Upon your decision to stop participating in the study, all data gathered will be destroyed.

Rights and Complaints:

If you are not satisfied with the way this study is performed, you may discuss your complaints with Dr. Kathy Peno, (faculty supervisor: ktpeno@gmail.com, (401) 523-1477) or Nicole Lyons (student researcher: nrsilvia@gmail.com, (401) 749-5700), anonymously, if you choose. In addition, if you have questions about your rights as a research participant, you may contact the office of the Vice President for Research and Economic Development, 70 Lower College Road, Suite 2, University of Rhode Island, Kingston, Rhode Island, telephone: (401) 874-4328.

You have read the Consent Form. Your questions have been answered. Your signature on this form means that you understand the information and you agree to participate in this study.

Signature of Participant

Typed/printed Name

Date
Signature of Researcher

Typed/printed name

Date

Your signature below means that you understand and agree to being audio recorded during the interviews.

Signature of Participant

Printed Name

$\underline{\text { Please sign both consent forms, keeping one for yourself }}$ 
Appendix F

Email Correspondence

(Recruit Participants)

Hello fellow school leader,

My name is Nicole Lyons and I am $\mathrm{PhD}$ candidate looking to gather participants for my study at the University of Rhode Island. I am conducting a research study about assistant principal and principal's perceptions of their leadership skill development after their inservice program. I am emailing you to ask if you would like to take part in my study. Being part of this study will take about 5 minutes to fill out the questionnaire, and if you are chosen, one, one-hour interview. Participation is completely voluntary.

If you are interested, please click on the link for the questionnaire.

If you are chosen to be a participant in my study, you will receive further correspondence within the next 4 weeks and we will work together to set up an interview time. If you have any questions, please do not hesitate to contact me at 401-749-5700, or by email at nrsilvia@gmail.com.

Thank you for your time.

Best,

Nicole Lyons

(Accepted to be a Participant)

Hello fellow school leader,

You have been chosen to participate in my study based on responses to the previous questionnaire. Please fill out the Doodle offering times you are available for an interview. Please bring the following to the interview:

1) Signed consent form (Click on the following link)

2) Artifact that represents your perceived skill level (Click on the following link)

3) Any questions you have for the researcher

Once you fill out the Doodle, you will receive a Google Calendar invite with the date, location, and time of your interview. Please remember your participation is completely voluntary.

Please do not hesitate to contact me at 401-749-5700, or by email at nrsilvia@gmail.com prior to your interview.

Best,

Nicole Lyons 


\section{Appendix G}

\section{Interview Protocol}

(Patton, 2004; Roulston, 2010)

The interview questions will be asked in a particular order that does not lead the interviewee; open ended questions will be asked in a particular sequence after rapport is built with the interviewee (Roulston, 2010).

1. Tell me about your pathway to leadership. How did you get to the position you are in now?

a. Do you have leadership experience in another field?

b. Have you always wanted to be a school leader/administrator?

i. What drove you to want to be a school leader?

2. Tell me about the context of your district (i.e. Student population, teacher population, Diversity, Urban/suburban, Free/Reduced lunch, etc.) (RQ \#3, RQ \#4)

3. What were your perceptions of being a school leader while you were in your pre-service program? (RQ \#2)

4. What are your perceptions of being a school leader now that you are one? (RQ \#2)

5. Where do you place yourself as a school leader on the Dreyfus Adult Skill Acquisition Model? (RQ \#1)

-Why do you place yourself at this stage? (RQ \#1 and RQ \#2)

-Speak to specific experiences you have had that you feel have helped you get to this stage of your development as a leader. (RQ \#2)

- Speak to experiences that you feel have hindered your development as a leader. (RQ \#4)

6. What are the most important leadership skills you feel make you an effective leader?

You feel you use on a daily basis? (RQ \#3, RQ \#5)

7. How do you practice these leadership skills on a daily basis? (RQ \#5)

8. Based on the school and district you lead in, what leadership skills/practices are the most relevant/make you successful in this context? (RQ \#3, RQ \#5)

9. In what areas of your leadership practice do you feel you need to improve?

-What do you perceive could help you improve in these areas? (RQ \#2)

10. What kinds of leadership practices do you feel support your own learning? (DragoSeverson, 2009) (RQ\#2)

-Do you seek out opportunities for your own learning? (RQ \#2) If yes- what opportunities and why? If no- Why not?

-What opportunities would you like to seek if any?

-What types of opportunities do you want to seek out?

11. If you could give advice to a new leader the first day on the job, what would it be?

Ask the participant if he or she has any questions for me. Then, inform them that they will be asked to member check the responses for accuracy and that I may be contacting them for a follow up interview if needed. 
Appendix $\mathrm{H}$

Issues of Trustworthiness of a Qualitative Study

\begin{tabular}{|l|c|c|c|c|}
\hline & $\begin{array}{r}\text { Credibili } \\
\text { ty }\end{array}$ & Transferability & Dependability & Confirmability \\
\hline $\begin{array}{l}\text { Purposive } \\
\text { Sampling }\end{array}$ & & $\mathrm{X}$ & & \\
\hline Triangulation & $\mathrm{X}$ & & $\mathrm{X}$ & \\
\hline $\begin{array}{l}\text { Interview } \\
\text { Structure/ } \\
\text { Researcher } \\
\text { Bias }\end{array}$ & $\mathrm{X}$ & & $\mathrm{X}$ & \\
\hline $\begin{array}{l}\text { Coding } \\
\text { Strategy }\end{array}$ & & & & \\
\hline $\begin{array}{l}\text { Member } \\
\text { Checking }\end{array}$ & & $\mathrm{X}$ & & \\
\hline Peer Review & & & & \\
\hline $\begin{array}{l}\text { Thick } \\
\text { Description }\end{array}$ & & & & \\
\hline $\begin{array}{l}\text { Document } \\
\text { Examination }\end{array}$ & & & & \\
\hline
\end{tabular}

The researcher will utilize the methods above to address issues of trustworthiness in this study as outlined by Creswell, (2014); Lincoln and Guba (1985); Maxwell, (2013); Patton, (2002); Roulston, (2010) 


\title{
APPENDIX G
}

\section{Overview of the Professional Standards of Educational Leaders}

\author{
WHAT IS THE LINK BETWEEN EDUCATIONAL LEADERSHIP AND STUDENT LEARNING? \\ The Standards embody a research-and practice-based understanding of the relationship between \\ educational leadership and student learning. Improving student learning takes a holistic view of \\ leadership. In all realms of their work, educational leaders must focus on how they are promoting \\ the learning, achievement, development, and well-being of each student. The Standards reflect \\ interdependent domains, qualities and values of leadership work that research and practice \\ suggest are integral to student success: \\ 1. Mission, Vision, and Core Values \\ 2. Ethics and Professional Norms \\ 3. Equity and Cultural Responsiveness \\ 4. Curriculum, Instruction and Assessment \\ 5. Community of Care and Support for Students \\ 6. Professional Capacity of School Personnel \\ 7. Professional Community for Teachers and Staff \\ 8. Meaningful Engagement of Families and Community \\ 9. Operations and Management \\ 10.School Improvement
}




\section{Bibliography}

Alvoid, L., \& Black, W. L. (2014). The changing role of the principal: How high-achieving districts are recalibrating School Leadership. Center for American Progress.

Argyris, A., \& Schön, D.A. (1974). Theory in practice. Increasing professional effectiveness. San Francisco, CA: Jossey-Bass Publishers.

Aubrey, B., \& Tilliette, B. (1990). Knowledge and teaching: Action learning in the enterprise. Paris: InterEditions.

Becker, H. S. (1970). Sociological work: Method and substance. Chicago: Aldine.

Becker, B. E., \& Huselid, M.A. (1998). "High Performance Work Systems and Firm Performance: A Synthesis of Research and Managerial Implications.” Research in Personnel and Human Resource Management, 16, 53-101.

Benner, P. (1982). From novice to expert. American Journal of Nursing, March, 402-407.

Benner, P. (1984). From novice to expert: Excellence and power in clinical nursing practice. San Francisco, CA: Prentice Hall.

Berliner, D. (2004). Expert teachers: Their characteristics, development, and accomplishments.

Retrieved from http://www.researchgate.net/publication/2566

Berliner, D.C. (2004b). Describing the behavior and documenting the accomplishments of expert teachers. Bulletin of Science, Technology \& Society, 24, 200-212.

Boyce, J., \& Bowers, A. J. (2016) Principal Turnover: Are there Different Types of Principals Who Move From or Leave Their Schools? A Latent Class Analysis of the 2007-08 Schools and Staffing Survey and the 2008-09 Principal Follow-up Survey. Leadership and Policy in Schools, 15(3), p. 237-272.

Bowers, A., \& White, B. (2014). Do principal preparation and teacher qualifications 
influence different types of school growth trajectories in Illinois? A growth mixture model analysis. Journal of Educational Administration, 52(5), 705-736.

Brazer, S.D., \& Bauer, S.C. (2013). Preparing instructional leaders: A model. Educational Administration Quarterly, 49 (4), 645-684.

Bressert, S. (2018). What is Emotional Intelligence (EQ)? Psych Central. Retrieved on February 27, 2019, from https://psychcentral.com/lib/what-is-emotionalintelligence-eq/

Brim, O. G. (1966). Socialization through the life cycle. In O. G. Brim \& S. Wheeler (Eds.), Socialization after childhood (pp. 1-50). New York, NY: John Wiley.

Burgess, S. \& Houf, B. (2017). Lead like a pirate. San Diego, CA: Dave Burgess Consulting, Inc.

Burkhauser, S., Gates, S. M., Hamilton, L. S., \& Ikemoto, G. S. (2012). First year principals in urban school districts: How actions and working conditions relate to outcomes. RAND Corporation.

Chandler, D. E., Murphy, W. M., Kram, K. E., \& Higgins, M. C. (2016) Bridging formal and informal mentoring. In K. Peno, E. M. Silva Mangiante, \& R. A. Kenahan (Series Eds.), Mentoring in formal and informal contexts. (pp.1-20). Charlotte, NC: IAP Inc.

Chapman, J. Recruitment, retention, and development of school principals. International Academy of Education. UNESCO: 2005.

Clark, D., Martorell, P., \& Rockoff, J. (2009). School Principals and School Performance. Working Paper 38. National Center for Analysis of longitudinal data in Education research. 
Coelli, M., \& Green, D. A. (2012). Leadership effects: School principals and student outcomes. Economics of Education Review, 31(1), 92-109.

Creswell, J. W. (2014). Research design: Qualitative, quantitative, and mixed methods approaches. (4th ed.). Thousand Oaks, CA: Sage.

Crow, G. M., \& Matthews, L. J. (1998). Finding one's way: How mentoring can lead to dynamic leadership. Thousand Oaks CA: Corwin Press Inc.

Culbertson, J. (2017). 7 reasons why districts need to invest in principal coaching. Insight Education Group. Retrieved from https://www.insighteducationgroup.com/blog/7reasons-why-districts-need-to-invest-in-principal-coaching

Darling-Hammond, L., LaPointe, M., Meyerson, D., Orr, M. \& Cohen, C. (2007).

Preparing School Leaders for a Changing World. Lessons from Exemplary Leadership Development Programs. Stanford, CA: Stanford University, Stanford Educational $\quad$ Leadership 2007, http://seli.stanford.edu/research/documents/sls_tech_report.pdf.

Darling-Hammond, L., Wise, A.E., \& Pease, S. R. (1983). Teacher Evaluation in the Organizational Context: A Review of the Literature. Review of Educational Research, 53(3), 285-328.

Davis, S., Darling-Hammond, L., LaPointe, M., \& Meyerson, D. (2005). School leadership study: Developing successful principals (review of research). Retrieved from Wallace Foundation website: www.wallacefoundation.org/knowledgesenter/school-leadership/principal-training/Documents/Developing-SuccessfulPrincipals.pdf 
Dillman, D. A., Smyth, J. D., \& Christina, L. M. (2014). Internet, phone, mail, and mixed-mode surveys: The tailored design method. (4th ed.). Hoboken, NJ: Wiley.

Donaldson, G. A. (2008). How leaders learn: Cultivating capacities for school improvement. New York: Teachers College Press.

Drago-Severson, E. (2009). Leading adult learning: Supporting adult development in our schools. Thousand Oaks, CA: Sage.

Drago-Severson, E. (2012). New opportunities for principal leadership: Shaping school climates for enhanced teacher development. Teachers College Record, 114(3), 1044.

Drago-Severson, E., \& Blum-DeStefano, J. (2018). Leading change together: developing educator capacity within schools and systems. Alexandria, VA: ASCD.

Dreyfus, H., \& Dreyfus, S. (1992). Mind over machine. NY, NY: Simon and Schuster.

Dreyfus, S. (2004). The five-stage model of adult skill acquisition. Bulletin of Science, technology, and Society. 24, 177-181.

Dreyfus, H. L., \& Dreyfus, S. E. (2004). Apprenticeship and learning to become an expert. University of Califorinia: Berkley.

Dreyfus, H. L., \& Dreyfus, S. E. (2008). Beyond expertise: Some preliminary thoughts on mastery. In K. Nielson, et al. (Ed.), A qualitative stance; Essay in honor of Steiner Kvale (pp. 113-124). Aarhus University Press.

Elmore, R. F. (1996). Getting to scale with good educational practices. Harvard 
$\begin{array}{llllll}\text { Educational } & \text { Review. } & 66 & \text { (1). } & \text { Retrieved }\end{array}$ http://www.project2061.org/publications/designs/online/pdfs/reprints/5 elmor1.p $\underline{\mathrm{df}}$

Elmore, R. F. (2004). Educating educators: A promising partnership between HGSE and public school leaders. Cambridge, M.A: Harvard Graduate School of Education. Retrieved from https://www.gse.harvard.edu/news/features/elmore07012004.html.

Eraut, M. (2008). How professionals learn through work. Survey Center for Professional Training and Education. University of Surrey.

Erlandson, D. A., Harris, E. L., Skipper, B. L., \& Allen, S. D. (1993). Doing naturalistic inquiry: A guide to methods. Newbury Park, CA: Sage.

Fosnot, C. M. (Ed.). (2005). Constructivism: Theory, perspective, and practice. (2nd ed.). New York: Teachers College Press.

Fry, B., Bottoms, G., \& O’Neil, K. (2005). The principal internship: How can we get it right? Atlanta, GA: SREB.

Fullan, M. (2003). Implementing change at the building level. In W. Owens \& L. S. Kaplan (Eds.), Best practices, best thinking and emerging issues in School Leadership. (pp. 31-36). Thousand Oaks, CA: Corwin.

Gallagher, A. \& Thordarson, K. (2018). Building a culture of yes: 5 strategies to unlock possible innovation in schools. ASCD 13 (14).

Goode, H. (2017). Why do many school principals burnout so quickly. Global Therapy. Retrieve from https://globalteletherapy.com/school-principal-burnout/ 
Gray, C., Fry, B., Bottoms, G., and O’Neill, K. (2007). Good principals aren’t bornthey're mentored. Southern Regional Education Board 7 (5), 1-96.

Hall, P., Childs-Bowen, D., Cunningham-Morris, A., Pajardo, P., \& Simeral, A. (2016).

The principal influence: A framework for developing leadership capacity in principals. ASCD.

Heck, R. H., \& Hallinger, P. (2014). Modeling the longitudinal effects of SLship on teaching and learning. Journal of Educational Administration,52(5), 653-681.

Herman, R., Gates, S.M., Arifkhanova, A., Bega, A., Chavez-Herrerias, E.R., Han, E., Harris, M., Tamargo, J., \& Wrabel, S. (2016). School Leadership interventions under the every student succeeds act: Evidence review. RAND Corporation.

Hoff, N. (Summer, 2018). Soft skills for strong School Leadership. Retrieved from https://www.smartbrief.com/original/2018/08/soft-skills-strong-school-leadership

Hofer, B. K., \& Pintrich, P. R. (1997). The development of epistemological theories: Beliefs about knowledge and knowing and their relation to learning. 67(1): pp.88140). University of Michigan.

Johnson, I. (2005) Why principals quit. Principal, 84 (3), 21-23.

Johnson, S. M. (1996). Leading to change: The challenge of the new superintendency. San Francisco, CA: Jossey-Bass.

Johnson, S.M. (2006). The workplace matters: Teacher quality, retention, and effectiveness. Retrived from National Education Association website: www.nea.org/assets/docs/HE/mf_wcreport.pdf

Johnston, W., Kaufman, J., \& Thompson, L.E. (2016). Support for instructional 
leadership: Supervision, mentoring, and professional development for U.S. school leaders: Findings from the American school leader panel. RAND Corporation.

Kaser, J., Mundry, S., Stiles, K., and Loucks-Horsley, S. (2013). Leading every day: Actions for effective leadership. Thousand Oaks, CA: Corwin.

Katzenbach, J., \& Smith, D. (2013). The discipline of teams. In HBR's 10 Must Reads

On Teams. Boston, MA: Harvard Business School Publishing Company.

Kegan, R. (1982). The evolving self: problem process in human development. Cambridge, MA: Harvard University Press.

Kegan, R. (1994). In over our heads: The mental demands of modern life. Cambridge, MA: Harvard University Press.

Kegan, R., \& Lahey, L.L. (1984). Adult leadership and adult development: A constructivist view. In B. Kellerman (Ed.) Leadership (pp. 190-230). Englewood Cliffs, NJ: Prentice-Hall.

King, P. M., \& Kitchener. K. S. (1994). Developing reflective judgment: Understanding and promoting intellectual growth and critical thinking in adolescents and adults. San Francisco: Jossey-Bass.

Kitchener, K. S., \& King, P. M. (1981). Reflective judgment: Concepts of justification and their relationship to age and education. Journal of Applied Developmental Psychology. 2. 89-116.

Kominiak, T. (Spring, 2018). The changing role of the school principal. Trust ED K12 Insight. Retrieved from https://www.k12insight.com/trusted/changing-role-schoolprincipal-2/

Kruse, S. D., and Louis, K. S. (2010). Building strong school cultures through intensified 
leadership. Source. Retrieved from http://www.advanc-ed.org/source/buildingstrong-school-culures-through-leadership

Lawrence-Lightfoot, S., \& Hoffman Davis, J. (1997). The art and science of portraiture. San Francisco, CA: Jossey-Bass.

Leithwood, L., Louis, K.S., Anderson, S., \& Wahlstrom, K. (2004). How leadership influences student learning. New York, NY: The Wallace Foundation.

Lincoln, Y., \& Guba, E. (1982). Establishing dependability and confirmability in naturalistic inquiry through an audit. Presented at the 66th Annual Meeting of the American Educational Research Association, New York, NY.

Llopis, G. (2013). 6 ways effective listening can make you a better leader. Forbes.

Retrievedfrom https://www.forbes.com/sites/glennllopis/2013/05/20/6-effectiveways-listening-can-make-you-a-better-leader/\#ef82f2917568

Maxwell, J. (2013). Qualitative research design: An interactive approach. Thousand Oaks, CA.: Sage, $3^{\text {rd }}$ ed.

Merriam, S. B. (1998). Qualitative research and case study applications in education. San Francisco: Jossey-Bass.

Miller, A. (2013). Principal turnover and student achievement. Economics of Education Review, 36, 60-72.

Mitchell, C. (2018). How principals can banish toxic adult behavior from their schools. Education Week. 38 (9), 18-20.

Murphy, M. (2006). Take the lead. TES: Only connect: Networked leading (pp. 24-25). United Kingdom: National Council for School Leadership.

National Policy Board for Education Administration (2015). Professional Standards for 
Educational Leaders 2015. Reston, VA: Author.

Neumerski, C.M. (2012). Rethinking instructional leadership, a review: What do we know about principal, teachers, and coach instructional leadership, and where should we go from here? Educational Administration Quarterly, 49 (2), 310-347.

Patton, M. Q. (2002). Qualitative research and evaluation methods. (3rd ed.). Thousand Oaks, CA.: Sage.

Peno, K., Silva Mangiante, E., \& Kenahan, R. (2014). Training medical faculty to use adult learning principles and mentoring in clinical teaching. In J. Holtz, S. Springer, and C. J. Boden-McGill (eds.), Building Sustainable Futures for Adult Learners, Charlotte, NC: Information Age Publishing.

Peno, K. \& Silva Mangiante, E. (2013). Rear View Mirror: A Retrospective by Retired Teachers on Learning to Teach from Novice to Expert. In C. J. Boden and K. P. King (Eds.), Developing and Sustaining Adult Learners, Charlotte, NC: Information Age Publishing.

Peno, K. \& Silva Mangiante, E. (2012). The Journey from Novice to Expert: Toward a Purposeful On-going Mentoring Model. In C. J. Boden and K. P. King (Eds.), Conversations about Adult Learning in a Complex World. Charlotte, NC: Information Age Publishing.

Protheroe, N. (2008). The K-8 principal in 2008: A ten-year study, eight in a series of research studies launched in 1928. In Educational Research Service (Ed.). Alexandria, VA: National Association of Elementary School Principals.

Riley, D., \& Meredith, J. (2017). State efforts to strengthen school leadership: Insights 
from CCSSO action groups. Retrieved from https://mail.google.com/mail/u/0/\#inbox/FMfcgxwBWTGgBHRXpcGrcCCRLRq $\underline{\text { rMSvh?projector }=1 \& \text { messagePartId }=0.4}$

Roulston, K. (2010). Reflective interviewing: A guide to theory and practice. Thousand Oaks, CA: SAGE.

Samuels, C. A. (2008). Managers help principals to balance time. Education Week 27(23), 18-19.

Schmidt-Davis, J., \& Bottoms, G. (2011). Who's next? Let's stop gambling on school performance and plan for principal succession. Retrived from Southern Regional Education Board website: http://publications.sreb.org/2011/11V19_Principal_Succession_Planning.pdf.

Schön, D. A. (1983). The reflective practitioner: How professionals think in action. Cambridge, MA: Basic Books, Inc.

School Leadership Network (2014). CHURN: The high cost of principal turnover. $\begin{array}{lll}\text { Retrieved } & 2017 \text { from: }\end{array}$ http://connectleadsucceed.org/sites/default/files/principal_turnover_cost.pdf

Silva Mangiante, E. \& Peno, K. (2016). Clinical educators' implementation of a mentoring model: Coaching elementary pre-service teachers for reform-based science. In K. Peno, E. Silva Mangiante, and R. Kenahan (Eds.), Mentoring in Formal and Informal Contexts. Charlotte: Information Age Publishing.

Superville, D. (2018). I want a job and a life: How to find balance in allconsuming work. Education Week, 38 (9), 8-10. 
Vanderhaar, J. E., Muñoz, M. A., \& Rodosky, R. J. (2006). Leadership as accountability for learning: The effects of school poverty, teacher experience, previous achievement, and principal preparation programs on student achievement. Journal of Personnel Evaluation in Education, 19(1-2), 17-33.

Vygotsky, L. S. (1978). Mind in society: The development of higher psychological processes.

Wallace Foundation. (2008). Becoming a school leader: preparing school principals for today's schools. Retrieved from https:/www.wallacefoundation.org/knowledgecenter/Documents/Becoming-a-Leader-Preparing-Principals-for-Todays$\underline{\text { Schools.pdf }}$

Wallace Foundation. (2013). The school principal as leader: guiding schools to better teaching and learning. Retrieved from https://www.wallacefoundation.org/knowledge-center/Documents/The-SchoolPrincipal-as-Leader-Guiding-Schools-to-Better-Teaching-and-Learning-2nd-Ed.p Wallace Foundation. (2013). Leadership matters: What the research says about the importance of principal leadership. Retrieved from https://www.wallacefoundation.org/knowledge-center/Documents/Becoming-aLeader-Preparing-Principals-for-Todays-Schools.pdf

Weiss, R. S. (1994). Learning from strangers: The art and method of qualitative interviewing. New York, NY.: Free Press.

Wills, G. (1994). Certain trumpets: The call of leaders. New York: Simon \& Schuster.

Yin, R. K. (2009). Case study research: Design and methods $\left(4^{\text {th }}\right.$ ed.). Thousand Oaks, CA: Sage. 
Yin, R. K. (2012). Applications of case study research ( $3^{\text {rd }}$ ed.). Thousand Oaks, CA:

Sage.

Young, M.D., \& Crow, G.M. (2017). Handbook of Research on the education of school leaders (2nd ed.). New York, NY: Routledge. 